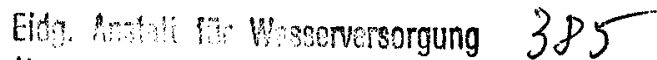 Abwassonowingug u. âawässerschutz \\ Sonderabdruck aus \\ SCH'WEIZERISCHE ZEITSCHRIFT FÜR HYDROLOGIE 15.4.71 BIRKHÄUSER VERLAG BASEL \\ Vol. 321970 Fasc. 1
}

\section{Dekontaminierung von radioaktiv verseuchtem Wasser} mit Torffiltern

\author{
Von Maria Magdolna Bezzegh-Galántai
}

Eidg. Anstalt für Wasserversorgung, Abwasserreinigung und Gewässerschutz, Dübendorf

Manuskript eingegangen am 4. August 1969 
1. Einleitung und Problemstellung . . . . . . . . . . . . . 227

2. Allgemeine Grundlagen und Hinweise zur Problemstellung . . . . . . . . 228

2.1 Torfe und Moove . . . . . . . . . . . . . . . . . . . . . . . . . . . . . 228

2.2 Ionensorptionan Torf . . . . . . . . . . . . . . . . . . . . . . . . . . 229

$2.3{ }^{90} \mathrm{Sr}_{-}{ }^{90} \mathrm{Y}$ im Zisternenwasser . . . . . . . . . . . . . . . . . . . . . . . . . 231

$2.4181 \mathrm{~J}$ im Zisternenwasser . . . . . . . . . . . . . . . . . . . . . . . . . . . 234

3. Laboratoriumsversuche mit ${ }^{90} \mathbf{S r}^{2+}-{ }^{90} \mathbf{Y}^{3+}$. . . . . . . . . . . . . . . . . 235

3.1 Material und Methoden . . . . . . . . . . . . . . . . . . . . . . . . . . 235

3.11 Herkunft der Torfproben . . . . . . . . . . . . . . . . . . . . . . . . 235

3.12 Chemische Zusammensetzung der Torfproben . . . . . . . . . . . . . . . . . 235

3.13 Pflanzliche Zusammensetzung der Torfproben . . . . . . . . . . . . . . . . . 235

3.14 Zersetzungsgrad der Torfproben . . . . . . . . . . . . . . . . . . . . . . 236

3.15 Messung der Kationenaustauschkapazität der Torfe . . . . . . . . . . . . . . . 237

3.16 Herstellung des Modellwassers . . . . . . . . . . . . . . . . . . . . . . . 237

3.17 Versuchsanordnung zur Bestimmung des Rückhaltevermögens der Torfe für ${ }^{90} \mathrm{Sr}^{2+{ }_{-} 90} \mathrm{Y}^{3+}$. . . . . . . . . . . . . . . . . . . . . . . . . 237

3.18 Präparierung der Torfkolonnen . . . . . . . . . . . . . . . . . . . . . 238

3.19 Radioaktivitätsmessung . . . . . . . . . . . . . . . . . . . . . 238

3.2 Kationenaustauschkapazität . . . . . . . . . . . . . . . . . . . . . . . . 238

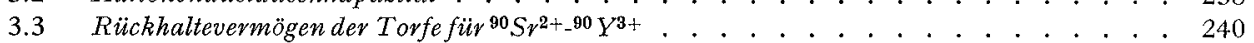

3.31 Vorversuche . . . . . . . . . . . . . . . . . . . . . . . . . . 240

3.32 Hauptversuche . . . . . . . . . . . . . . . . . . . . . . . . . . . . . 248

3.321 Beziehung zwischen der zurückgehaltenen Aktivität und der Torfmenge . . . . . . 248

3.322 Beziehung zwischen der zurückgehaltenen Aktivität und der Art der Torfe. Einfluss der Trocknung und des Tieffrierens . . . . . . . . . . . . . . . . . . . . . . 252

3.323 Einfluss der Fliessgeschwindigkeit . . . . . . . . . . . . . . . . . . . . . . 259

3.324 Einfluss von Volumen und Korngrösse des Torfmaterials . . . . . . . . . . . . 261

3.33 Schlussfolgerungen für die Praxis . . . . . . . . . . . . . . . . . . . . . . 263

4. Rückhaltevermögen der Torfe für ${ }^{131} \mathbf{J}$. . . . . . . . . . . . . . . . . . 264

4.1 Evgebnisse von Laboratoriumsexperimenten . . . . . . . . . . . . . . . . . . . 264

4.2 Schlussfolgerungen aus den Laboratoriumsversuchen mit ${ }^{131} J$. . . . . . . . . . . . . . . 266 
5. Versuche in halbtechnischem Maßstab mit ${ }^{90} \mathrm{Sr}-{ }^{90} \mathrm{Y}$ - und ${ }^{131} \mathrm{~J}$-haltiger

Modellösung und Regenwasser . . . . . . . . . . . . . . . . . . . . 266

5.1 Kesultate... . . . . . . . . . . . . . . . . . . . . . . . . . . . . . . 266

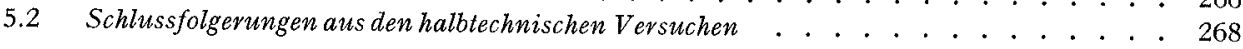

6. Zusammenfassung . . . . . . . . . . . . . . . . . . . . . . . . . . 268

Literaturverzeichnis . . . . . . . . . . . . . . . . . . . . . . . . . . . 270

\section{Einleitung und Problemstellung}

Das Sorptionsvermögen der Torfe hatte bis in die letzten Jahre fast nur landwirtschaftliche und balneotherapeutische Bedeutung. Eine neue Möglichkeit zur Verwertung dieser Eigenschaft öffnet sich nun auf dem Gebiet der Nuklearforschung. Es werden in zunehmender Zahl Studien über die Anwendung des Torfes als natürlicher Ionenaustauscher und Adsorbent zur Dekontaminierung radioaktiver Wässer durchgeführt.

Anhand eigener Laborversuche und Untersuchungen im halbtechnischen Maßstab [1] konnte gezeigt werden, dass der Torf in naturbelassenem Zustand radioaktive Spaltprodukte zurückzuhalten vermag. Ferner ergaben spezielle Experimente, dass in demineralisiertem Wasser, welchem Spuren von ${ }^{90} \mathrm{Sr}^{2+}{ }^{90} \mathrm{Y}^{3+}$ zugefügt wurden, die Aktivität mittels Perkolation durch Torfkolonnen auf unter 1\% herabgesetzt werden kann.

Im Anschluss an diese Veröffentlichung prüften WINkLER und GENS [2] die Eignung von Torf zur Reinigung radioaktiver Abwässer. Die Autoren zeigten am Beispiel der Untersuchungen über den Austausch von $\mathrm{Cs}^{+-}, \mathrm{Sr}^{2+}-$ und $\mathrm{Ce}^{3+-}$ Ionen an vorbehandeltem Torf, dass das Torfmaterial kationisch vorliegende Radioisotope aus Wasser abzutrennen vermag. Seine Anwendbarkeit wird jedoch beschränkt durch die bei pH-Werten über 6 bis 7 beginnende Lösung von Huminsäuren, das geringe Sorptionsvermögen für Alkaliionen und den störenden Einfluss inaktiver Salze, wenn sie in zu hohen Konzentrationen vorliegen.

In einer späteren Arbeit untersuchten SAchse und WinkLer [3] die Möglichkeit zur Verwendung eines Torf-Ton-Austauschers zur Reinigung radioaktiver Lösungen. Es wurde ein aus Torf und bentonitischen Tonen zusammengesetzter, kornstabiler Austauscher hergestellt und in Säulen bis zu einer maximalen Füllmenge von $500 \mathrm{~g}$ erprobt. Eine solche Kombination von Austauschmaterialien vermindert weitgehend die Probleme, welche bei der Verwendung eines reinen Tonaustauschers auftreten (Quelleffekte, Bildung von Tonkolloiden usw.), und vermeidet die unerwünschte Alkali-Humat-Bildung bei der Benützung von organischen, huminsäurehaltigen Austauschern. Infolge der Bildung von Hydrolysekolloiden traten hingegen Schwierigkeiten bei der Sorption dreiwertiger Elemente auf, besonders wenn keine Trägersubstanzen vorhanden waren. Durch eine Fällung vor dem Ionenaustausch liessen sich jedoch auch in diesen Fällen brauchbare Reinigungseffekte erreichen.

Untersuchungen mit vorbehandeltem Torf erfolgten ferner durch Schmid, STIPANits et al. [4]. Für ${ }^{137} \mathrm{Cs}^{+},{ }^{89} \mathrm{Sr}^{2+},{ }^{60} \mathrm{Co}^{2+}$ und ${ }^{140} \mathrm{Ba}^{2+}$ wurden unter den gewählten Versuchsbedingungen Durchbruchskapazitäten (aufgenommene Ionenmenge bis zum Durchbruch) von 0,05 bis $0,1 \mathrm{mval} / \mathrm{g}$ Torf und Sättigungskapazitäten (maximal 
aufgenommene Ionenmenge) je nach $\mathrm{pH}$ und Isotop zwischen 0,3 und $0,6 \mathrm{mval} / \mathrm{g}$ festgestellt. Eine von Träger- und Zusatzelektrolyt freie Lösung mit einer Aktivität von $1 \mu \mathrm{Ci}$ konnte an der Torfsäule quantitativ entaktiviert werden.

SZALAY und SZILÁGYI [5] berechneten anhand von Untersuchungen an Torfpräparaten für eine Tonne Torf eine Sorptionskapazität von etwa 1 Megacurie ${ }^{90} \mathrm{Sr}$ bzw. ${ }^{137} \mathrm{Cs}$.

Als günstigster pH-Wert zur Spaltproduktebindung wurde ein Bereich zwischen $\mathrm{pH} 4$ und 6 angegeben.

ZARNOWIECKI, KOSTYRKo et al. [6] prüften die Dekontaminierungsvorgänge mit verschiedenen Torftypen gegenüber ${ }^{90} \mathrm{Sr}-{ }^{90} \mathrm{Y}$ und ${ }^{137} \mathrm{Cs}$ Spaltprodukten sowie die Rückhaltung der Ionen $\mathrm{Na}^{+}, \mathrm{Co}^{2+}, \mathrm{Zn}^{2+}, \mathrm{Sr}^{2+}, \mathrm{Y}^{3+}, \mathrm{Ru}^{3+}, \mathrm{Cs}^{+}$und $\mathrm{Tl}^{+}$an Torfmaterialien.

In anderem Zusammenhang befassten sich ANDRASCHKo, STIPANITS et al. [7] mit den Austausch- und Adsorptionsmechanismen bei der Anreicherung von Spurenelementen (im besonderen von Uran) an Torfen unter natürlichen Bedingungen. Sie fanden für die maximale Ionenaustauschkapazität von Torf gegenüber $\mathrm{Mg}$, Fe und U Werte zwischen 0,3 und $0,5 \mathrm{mval} / \mathrm{g}$ Torf.

Die Untersuchungen über die Anionen-Sorption an Torf sind noch recht mangelhaft. In der Literatur wurde jedoch verschiedentlich darauf hingewiesen, dass an Torf in der Regel kein Anionenumtausch eintritt [8].

In der vorliegenden Arbeit wird untersucht, inwieweit sich Spuren von ${ }^{90} \mathrm{Sr}-{ }^{90} \mathrm{Y}$ und ${ }^{131} \mathrm{~J}$ mittels eines chemisch nicht vorbehandelten Torfmaterials aus Wasser entfernen lassen. Dabei werden die Versuchsparameter so gewählt, dass anhand der erzielten Ergebnisse Schlïsse auf die Möglichkeit der Entaktivierung radioaktiver Zisternenwässer gezogen werden können.

\section{Allgemeine Grundlagen und Hinweise zur Problemstellung}

\subsection{Torfe und Moore}

Der Torf ist ein Bodenmaterial, das mindestens $30 \%$ organische Substanz enthält. Er entsteht aus abgestorbenen Pflanzen unter weitgehend anaeroben Verhältnissen bei grossem Wasserüberschuss und wenn der mikrobielle Abbau. gehemmt wird, so dass sich die organischen Stoffe anhäufen können [9].

Erreicht eine oberflächliche Torfschicht in entwässertem Zustand eine Mächtigkeit von mindestens $30 \mathrm{~cm}$, so spricht man von Mooren [10]. Bei den Mooren unterscheidet man zwischen den im Grundwasserbereich entstandenen Niedermooren oder topogenen Mooren, den unabhängig vom Grundwasser in stauender Nässe entstandenen Hochmooren oder ombrogenen Mooren (= Regenwassermoore) und den dazwischenstehenden Übergangsmooren [9].

Im landwirtschaftlichen Sprachgebrauch und auch in der Fachliteratur wird ein Niedermoor vielfach als "Flachmoor", "Niederungsmoor", "organischer Grundwasserboden», «Fehn», «Moos» und "Ried» bezeichnet. Für Hochmoor besteht auch der Ausdruck «Filz» (vor allem in Bayern).

Den drei Moortypen können charakteristische Pflanzengesellschaften zugeordnet werden. So zählt man zu den typischen Niedermoorpflanzen: Schilf (Phragmites communis), Rohrkolben (Typha), Seggen (Carex), Erle (Alnus) und Weide (Salix), zu jenen der Hochmoorpflanzen: Torfmoos (Spagnum sp.), Wollgras (Eriophorum 
vaginatum), Simse (Scirpus caespitosus), Sumpfbinse (Scheuchzeria palustris). Moosbeere (Oxycoccus quadripetalus), Andromeda (Andromeda polifolia) und Sonnentau (Drosera rotundifolia). In den Übergangsmooren kommen sowohl typische Hochmoorals auch Niedermoorpflanzen vor, neben einer Vegetation, deren Wachstumsbedingungen zwischen jenen der Hoch- und Niedermoorpflanzen stehen.

Bei der Entstehung des Niedermoortorfes spielen Aktinomyzeten (Strahlenpilze) und kleine Wassertiere eine wichtige Rolle. In den Niedermoortorfen sind deshalb neben den wenig zersetzten Pflanzenresten und dem Feinhumus auch Tierrückstände und tierische Ausscheidungsprodukte vorzufinden. In wechselnden Mengen enthalten sie ferner anorganische Substanzen.

Die Vertorfung in den Hochmooren erfolgt hingegen weitgehend abiologisch. Im Torf fehlen also sowohl die Tierrückstände als auch die Ausscheidungsprodukte. Die jüngeren Torfe enthalten nahezu unveränderte torfbildende Pflanzenteile, die älteren Torfe ausser den Pflanzenresten den durch die abiologische Humifizierung entstandenen kolloiden Feinhumus. Gegenüber den Niedermoortorfen weisen sie geringere Mengen anorganischer Substanzen, einen niedrigeren $\mathrm{pH}$-Wert und einen sehr kleinen Stickstoffgehalt auf.

\subsection{Ionensorption an Torf}

Durch den Abbau der Moorpflanzen, deren Zusammensetzung auch innerhalb derselben Torfart stark variieren kann, entstehen die verschiedensten chemischen Verbindungen. Bei den Torfen kann deshalb von einer einheitlichen Substanz keine Rede sein, sondern nur von Stoffkomplexen, deren Struktur teilweise noch völlig unbekannt ist. Die Ionensorption können wir demzufolge nicht an einzelnen, chemisch gut definierten Verbindungen, sondern nur als summarischen Effekt an diesen heterogenen Stoffkomplexen prüfen.

Im folgenden geben wir einen kurzen Überblick über den Sorptionsvorgang an Torfmaterialien, insbesondere über den Ionenaustausch, welcher für die vorliegende Arbeit von Interesse ist. Es wird dabei nicht auf theoretische Einzelheiten eingegangen und kein Anspruch auf Vollständigkeit erhoben, sondern wir werden nur auf einige Punkte hinweisen, welche für die Interpretation unserer Resultate wichtig sind.

Die Torfsubstanzen liegen meist in kolloider Form vor, weisen einen hydrophilen Charakter auf und besitzen ein mehr oder weniger quellbares Gerüst. Die kolloiden Teilchen sind fähig, sowohl Moleküle und Ionen im gasförmigen Zustand als auch aus Lösungen zu sorbieren. Die Sorption aus Lösungen kann auf zwei Arten erfolgen: 1. die Moleküle oder Ionen lagern sich an der Oberfläche der Torfsubstanz an, ohne gleichzeitige Freisetzung anderer Moleküle oder Ionen in die Lösung (z. B. Sorption von Wassermolekülen oder von niedermolekularen Verbindungen mit Dipoleigenschaften); 2. die Ionen lagern sich an der Oberfläche der Torfsubstanzen an, wobei gleichzeitig eine äquivalente Menge anderer Ionen in die Lösung abgegeben wird. Je nach beteiligten Ionen unterscheidet man zwischen Kationen- und Anionenaustausch.

Der Kationenaustausch lässt sich am Beispiel eines Versuches mit einer Bodenprobe, welche in einer $\mathrm{NH}_{4}$ Cl-Lösung geschüittelt oder mit einer $\mathrm{NH}_{4}$ Cl-Lösung gewaschen wird, wie folgt veranschaulichen: 


$$
\begin{aligned}
& \mathrm{H}^{+} \frac{\mathrm{Ca}^{2+} \mathrm{Mg}^{2+}}{\frac{\text { Austauscher }}{\mathrm{K}^{+} \mathrm{Na}^{+}} \mathrm{Al}^{3+}+10 \mathrm{NH}_{4}^{+} \rightleftarrows} \\
& \mathrm{NH}_{4}^{+} \frac{2 \mathrm{NH}_{4}^{+} 2 \mathrm{NH}_{4}^{+}}{\frac{\text { Austauscher }}{\mathrm{NH}_{4}^{+} \mathrm{NH}_{4}^{+}} 3 \mathrm{NH}_{4}^{+}+\mathrm{Ca}^{2+}+\mathrm{Mg}^{2+}+\mathrm{K}^{+}+\mathrm{Na}^{+}+\mathrm{Al}^{3+}+\mathrm{H}^{+}}
\end{aligned}
$$

Aus dieser Gleichung ist zu ersehen, dass die ursprünglich am Boden (Austauscher) haftenden Kationen (austauschbare Kationen) in äquivalenter Menge verdrängt werden und die $\mathrm{NH}_{4}^{+-}$-Ionen (eintauschende Kationen) sich bis zur Einstellung des Gleichgewichtes an die Bodenoberfläche anlagern. Einen vollständigen Austausch erzielt man in der Praxis, wenn der Boden entweder mit einer wiederholt erneuerten $\mathrm{NH}_{4} \mathrm{Cl}$ Lösung geschüttelt oder mit ihr mehrmals durchgewaschen wird. Die $\mathrm{Cl}^{-}-$Ionen werden vom Boden praktisch nicht sorbiert, sie sind deshalb in der Gleichung nicht berücksichtigt worden.

Für den Kationenaustausch an Torfen sind nach den heutigen Auffassungen in erster Linie die Huminstoffe, insbesondere die Huminsäuren, verantwortlich. Aber auch andere Substanzen, wie die Lignine, die Nukleinsäuren, verschiedene aliphatische Säuren, Tannine, Polyuronide und noch weitere organische Verbindungen, sind an den Sorptionsvorgängen beteiligt. Als funktionelle Gruppen kommen COOH-, phenolische OH- und NH-Gruppen in Betracht. Das Ausmass des Kationenaustausches wird durch die Anzahl und die Säurestärke der funktionellen Gruppen bedingt. Da die Säurestärke ausser von den benachbarten säurebestimmenden Gruppen auch stark vom $\mathrm{pH}$ abhängt, spielen bei den Austauschvorgängen an Torfmaterialien die pH-Verhältnisse eine besonders wichtige Rolle. Bei erhöhtem $\mathrm{pH}$ steigt die Austauschfähigkeit des Torfes an. Dies ist auf die unterschiedliche Dissoziation der funktionellen Gruppen zurückzuführen. Während die Dissoziation der COOH-Gruppen schon im sauren Bereich erfolgt, beginnt sie bei den phenolischen OH-Gruppen erst im schwach sauren pH-Bereich und erstreckt sich bis zu pH-Werten von 10 bis 11 . Dieses Verhalten ist für die Bestimmung der austauschbaren Kationen, d.h. der "Austauschkapazität», von Bedeutung. Zu allen Austauschkapazitätswerten sind deshalb die pH-Verhältnisse, bei welchen die Bestimmung erfolgte, anzugeben, da sonst die Messresultate keine vergleichbare Kenngrösse darstellen.

Neben dem pH-Wert hängt die Austauschkapazität des Torfmaterials von der Art des eintauschenden Kations ab. So werden die zweiwertigen gegenüber den einwertigen Ionen von den organischen Substanzen bevorzugt. Messungen an Huminsäuren und an weiteren organischen Substanzen der Böden ergaben beispielsweise, dass im Gleichgewicht mit einer $0,1 \mathrm{~N}$ Azetatlösung $\left(\mathrm{pH}=7\right.$ ) äquivalente Mengen $\mathrm{Ca}^{2+}$ und $\mathrm{NH}_{4}^{+}$im Verhältnis von 92:8 eingetauscht werden. Analog liess sich eine hohe Selektivität für $\mathrm{Ca}^{2+}$ gegenüber $\mathrm{Na}^{+}$nachweisen.

In der Regel erfolgt der Eintausch im Sinne der lyotropen Reihen, d.h. die Eintauschintensität hängt von der Grösse und Wertigkeit des Ions und damit von seiner Struktur (Metallkation + Hydrathülle) ab.

Je grösser der Durchmesser der nicht hydratisierten Ionen ist, um so kleiner ist ihre Hydratation und um so grösser wird die Eintauschintensität innerhalb der Reihe gleichwertiger Ionen. 
Mehrwertige Ionen haben zwar gegenüber den einwertigen eine grössere Hydratationszahl, ihre Eintauschintensität liegt jedoch, infolge der Uberlagerung durch die Wertigkeit, höher als bei den einwertigen Ionen.

Für die organische Substanz des Bodens wurde die folgende Reihe det Eintauschstärke angenommen [9]:

$$
\mathrm{Pb}>\mathrm{Cu}>\mathrm{Ni}>\mathrm{Co}>\mathrm{Zn}>\mathrm{Mn}>\mathrm{Ba}>\mathrm{Ca}>\mathrm{Mg} \gg \mathrm{NH}_{4}>\mathrm{K}>\mathrm{Na}
$$

Die Kationenaustauschkapazität der Torfe hängt ferner von der Haftfestigkeit der austauschbaren Kationen ab. Je höher die Haftfestigkeit des Kations ist, um so kleiner wird seine Austauschfähigkeit. Da die Haftfestigkeit, analog zur Eintauschintensität, von der Wertigkeit, dem Durchmesser und dem Hydratationszustand der Kationen in gleichsinniger Richtung abhängt, ergibt sich für die Haftfestigkeit der Kationen dieselbe Reihenfolge wie für die Eintauschintensität.

Für die Höhe der Austauschkapazität ist noch die Konzentration der Lösung massgebend. Mit zunehmender Konzentration steigt die Austauschkapazität. Liegen Kationen mit verschiedener Wertigkeit vor, so werden die höherwertigen um so mehr bevorzugt, je stärker die Lösung verdünnt wird.

Weitere Effekte, wie beispielsweise die Komplexbildung, die Dissolution und die Peptisation der Torfkolloide, welche je nach der Zusammensetzung des Torfmaterials und der Art der einzutauschenden Ionen zusätzlich auftreten können, stellen selbstverständlich für das Ausmass der Austauschfähigkeit weitere wichtige Faktoren dar. Sie sind jedoch teilweise noch viel zuwenig abgeklärt, so dass wir an dieser Stelle von der Diskussion dieser Vorgänge absehen. Es soll hier nur soviel vermerkt werden, dass Dissolution und Peptisation der schwerlöslichen Ca-Humate oder Huminsäuren durch Alkalihydroxide oder Alkalisalze gemäss den folgenden, nicht stöchiometrischen Gleichungen erfolgen kann:

$$
\begin{aligned}
& \mathrm{Ca}-\mathrm{R}_{\mathrm{Hum}}+\mathrm{Na} \text {-Oxalat } \rightleftarrows \mathrm{Ca} \text {-Oxalat }+\mathrm{Na}-\mathrm{R}_{\mathrm{Hum}} \\
& \mathrm{H}-\mathrm{R}_{\mathrm{Hum}}+\mathrm{Na} \text {-Azetat } \rightleftarrows \text { Essigsäure }+\mathrm{Na}-\mathrm{R}_{\text {Hum }}
\end{aligned}
$$

Die Komplexbildung ist besonders bei den Schwermetallkationen möglich, wie es $z$. B. für $\mathrm{Cu}$-Ionen nachgewiesen wurde [11].

\section{$2.3{ }^{90}{ }^{5 r}{ }^{90} Y$ im Zisternenwasser}

${ }^{90} \mathrm{Sr}$ ist ein in der Natur nicht vorkommendes, künstlich erzeugtes radioaktives Isotop des Erdkalielementes Strontium. Es entsteht bei Kernspaltungsprozessen in den Kernwaffen und den Reaktoren aus den ${ }^{235} \mathrm{U}$ - und ${ }^{239} \mathrm{Pu}$-Spaltmaterialien sowie aus dem für die Spalt-Fusions-Bomben verwendeten ${ }^{238} \mathrm{U}-\mathrm{Mantel}$ als Spaltprodukt. Es zerfällt unter Aussendung von Betastrahlung mit einer maximalen Energie von $0,54 \mathrm{MeV}$, wobei sein Tochterprodukt ${ }^{90} \mathrm{Y}$ entsteht. Zwischen dem Mutterisotop und dem Tochterprodukt besteht ein radioaktives Gleichgewicht, d.h. dass ${ }^{90} \mathrm{Sr}$ normalerweise nur zusammen mit seinem Tochterisotop ${ }^{90} \mathrm{Y}$ vorkommt, das praktisch gleichviel Aktivität aufweist wie das Mutterisotop. Der Zerfall von ${ }^{90} \mathrm{Y}$ erfolgt wiederum unter Aussendung von Betastrahlung, welche eine maximale Energie von 2,24 MeV aufweist. Das Endprodukt ist das stabile ${ }^{90} \mathrm{Zr}$. Die physikalische Halbwertszeit des 
Mutterisotopes ${ }^{90} \mathrm{Sr}$ beträgt 28 Jahre. Das Tochterisotop zerfällt mit einer Halbwertszeit von 64 Stunden.

Obwohl ${ }^{90} \mathrm{Sr}$ in der Natur nicht vorkommt, ist es heute trotzdem in der ganzen Biosphäre verbreitet. Seine Verteilung über die Erdoberfläche erfolgt durch den troposphärischen und stratosphärischen Ausfall (Fallout), welcher (im Gegensatz zum örtlichen Ausfall) in niederschlagsreichen Gebieten fast ausschliesslich mit dem Niederschlag, in Trockengebieten vorwiegend durch Staubablagerung, auf die Erdoberfläche gelangt. In Trockengebieten ist der Ausfall geringer als in niederschlagsreichen. In Europa wurde oft mit zunehmender Höhenlage ein deutlicher Anstieg der Ablagerung beobachtet, eine Folge der mit der Höhe zunehmenden Niederschlagsmenge.

Das ${ }^{90} \mathrm{Sr}$ fand in den letzten Jahren besondere Beachtung, weil die physiologische Gefährlichkeit des Kernbombenausfalls, der älter als einige Monate ist, in erster Linie von seinem Gehalt an ${ }^{90} \mathrm{Sr}$ bestimmt wird. Die Tab. 1 und 2 zeigen die Zusammensetzung der Spaltprodukte aus einer ${ }^{235} \mathrm{U}$ - und ${ }^{239} \mathrm{Pu}-$ Nominalbombe in verschiedenen Zeitpunkten nach der Explosion. In den Tabellen wurden nur jene Spaltprodukte aufgeführt, welche im Zeitraum von 10 Tagen bis zu 30 Jahren nach der Explosion einen Anteil von mehr als 1\% der Gesamtaktivität der Spaltprodukte erreichen [12].

Tab.1. Die Radioaktivität der Spaltprodukte einer ${ }^{235} \mathrm{U}$-Nominalbombe. (Ein Strich bedeutet, dass der Anteil des Radionuklids auf unter 1\% der Gesamtaktivität abgesunken ist.)

\begin{tabular}{|c|c|c|c|c|c|c|}
\hline \multirow[t]{2}{*}{ Radionuklid } & \multicolumn{6}{|c|}{ Beta-Aktivität der Radionuklide einer ${ }^{\mathbf{2 3 5}} \mathrm{U}$-Nominalbombe in Kilocurie nach } \\
\hline & 10 Tagen & 1 Monat & 4 Monaten & $1 \mathrm{Jahr}$ & 10 Jahren. & 30 Jahren \\
\hline${ }^{89} \mathrm{Sr}$ & 382 & 294 & 93,5 & 4,4 & - & - \\
\hline $90 \mathrm{Sr}$ & 2,4 & 2,4 & 2,4 & 2,34 & 1,85 & 1,13 \\
\hline${ }^{90} \mathrm{Y}$ (Tochter & 2,4 & 2,4 & 2,4 & 2,34 & 1,85 & 1,13 \\
\hline${ }^{91} \mathrm{Y}$ & 455 & 359 & 122 & 6,37 & - & 一. \\
\hline${ }^{95} \mathrm{Zr}$ & 540 & 436 & 161 & 10,9 & - & - \\
\hline${ }^{95} \mathrm{Nb}$ (Tochter) & 96,6 & 226 & 232 & 23,1 & - & - \\
\hline${ }^{99} \mathrm{Mo}$ & 1040 & - & - & - & - & - \\
\hline${ }^{103} \mathrm{Ru}$ & 470 & 330 & 70,2 & $\ldots$ & - & - \\
\hline${ }^{106} \mathrm{Ru}$ & 7,26 & 7,0 & 5,65 & 3,63 & - & - \\
\hline${ }^{106}$ Rh (Tochter) & 7,26 & 7,0 & 5,65 & 3,63 & - & - \\
\hline $131 \mathrm{~J}$ & 910 & 164 & - & - & $\rightarrow$ & - \\
\hline${ }^{132} \mathrm{Te}$ & 886 & - & - & - & - & - \\
\hline${ }^{132} \mathrm{~J}$ (Tochter) & 920 & - & - & - & - & - \\
\hline${ }^{133} \mathrm{Xe}$ & 2260 & 166 & - & - & - & - \\
\hline${ }^{137} \mathrm{Cs}$ & 3,14 & 3,14 & 3,14 & 3,06 & 2,5 & 1,6 \\
\hline${ }^{140} \mathrm{Ba}$ & 1470 & 500 & - & - & -- & - \\
\hline${ }^{140} \mathrm{La}$ (Tochter) & 1650 & 573 & - & - & - & - \\
\hline${ }^{141} \mathrm{Ce}$ & 730 & 476 & 71,8 & - & - & - \\
\hline${ }^{143} \mathrm{Pr}$ & 14.00 & 525 & - & - & - & - \\
\hline${ }^{144} \mathrm{Ce}$ & 92 & 87 & 70 & 38,7 & - & - \\
\hline${ }^{144} \operatorname{Pr}$ (Tochter) & 92 & 87 & 70 & 38,7 & - & - \\
\hline${ }^{147} \mathrm{Nd}$ & 846 & 256 & - & - & - & - \\
\hline${ }^{147} \mathrm{Pm}$ (Tochter) & 8,5 & 15,3 & 17,3 & 14,5 & 1,3 & - \\
\hline${ }^{151} \mathrm{Sm}$ & 0,24 & 0,24 & 0,24 & 0,24 & 0,23 & 0,19 \\
\hline Gesamtaktivität & 14267 & 4517 & 927 & 152 & 7,7 & 4,05 \\
\hline
\end{tabular}




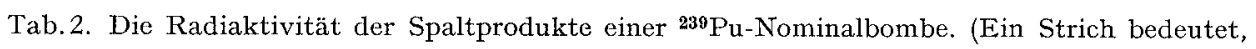
dass der Anteil des Radionuklids auf unter 1\% der Gesamtaktivität abgesunken ist.)

\begin{tabular}{|c|c|c|c|c|c|c|}
\hline \multirow[t]{2}{*}{ Radionuklid } & \multicolumn{6}{|c|}{ Beta-Aktivität der Radionuklide einer ${ }^{239} \mathrm{Pu}$-Nominalbombe in Kilocurie nach } \\
\hline & 10 Tagen & 1 Monat & 4 Monaten & $1 \mathrm{Jahr}$ & 10 Jahren & 30 Jahren \\
\hline${ }^{89} \mathrm{Sr}$ & 164 & 126 & 40 & 1,87 & - & $\cdots$ \\
\hline${ }^{90} \mathrm{Sr}$ & 1,25 & 1,25 & 1,25 & 1,22 & 0,97 & 0,59 \\
\hline${ }^{90} \mathrm{Y}$ (Tochter) & 1,25 & 1,25 & 1,25 & 1,22 & 0,97 & 0,59 \\
\hline${ }^{91} \mathrm{Y}$ & 255 & 190 & 64,5 & 3,36 & - & - \\
\hline${ }^{95} \mathrm{Zr}$ & 420 & 340 & 125 & 8,5 & - & - \\
\hline${ }^{95} \mathrm{Nb}$ (Tochter) & 75 & 176 & 181 & 18,0 & - & - \\
\hline${ }^{99} \mathrm{Mo}$ & 990 & - & - & - & - & - \\
\hline${ }^{108} \mathrm{Ru}$ & 752 & 528 & 112 & - & - & - \\
\hline${ }^{106} \mathrm{Ru}$ & 99 & 95 & 77 & 49,3 & - & - \\
\hline${ }^{106} \mathrm{Rh}$ (Tochter) & 99 & 95 & 77 & 49,3 & - & - \\
\hline${ }^{131} \mathrm{~J}$ & 1440 & 259 & - & - & - & - \\
\hline${ }^{132} \mathrm{Te}$ & 1260 & - & - & - & - & - \\
\hline${ }^{132} \mathrm{~J}$ (Tochter) & 1310 & - & - & - & - & - \\
\hline${ }^{133} \mathrm{Xe}$ & 2160 & 158 & - & - & - & - \\
\hline${ }^{137} \mathrm{Cs}$ & 2,94 & 2,94 & 2,94 & 2,86 & 2,34 & 1,5 \\
\hline${ }^{140} \mathrm{Ba}$ & 1270 & 432 & - & - & -- & - \\
\hline${ }^{140} \mathrm{La}$ (Tochter) & 1420 & 494 & - & -- & - & - \\
\hline${ }^{141} \mathrm{Ce}$ & 648 & 422 & 63,6 & - & - & - \\
\hline${ }^{143} \operatorname{Pr}$ & 1320 & 495 & 11,0 & - & - & -- \\
\hline${ }^{144} \mathrm{Ce}$ & 71 & 67 & 54 & 30 & - & - \\
\hline${ }^{144} \operatorname{Pr}$ (Tochter) & 71 & 67 & 54 & 30 & - & - \\
\hline${ }^{147} \mathrm{Nd}$ & 679 & 205 & - & -- & - & - \\
\hline${ }^{147} \mathrm{Pm}$ (Tochter) & 6,8 & 12,3 & 13,9 & 11,6 & 1,04 & - \\
\hline${ }^{161} \mathrm{Sm}$ & 0,68 & 0,68 & 0,68 & 0,68 & 0,65 & 0,54 \\
\hline Gesamtaktivität & $\mathbf{1 4 5 1 6}$ & 4168 & 880 & 208 & 5,97 & 3,22 \\
\hline
\end{tabular}

Bei der Spaltung von ${ }^{238} \mathrm{U}$ in thermonuklearen Bomben entspricht die Zusammensetzung der Spaltprodukte mit unbedeutenden Abweichungen derjenigen einer ${ }^{239} \mathrm{Pu}$ Spaltbombe. Beim ${ }^{90} \mathrm{Sr}$ trifft eine ganze Reihe negativer Eigenschaften zusammen. So bringt es, infolge seiner langen physikalischen Halbwertszeit, die Voraussetzung zu einer Akkumulierung in der Biosphäre mit sich. Wegen seiner chemischen Verwandtschaft mit dem Ca wird es nach seiner Aufnahme im Körper fast ausschliesslich in den Knochen abgelagert und dort nur schwer wieder ausgeschieden. Es kann dann im Körper somatische Schädigungen hervorrufen. Als seine biologische Halbwertszeit (Zeitintervall, in welchem die inkorporierte Menge durch Ausscheidung auf die Hälfte reduziert wird) wurden 50 Jahre festgestellt [13].

Unter Berücksichtigung der chemisch-physikalischen Eigenschaften von ${ }^{90} \mathrm{Sr}$ und der gesammelten biologisch-medizinischen Daten wurde im Trinkwasser eine maximal zulässige Konzentration von gelöstem ${ }^{90} \mathrm{Sr}$ von $1000 \mathrm{pCi} / 1$ für beruflich strahlen-exponierte Personen festgelegt. Bei kleineren Bevölkerungsgruppen wird mit einem Sicherheitsfaktor von 10 gerechnet; die zulässige Konzentration weist dann einen Wert von $100 \mathrm{pCi} / 1$ auf.

Da in Einzelsiedlungen, besonders im Schweizer Jura, häufig das vom radioaktiven Ausfall primär gefährdete Regenwasser in Zisternen gesammelt und als Trink- 
wasser benützt wird, war es in der Zeitperiode der grossen Testversuche (1957/58) fragwürdig, ob die Toleranzgrenzen beim Genuss von Regenwasser eingehalten werden könnten. Es hat sich zwar gezeigt, dass diese Grenzen nirgendwo überschritten wurden; man suchte jedoch sofort nach Wegen, um das Wasser auf möglichst einfache und billige Art zu entaktivieren. Dies ist der Beweggrund der vorliegenden Arbeit, wobei wir uns zum Ziele setzten, den Torf als Entaktivierungsmaterial unter genau definierten Versuchsbedingungen zu prüfen. Von komplizierten chemischen Vorbehandlungen haben wir abgesehen, da die Entaktivierung radioaktiver Zisternenwässer nur unter einfachen und billigen Bedingungen sinnvoll ist.

\section{$2.4131 \mathrm{~J}$ im Zisternenwasser}

Das ${ }^{131} \mathrm{~J}$ ist ein Beta-Gamma strahlendes radioaktives Isotop, dessen Zerfall zum stabilen ${ }^{131} \mathrm{Xe}$ führt. Es entsteht bei den Spaltungsprozessen der ${ }^{235} \mathrm{U}-,{ }^{239} \mathrm{Pu}-$ und ${ }^{238}$ U-Atomkerne in den Kernwaffen und den Reaktoren (vgl. Tab. 1 und 2). Seine physikalische Halbwertszeit beträgt rund 8 Tage; es zählt deshalb zu den kurzlebigen Isotopen, welche in älteren Spaltprodukten keine Gefahr darstellen. Die physiologische Gefährlichkeit frischer Spaltprodukte wird hingegen im wesentlichen durch den Anteil an ${ }^{131} \mathrm{~J}$ bestimmt.

Nach einer Inkorporation reichert sich das ${ }^{131} \mathrm{~J}$ weitgehend selektiv in der Schilddrüse an, wo es bei einer Überschreitung der zulässigen Dosis somatische Schädigungen verursachen kann. Das gespeicherte ${ }^{131} \mathrm{~J}$ wird nach wenigen Tagen in Form von Thyroxin aus der Schilddrüse weggeführt. Das Zeitintervall, in welchem sich die maximal aufgenommene Menge des Radiojods in der Schilddrüse auf die Hälfte reduziert (durch Ausscheidung aus der Schilddrüse und Zerfall), beträgt nach zahlreichen Untersuchungen 4-7 Tage $[14,15]$.

Das ${ }^{131} \mathrm{~J}$ weist auch bei normalen Temperaturen eine hohe Flüchtigkeit auf. Es ist deshalb schwierig, sein Entweichen aus Reaktoren vollständig zu verhindern, so dass stets mit einer Kontamination der Reaktorumgebung zu rechnen ist. Insbesondere kann eine hohe Kontamination infolge eines Reaktorunfalles, bei welchem das ${ }^{131} \mathrm{~J} \mathrm{zu}$ den wichtigsten der entweichenden Isotopen zählt, eintreten.

Das in den Kernwaffen entstandene ${ }^{131} \mathrm{~J}$ verbreitet sich analog dem ${ }^{90} \mathrm{Sr}$ durch den troposphärischen Niederschlag über die Erdoberfläche und gefährdet Zisternenwasser bzw. Trinkwasser kleinerer Bevölkerungsgruppen durch radioaktive Kontamination in gleicher Weise wie ${ }^{90} \mathrm{Sr}$. Im Gegensatz zum ${ }^{90} \mathrm{Sr}$ stellt das ${ }^{131} \mathrm{~J}$ - infolge seiner kurzen physikalischen Halbwertszeit - nur beim Genuss des mit jüngeren Spaltprodukten verunreinigten Zisternenwassers eine Gefahr dar. Erreichte ein Zisternenwasser die Aktivitätskonzentration von $2000 \mathrm{pCi}$ von ${ }^{131} \mathrm{~J} / \mathrm{l}$, d.h. die maximal zulässige Konzentration im Trinkwasser für kleinere Bevölkerungsgruppen (= ein Zehntel des für beruflich strahlenexponierte Personen bei dauerndem Gebrauch festgelegten Wertes), so müsste das Wasser der dauernden Konsumation entzogen oder dekontaminiert werden. In solchen Fällen könnte der Torf als Entaktivierungsmaterial gute Dienste leisten. Aus diesem Grunde führten wir neben den Dekontaminierungsversuchen mit ${ }^{90} \mathrm{Sr}-90 \mathrm{Y}$ auch einige Experimente mit ${ }^{131} \mathrm{~J}$-haltigem Modellwasser durch. Die vorliegende Arbeit fasst die Resultate dieser Versuche zusammen, die wir aber aus verschiedenen Gründen nicht als abschliessend betrachten. 


\section{Laboratoriumsversuche mit ${ }^{90} \mathbf{S r}^{2+}+{ }^{90} \mathbf{Y}^{3+}$}

\subsection{Material und Methoden}

\subsection{Herkunft der Torfproben}

Die Torfproben wurden im Neuenburger Jura in Sous Martel Dernier NE (SE Pt. 1002) und Bois des Lattes NE (N Pt. 998) erhoben. Blöcke von $25 \times 20 \times 25 \mathrm{~cm}$ aus den oberen $10-40 \mathrm{~cm}$ (Torf Nr. 1) und den unteren 90-120 cm (Torf Nr. 2) Bodenschichten wurden mittels Spaten entnommen und in Plastiksäcke abgefüllt. Analoge Probeentnahmen erfolgten aus den unter Moorwasser liegenden Torfen (Torf Nr. 3), wobei die ausgestochenen Blöcke leicht gepresst und nach der «Entwässerung» ebenfalls in Plastiksäcken gesammelt wurden.

Um eine Zersetzung des Torfmaterials während der Lagerung zu vermeiden, wurden die Proben zur einen Hälfte bei $20^{\circ} \mathrm{C}$ getrocknet und zur andern Hälfte bei $-20^{\circ} \mathrm{C}$ tiefgekühlt. Vor Beginn eines Versuches wurde das tiefgekühlte Material während etwa 3 Stunden aufgetaut.

\subsection{Chemische Zusammensetzung der Torfproben}

Die chemischen Analysen der Torfproben wurden von der Eidg. Agrikulturchemischen Versuchsanstalt Liebefeld, Bern, vorgenommen. Tab. $3^{1}$ ) zeigt die Ergebnisse der Allgemein- und Stoffgruppenanalyse der drei Torfmuster.

\subsection{Pflanzliche Zusammensetzung der Torfproben ${ }^{2}$ )}

Die mikroskopische Untersuchung der Proben wurde von der Botanischen Anstalt der Universität Basel durchgeführt. Der Befund sei hier unverändert wiedergegeben:

\section{"Cypraceae-Radizellen-Torf (Torf Nr. 1)}

Feine Wurzelstöcke dominieren; an den häufig auftretenden, fast quadratischen, stark verdickten Epidermiszellen ist die Zugehörigkeit des grössten Teils zur Familie der Cypraceae leicht erkennbar. Eine weitere Bestimmung ist kaum möglich. Hinzu kommen noch recht erhaltene Sproßstücke des Laubmooses Aulacomnium palustre. Blättchen von Sphagnum-Arten sind selten. Ein solcher Torf kann bei nährstoffarmen Bedingungen entstehen.

\section{Sphagnum-Torf (Torf Nr.2)}

Blättchen eines Torfmooses aus der Sektion Cymbifolia dominieren sehr stark. Blättchenquerschnitte an einem relativ gut erhaltenen Torfmoosstück ergaben die Zugehörigkeit zu Sphagnum medium. Es ist sehr wahrscheinlich, dass sich die ganze Probe vorwiegend aus dieser Art zusammensetzt. Jedenfalls handelt es sich hier um einen Torf, der unter nährstoffarmen, mehr oder weniger stark sauren, nassen Bedingungen gebildet wurde.

Cypraceae-Radizellen-Torf (Torf Nr.3)

Ausser zahllosen Cypraceae-Radizellen und vielen Epidermisresten sind nur ganz wenige, sicher bestimmbare Fragmente von Pflanzen vorhanden, z.B. einige wenige

1) Vgl. auch Tab.8, Analyse der Torfe der zweiten Probeentnahme.

2) Vgl. auch Seiten 254-255, Analysen der Torfe der zweiten Probeentnahme. 
Tab.3. Ergebnisse der Allgemein- und Stoffgruppenanalyse von drei Torfproben.

\begin{tabular}{|c|c|c|c|}
\hline \multirow[t]{2}{*}{ Art der Bestimmung } & \multicolumn{3}{|c|}{ Bezeichnung der Probe } \\
\hline & Torf Nr. 1 & Torf Nr. 2 & Torf Nr. 3 \\
\hline $\mathrm{H}_{2} \mathrm{O}$ in Originalsubstanz $(\%)$ & 88,34 & 89,87 & 90,15 \\
\hline $\mathrm{H}_{2} \mathrm{O}$ in lufttrockener Substanz $(\%) \quad \ldots$ & 7,04 & 7,33 & 8,43 \\
\hline $\mathrm{pH}$ in $\mathrm{H}_{2} \mathrm{O}$-Aufschwemmung $\ldots$. & 3,6 & 4,2 & 5,3 \\
\hline Asche in Trockensubstanz (\%) & $4,21 / 4,22$ & $2,45 / 2,65$ & $7,14 / 8,32$ \\
\hline $\mathrm{Ca}$ in Trockensubstanz $\left.(\mathrm{mg} \mathrm{Ca} / \mathrm{g})^{1}\right) \ldots$ & 4 & 5 & 22 \\
\hline Organische Substanz in der Trockensubstanz (\%) & 95,79 & $97,55 / 97,45$ & $92,86 / 91,68$ \\
\hline $\mathrm{N}$ in Trockensubstanz $(\%) \ldots \ldots$ & 2,4 & 1,4 & 2,46 \\
\hline $\mathrm{C}$ in Trockensubstanz $(\%), \ldots \ldots$ & 52,5 & 53,1 & 52,5 \\
\hline $\mathrm{C}: \mathrm{N} \cdot \because \cdot \cdot \cdots$ & 21,9 & 37,9 & 21,3 \\
\hline $\mathrm{C}$ in organischer Substanz $(\%)$ & 54,8 & 54,6 & 57,3 \\
\hline \multicolumn{4}{|l|}{$\begin{array}{l}\text { Stoffgruppenanalyse: } \\
\text { In Benzol-Alkohollöslich: }\end{array}$} \\
\hline \multirow[b]{3}{*}{ organische Substanz $(\%)$} & 7,35 & $10,65 / 11,5$ & 4,17 \\
\hline & 0,011 & $0,103 / 0,114$ & 0,043 \\
\hline & 7,34 & $10,55 / 11,49$ & 4,13 \\
\hline \multicolumn{4}{|l|}{ In Heisswasserlöslich: } \\
\hline \multirow[t]{3}{*}{ Filtrat: Trockensubstanz } & 5,11 & $3,07 / 3,21$ & 0,74 \\
\hline & 0,20 & 0,25 & 0,57 \\
\hline & 4,91 & 2,96 & 0,17 \\
\hline Benzol-Alkohol $+\mathrm{H}_{2}$ Olöslich & 87,72 & $85,68 / 84,24$ & 90,12 \\
\hline $\begin{array}{l}\text { Trockensubstanz }(\%) \quad \cdot \cdot \cdot \\
\text { In } 2 \% \text { HCllöslich: }\end{array}$ & 12,46 & 14,22 & 4,91 \\
\hline \multirow[b]{4}{*}{ reduzierte Substanz als Gilukose $(\%)$} & 23,49 & $24,69 / 25,77$ & 26,42 \\
\hline & 0,25 & $1,94 / 1,68$ & 6,40 \\
\hline & 23,24 & $22,75 / 24,09$ & 20,02 \\
\hline & 15,11 & $15,65 / 16,26$ & 11,74 \\
\hline $\begin{array}{l}\text { Rückstand }(\%) \\
\text { In } 80 \%{ }_{2} \mathrm{H}_{2} \mathrm{SO}_{4} l o ̈ s l i c h \text { : }\end{array}$ & 62,37 & $56,59 / 57,94$ & 66,81 \\
\hline \multirow{3}{*}{$\begin{array}{ll}\text { Filtrat: } & \text { Trockensubstanz (berechnet) } \\
& (\%) \\
& \text { reduzierte Substanz }(\%) \\
& \text { Asche }(\%)\end{array}$} & 18,11 & 15,27 & 10,18 \\
\hline & 8,52 & 4,56 & 3,42 \\
\hline & 1,18 & 0,29 & 0,30 \\
\hline Rückstand $=$ Rohlignin $(\%) . \ldots$ & 44,26 & 41,32 & 56,63 \\
\hline Rückstand $=$ Asche $(\%) \ldots . \ldots$. & 3,40 & 1,25 & 0,49 \\
\hline
\end{tabular}

Die Stoffgruppenanalyse wurde durchgeführt in Anlehnung an die Vorschrift von E. KrvineN, Über die organische Zusammensetzung der Torfarten; Agrogeologisia Julkaisuja Nr. 36. Helsinki 1934.

1) Messung durchgeführt in der EAWAG, Zürich.

Blättchen von Sphagnum recurvum, was immerhin deutlich auf Flachmoorbildung hinweist."

\subsection{Zersetzungsgrad der Torfproben}

Die Bestimmung des Zersetzungsgrades erfolgte durch das Torfinstitut des Deutschen Brennstoffinstituts in Rostock, Deutschland. Die Torfproben wurden sowohl in getrocknetem Zustand $\left(20^{\circ} \mathrm{C}\right)$ als auch nach Tieffrieren $\left(-20^{\circ} \mathrm{C}\right)$ geprüft. Tab. 4 zeigt die erzielten Resultate. 
Tab. 4. Zersetzungsgrad der Torfe nach v. Post.

\begin{tabular}{llll}
\hline Torf Nr. & Zersetzungsgrad nach v. Post : & Durchfroren & Getrocknet \\
\hline 1 & & $2-3$ & 2 \\
2 & 3 & 4 \\
3 & 5 & $6-7$ \\
\hline
\end{tabular}

3.15 Messung der Kationenaustauschkapazität der Torfe

Die Ermittlung der Kationenaustauschkapazität der Torfproben erfolgte mittels Kolonnenverfahren auf vier verschiedenen Wegen:

a) Überführung der austauschaktiven Gruppen in Na- und danach in $\mathrm{Mg}$-Form mittels $\mathrm{NaCl}$ bzw. $\mathrm{MgSO}_{4}(\mathrm{pH}=3-5)$;

b) Überführung der austauschaktiven Gruppen in $\mathrm{NH}_{4^{-}}$und danach in Ca-Form mittels $\mathrm{NH}_{4}$-Azetat bzw. Ca-Azetat $(\mathrm{pH}=7)$ und

c) Überführung der austauschaktiven Gruppen in Na- und danach in Mg-Form mittels Na-Azetat bzw. Mg-Azetat ( $\mathrm{pH}=8)$.

Für eine ausführliche Beschreibung dieser Methoden sei auf die bereits zitierte Veröffentlichung der EAWAG verwiesen [1].

d) Als vierte Methode wurde das Barium-Durchwaschverfahren für die Ermittlung der T-, H- und S-Werte angewendet [16].

\section{Prinzip der Methode}

Durch Behandlung der Bodenprobe mit auf $\mathrm{pH} 7$ gepufferter $\mathrm{BaCl}_{2}$-Lösung werden alle im Boden austauschbar gebundenen Kationen einschliesslich der H-Ionen gegen Ba ausgetauscht, wobei wiederholtes Durchwaschen einen nahezu vollständigen Umtausch gewährleistet. Nach Auswaschen der in den Poren des Bodens zurückgebliebenen Bariumlösung wird das sorbierte Barium mit $\mathrm{MgCl}_{2}$-Lösung ausgetauscht und im Filtrat als $\mathrm{BaSO}_{4}$ bestimmt. Die ausgetauschten H-Ionen werden im ersten Umtauschfiltrat durch Titration mit $\mathrm{NaOH}$ ermittelt.

\subsection{Herstellung des Modellwassers}

Für jede Versuchsserie sind mindestens 201 «Modellwasser» hergestellt worden: $600 \mathrm{mg} \mathrm{CaCO}{ }_{3}$ wurden in 201 demineralisiertem Wasser $\left(=12 \mathrm{mg} \mathrm{Ca}^{2+} / 1\right)$ unter $\mathrm{Zu}$ gabe von wenigen Tropfen $\mathrm{HCl}$ aufgelöst, ${ }^{90} \mathrm{Sr}^{2+}{ }^{20} \mathrm{Y}^{3+}{ }_{-} \mathrm{Lösung}^{3}$ ) (mit Spuren von inaktiven $\mathrm{Sr}$ - und $\mathrm{Y}$-Trägern) zugefügt und das $\mathrm{pH}$ mit $\mathrm{NH}_{4} \mathrm{OH}$ auf 6,8 eingestellt. Die Aktivität der zur Perkolation verwendeten Modellwässer betrug stets $0,2-0,3 \mu \mathrm{Ci} / 1$ (nur in einem Fall $2 \mu \mathrm{Ci} / \mathrm{l}$ ).

\subsection{Versuchsanordnung zur Bestimmung des Rückhaltevermögens} der Torfe für ${ }^{90} \mathrm{Sr}^{2+-90} \mathrm{Y}^{3+}$

Zur Bestimmung des Rückhaltevermögens der Torfe für ${ }^{90} \mathrm{Sr}^{2+-}{ }^{90} \mathrm{Y}^{3+}$ wurden Perkolationsversuche in ein- und mehrstufigen (hintereinander geschalteten) Ionenaustauschersäulen aus Glas (Innendurchmesser $=23 \mathrm{~mm}$ ) durchgeführt. Das Modellwasser wurde aus einer 10litrigen Mariotteschen Flasche aus Kunststoff dosiert und von unten nach oben - um ein starkes Zusammenpressen des Torfes zu vermeiden -

3) Standardlösung vom Radiochemical Centre, Amersham, England. 
mit einer Fliessgeschwindigkeit von $3,6 \mathrm{~cm} / \mathrm{min}$ perkoliert. Die Eluate wurden fraktionenweise aufgefangen und ihre Beta-Aktivität gemessen. Neben der Bestimmung der Radioaktivität wurden auch der Ca-Gehalt (komplexometrisch nach ScHWARzENBACH [17] und der pH-Wert (elektrometrisch, Gerät E396, Metrohm AG Herisau) ermittelt.

\subsection{Präparierung der Torfkolonnen}

Das Einfüllen der Torfproben in die Ionenaustauschersäulen bereitete grosse Schwierigkeiten. Es musste eine Methode gefunden werden, welche genügende Durchlässigkeit und konstante Fliessgeschwindigkeit ermöglichte, ohne dass in den Kolonnen Verstopfungen und Kanalbildungen entstanden.

Für die vorliegenden Versuche wurden schliesslich drei verschiedene Füllungsmethoden gewählt.

a) Einfüllen des Torfes in die Ionenaustauschersäule nach vorheriger Aufschwemmung mit dem Modellwasser:

Eine aliquote Menge des bei $20^{\circ} \mathrm{C}$ getrockneten Torfmaterials wurde in einem Becherglas mit dem Modellwasser aufgeschwemmt, mit einem Kunststoffspatel verrührt, in die Ionenaustauschersäule gefüllt und schliesslich der Torfschlamm während 24 Stunden stehengelassen. Danach liess man das Modellwasser von unten nach oben durch die Kolonne perkolieren.

b) Direkteinfüllung des aufgetauten Torfmaterials und anschliessende Perkolation des Modellwassers:

Eine aliquote Menge des in tiefgefrorenem Zustand $\left(-20^{\circ} \mathrm{C}\right)$ aufbewahrten und danach aufgetauten Torfmaterials wurde in die Ionenaustauschersäule eingefüllt und die Luft mit dem von unten nach oben langsam in die Kolonne einströmenden Modellwasser verdrängt. Die Perkolation erfolgte nach 24 Stunden in derselben Fliessrichtung.

c) Direkteinfüllung des getrockneten oder aufgetauten Torfmaterials und Verdrängung der Luft mittels demineralisiertem, ausgekochtem Wasser unter Vakuum:

Eine aliquote Menge des bei $20^{\circ} \mathrm{C}$ getrockneten bzw. des nach Tieffrieren aufgetauten Torfmaterials wurde in die Ionenaustauschersäule eingefüllt und die Luft mittels demineralisiertem und ausgekochtem Wasser verdrängt, welches unter Vakuum von unten nach oben langsam in die Kolonne einströmte. Die Perkolation des Modellwassers erfolgte 24 Stunden später in derselben Fliessrichtung.

\subsection{Radioaktivitätsmessung}

Die Radioaktivitätsmessungen erfolgten mit einem dekadischen Impulsuntersetzer (ELB 2 der Firma Landis \& Gyr, Zug) und einem Stirnfenster-Halogenzählrohr (mit Glimmerfenster, etwa $1,2 \mathrm{mg} / \mathrm{cm}^{2}$ Flächengewicht), abgeschirmt durch einen Mantel aus $1 \mathrm{~cm}$ Eisen und $4 \mathrm{~cm}$ Blei. Der Nulleffekt (background) beträgt etwa 15-16 Impulse pro Minute.

\subsection{Kationenaustauschkapazität}

Die Kationenaustauschkapazität der Torfproben, ermittelt nach den unter 3.15 a)-c) erwähnten Methoden, ist in Tab. 5 zusammengefasst.

Die Austauschkapazitäten beziehen sich auf $1 \mathrm{~g}$ eines bei $103^{\circ} \mathrm{C}$ getrockneten Materials. Sie zeigen, dass 
Tab. 5. Kationenaustauschkapazität der Torfe.

\begin{tabular}{|c|c|c|c|}
\hline \multicolumn{4}{|c|}{ Kationenaustauschkapazität in mäq/g Torf } \\
\hline Austausch & $\begin{array}{l}\mathrm{NaCl} / \mathrm{MgSO}_{4} \\
(\mathrm{pH}=3-5)\end{array}$ & $\begin{array}{l}\mathrm{NH}_{4} \text {-Azetat/Ca-Azetat } \\
(\mathrm{pH}=7)\end{array}$ & $\begin{array}{l}\text { Na-Azetat/Mg-Azetat } \\
(\mathrm{pH}=8)\end{array}$ \\
\hline \multicolumn{4}{|c|}{ Nach Trocknen $\left(20^{\circ} \mathrm{C}\right)$} \\
\hline Torf Nr. 1 & 0,5 & 0,8 & 1,2 \\
\hline Torf Nr. 2 & 0,4 & 0,6 & 1,0 \\
\hline Torf Nr. 3 & 0,3 & 0,5 & 0,5 \\
\hline \multicolumn{4}{|c|}{ Nach Tieffrieren $\left(-20^{\circ} \mathrm{C}\right)$} \\
\hline Torf Nr. 1 & 0,9 & 0,9 & 1,5 \\
\hline Torf Nr. 2 & 0,6 & 0,9 & 1,3 \\
\hline Torf Nr. 3 & 1,4 & 1,0 & 1,7 \\
\hline
\end{tabular}

a) die Austauschkapazität der Torfe je nach der gewählten Analysenmethode und der Art der Proben variiert und

b) die Torfe nach Tieffrieren eine grössere Austauschkapazität aufweisen als nach dem Trocknungsprozess bei $20^{\circ} \mathrm{C}$. Dieser Unterschied kommt insbesondere beim Torf Nr. 3 zum Ausdruck.

Anhand des Barium-Durchwaschverfahrens wurde geprüft, welcher Anteil der Gesamt-Kationenaustauschkapazität (T-Wert) von den austauschbaren Basen (SWert) und welcher Anteil vom «H-Wert» herrührt. Als austauschbare Basen werden in der Bodenkunde in erster Linie die austauschbaren $\mathrm{Ca}-, \mathrm{Mg}-, \mathrm{K}$ - und $\mathrm{Na}-\mathrm{I}$ onen bezeichnet. Unter H-Wert versteht man den Austausch von $\mathrm{H}$ - und Al-Ionen [16]. Die T-, S- und H-Werte der drei Torfproben sind in Tab. 5 a zusammengefasst. Zum Vergleich sind auch die Ca-Gehalte der Proben angegeben.

Tab.5a. Austauschkapazität der Torfe nach dem Barium-Durchwaschverfahren $(\mathrm{ph}=7)$.

\begin{tabular}{|c|c|c|c|c|c|c|}
\hline \multicolumn{7}{|c|}{ Austauschkapazität in mäq/g wasserfreier Substanz } \\
\hline & \multicolumn{3}{|c|}{ Luftgetrocknet } & \multicolumn{3}{|c|}{ Tiefgefroren } \\
\hline & Torf Nr. 1 & Torf Nr.2 & Torf Nr.3 & Torf Nr. 1 & Torf Nr. 2 & Torf Nr.3 \\
\hline T-Wert . . . . . . & 0,6 & 0,4 & 0,4 & 0,6 & 0,6 & 1,1 \\
\hline H-Wert . . . . & 0,6 & 0,3 & 0,2 & 0,6 & 0,3 & 0,2 \\
\hline $\begin{array}{l}\text { S-Wert } \cdot \cdot \cdot \cdot \cdot \cdot \\
(\mathrm{T}-\mathrm{H})\end{array}$ & 0 & 0,1 & 0,2 & 0 & 0,3 & 0,9 \\
\hline $\begin{array}{l}\mathrm{mg} \mathrm{Ca} / \mathrm{g} \cdot \dot{*} \cdot \cdot \cdot \\
\text { wasserfreie Substanz }\end{array}$ & 4 & 5 & 22 & 4 & 5 & 22 \\
\hline
\end{tabular}

Aus diesen Messergebnissen geht hervor, dass der Anteil des «H- bzw. S-Austausches» an der Gesamt-Kationenaustauschkapazität je nach Torfart variiert. Bei Torf Nr. 1 handelt es sich offenbar ausschliesslich um «H-Austausch», da der ermittelte T-Wert jenem des H-Wertes entspricht. Bei den Torfen Nr. 2 und Nr. 3 rührte hingegen die Gesamt-Kationenaustauschkapazität teilweise vom H- bzw. vom Basenaustausch her. 
Ein Vergleich der Resultate innerhalb der getrockneten bzw. der tiefgefrorenen Proben ergibt, dass der grösste Basenaustausch und der kleinste $\mathrm{H}$-Wert stets beim Torf Nr. 3 auftreten.

Während die H-Werte der tiefgefrorenen Proben gegenüber den getrockneten Materialien unverändert blieben, lagen die S-Werte - analog der Gesamtaustauschkapazität - nach Tieffrieren höher als jene der getrockneten Torfe. Daraus folgt, dass die erhöhte Austauschfähigkeit der tiefgefrorenen Materialien gegenüber den getrockneten Proben ausschliesslich auf eine erhöhte Basenaustauschfähigkeit der tiefgefrorenen Torfe zurückzuführen ist.

Die Übereinstimmung der Reihenfolge der S-Werte mit jenen des Ca-Gehaltes der verschiedenen Torfe (Torf Nr. $3>\mathrm{Nr} .2>\mathrm{Nr} .1$ ) lässt vermuten, dass eine Beziehung zwischen dem Basenaustausch und dem Ca-Gehalt der Torfe besteht: der CaGehalts-Anstieg ist mit der Erhöhung des Basenaustausches gekuppelt. Eine ähnliche Korrelation fanden Puustjärvi [18], Fischer und Kadner [19] zwischen dem CaGehalt und der Gesamtaustauschkapazität der Torfe, d.h. zwischen dem Ca-Gehalt und den T-Werten. Unsere Beobachtungen weichen von jenen dieser Autoren insofern ab, als eine Zunahme der Gesamtaustauschkapazität mit der Erhöhung des Ca-Gehaltes der Torfe nur bei den tiefgefrorenen Proben zu verzeichnen ist. Bei den getrockneten Torfen wurde eine Abnahme der Gesamtaustauschkapazität mit der Zunahme des $\mathrm{Ca}-G e h a l t e s$ festgestellt. Dies ist vermutlich darauf zurückzuführen, dass die Torfprobe Nr. 3 mit dem grössten Ca-Gehalt bei der Trocknung die grösste Kapazitätsabnahme erfuhr.

Es soll in diesem Zusammenhang darauf hingewiesen werden, dass Torf Nr. 3 neben dem grössten Ca-Gehalt auch den höchsten Zersetzungsgrad der drei Torfproben aufwies. Vielleicht ist dies die Ursache seiner hohen Austauschkapazitätsabnahme infolge der Trocknung. FIScher und KADNER [19] stellten nämlich eine gewisse Korrelation zwischen der Austauschkapazitätsabnahme beim Trocknen und dem Zersetzungsgrad fest. Sie fanden bei den Torfproben, welche aus verschiedenen Schichttiefen eines Profils herrührten, dass die stärker zersetzten Torfe aus den unteren Schichten beim Trocknen eine wesentlich grössere Abnahme der Austauschkapazität erfuhren als die schwächer zersetzten Torfe aus den oberen Schichten. Für die auffallenden Austauscheigenschaften des Torfes Nr. 3 sind sicherlich noch weitere Faktoren verantwortlich. So weist er den höchsten $\mathrm{pH}$-Wert, den grössten Asche-, Stickstoff- und Rohligningehalt auf, und er trägt noch weitere Merkmale subhydrisch entstandener Niedermoortorfe. Vom pH-Wert weiss man, dass seine Erhöhung eine Austauschkapazitätszunahme bewirkt. Auch dem Humus-Lignin soll nach der Auffassung von PuUstjärvi [18] eine grosse Bedeutung zukommen. Bei den Austauschprozessen spielen alle diese Grössen eine mehr oder weniger wichtige Rolle, das Gesamtresultat hängt von den vorherrschenden Faktoren ab.

\subsection{Rückhaltevermögen der Torfe für ${ }^{90} S r^{2+}-^{90} Y^{3+}$}

\subsection{Vorversuche}

$\mathrm{Zu}$ unserer Orientierung wurden zunächst einige grobe Vorversuche durchgeführt, wobei die Eluate in 1- bis 2litrigen Fraktionen zur Untersuchung gelangten. Zielsetzung dieser Experimente war in erster Linie die Erarbeitung einer geeigneten $\mathrm{Me}-$ 
thode zur Einfüllung des Torfmaterials in die Ionenaustauschersäulen, welche eine lange Perkolation ohne Verstopfung in den Kolonnen gestattete. Ferner war die Grösse der notwendigen Menge des Versuchsmaterials (Torfmenge, Volumen des Modellwassers usw.) festzustellen. Auch wollten wir uns einige qualitative Informationen über den Gesamtprozess verschaffen.

$\mathrm{Zu}$ Beginn wurden etwa $15 \mathrm{~g}$ (bezogen auf getrocknetes Material, $103^{\circ} \mathrm{C}$ ) von Torf Nr. 1 nach der Methode " $a$ » in die ein- und dreistufigen Ionenaustauschersäulen eingefüllt und das Modellwasser von unten nach oben perkoliert. Da die Durchlässigkeit infolge zu hoher Einwaage ziemlich rasch nachliess, wurde der Versuch unter denselben Bedingungen mit $12 \mathrm{~g}$ Torfmaterial wiederholt. Mit dieser Einwaage konnte wohl eine bessere Durchlässigkeit erzielt werden; es entstanden jedoch Kanäle und Verstopfungen in der Kolonne. Die Messergebnisse (Abb. 1) können deshalb nur mit
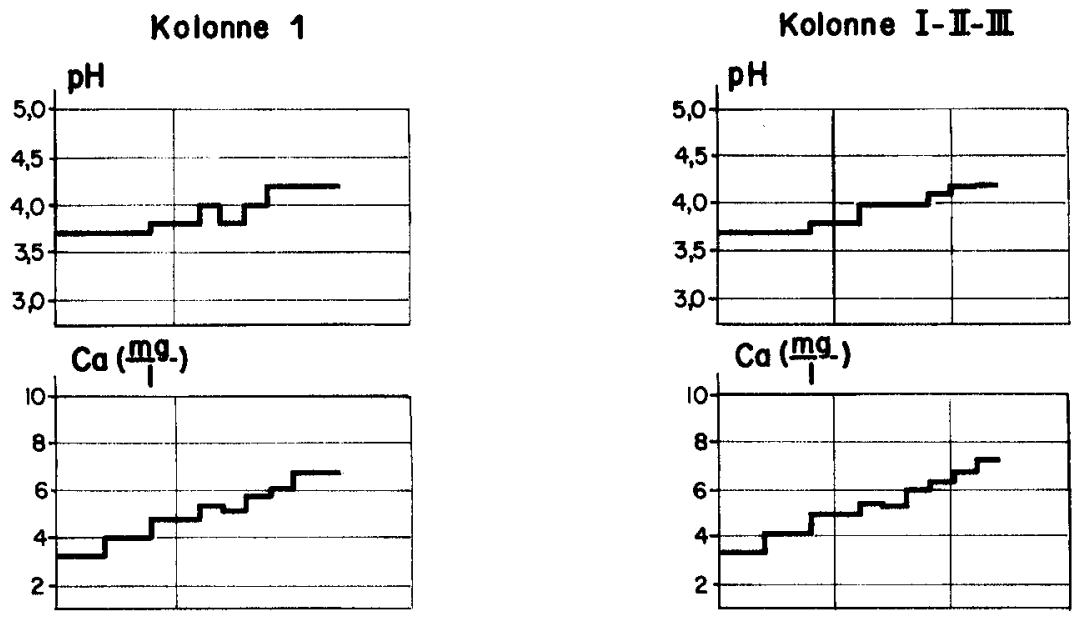

Zurückgehaltene Aktivität

\section{Zurückgehaltene Aktivität}
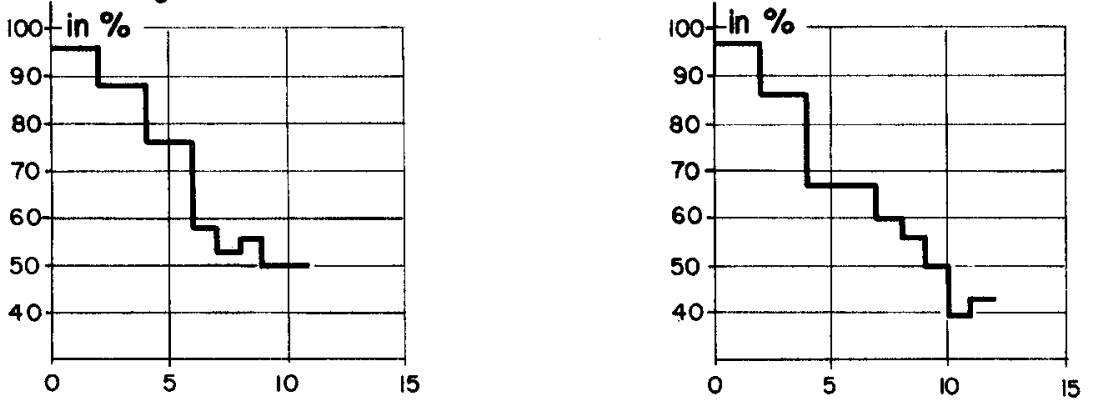

$\rightarrow$ Volumen des Torffiltrates (l)

Abb.1. Perkolationsversuche mit Torf Nr.1, Kolonnenfüllung nach Methode a. Einwaage äquivalent mit $12 \mathrm{~g}$ eines bei $103^{\circ} \mathrm{C}$ getrockneten Materials. Aktivität der Eingangslösung $=0,2 \mu \mathrm{Ci} / 1$, $\mathrm{Ca}-\mathrm{Gehalt}=0,6 \mathrm{mäq} / \mathrm{l}$. 
Kolonne 1
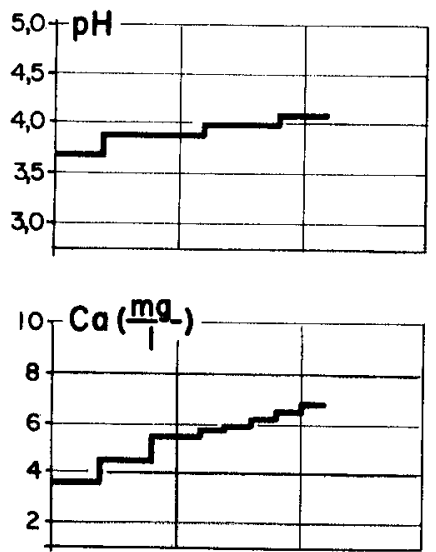

Zurückgehaltene Aktivitäł

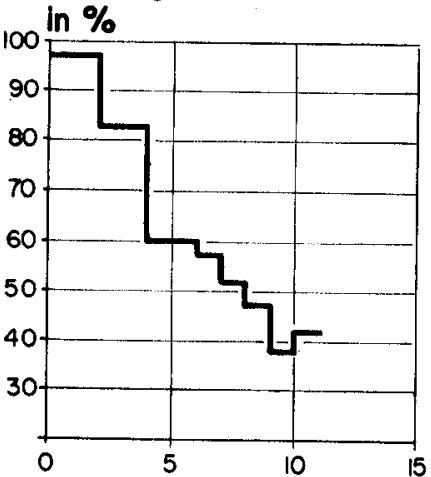

Kolonne I-II-III
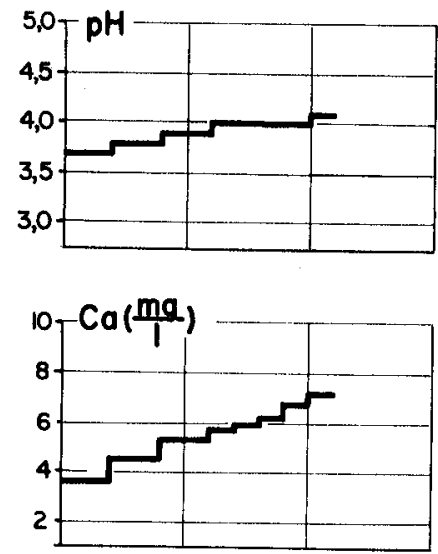

Zurückgehaltene Akfiviłdł

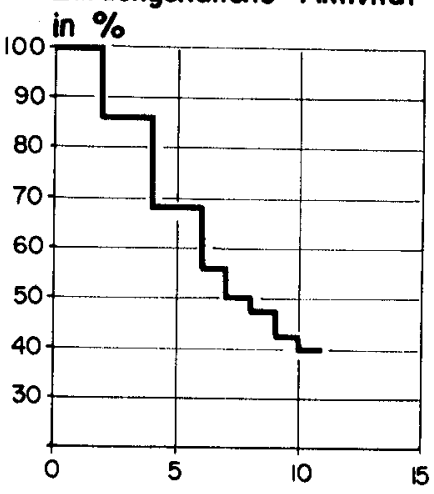

Volumen des Torffiltrates (I)

Abb.2. Perkolationsversuche mit Torf Nr.1, Kolonnenfüllung nach Methode a. Einwaage äquivalent mit $12 \mathrm{~g}$ eines bei $103^{\circ} \mathrm{C}$ getrockneten Materials. Aktivität der Eingangslösung $=2 \mu \mathrm{Ci} / 1$, Ca-Gehalt $=0,6 \mathrm{mäq} / \mathrm{l}$.

Vorbehalt berücksichtigt werden. In der Darstellung ist zuunterst die zurückgehaltene Aktivität in der Torfkolonne, bezogen auf die Eingangsaktivität $(0,2 \mu \mathrm{Ci} / \mathrm{l})$, in Prozent angegeben. In der Mitte sind die Ca-Gehalte und zuoberst die pH-Werte der Eluate aufgeführt. Die Kurven auf der linken Seite zeigen jeweils die Versuchsergebnisse mit einer Kolonne ( Kolonne 1》), auf der rechten Seite sind die Werte der dreistufigen Kolonnenversuche ("Kolonne I-II-III») aufgezeichnet. Die Resultate für die Wiederholung dieses Versuches sind in Abb. 2 gleichartig dargestellt. Die Eingangsaktivität wies hier eine Konzentration von $2 \mu \mathrm{Ci} / \mathrm{l}$ auf. Die Untersuchungen verliefen mit ähnlichen Schwierigkeiten wie vorher.

Trotz den Störungen, welche während der Perkolationen auftraten, zeigte sich deutlich, dass bei einer Abnahme an zurückgehaltener Aktivität in der Kolonne eine 
Kolonne 1
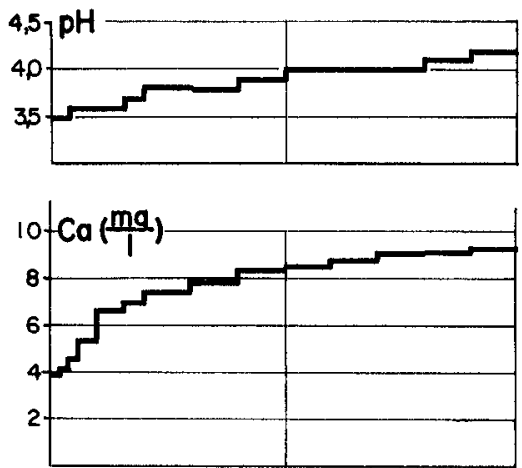

Zurückgehaltene Aktivität

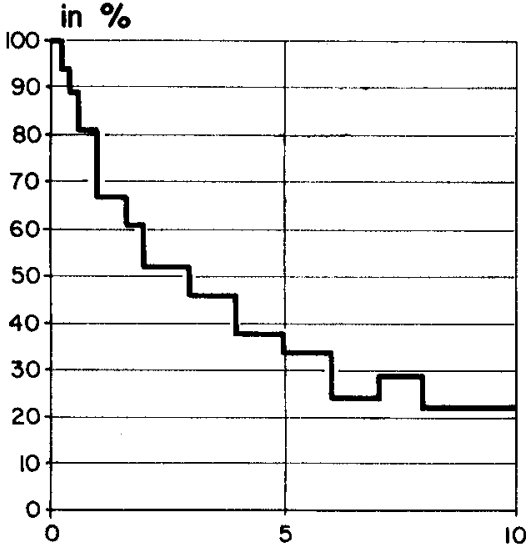

Kolonne I- II - III
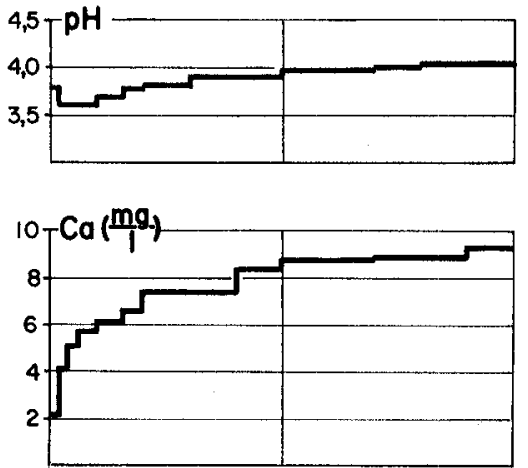

Zurückgehaltene Aktivität in $\%$

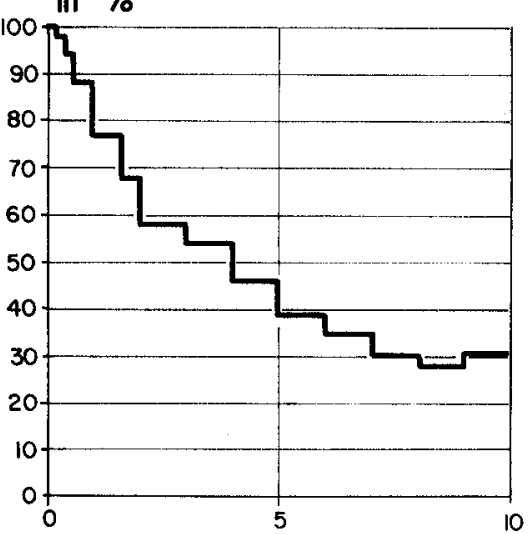

Volumen des Torffiltrates (I)

Abb.3. Perkolationsversuche mit Torf Nr.1, Kolonnenfüllung nach Methode c (bei $20^{\circ} \mathrm{C}$ getrockneter Torf). Einwaage äquivalent mit $6 \mathrm{~g}$ eines bei $103^{\circ} \mathrm{C}$ getrockneten Materials. Aktivität der Eingangslösung $=0,2 \mu \mathrm{Ci} / 1$, Ca-Gehalt $=0,6 \mathrm{mäq} / 1$.

Zunahme im.Ca-Gehalt der Eluate eintritt. Analog lässt sich ein leichter Anstieg des $\mathrm{pH}-$ Wertes feststellen.

Ein wesentlicher Unterschied zwischen den Ergebnissen der einstufigen und der dreistufigen Kolonnen konnte nirgends festgestellt werden. Für die Praxis dürfte jedoch ein mehrstufiges System gegenüber der Verwendung einer einzelenen Säule verschiedene Vorteile bieten. So lassen sich zum Beispiel die Kolonnen beim mehrstufigen System kleiner dimensionieren und dadurch einfacher handhaben. Ferner können sie nach der Aktivitätssättigung einzeln ausgewechselt und mit einer frischen Fülllung sofort ersetzt werden. Erfolgt der Anschluss der neuen Kolonne jeweils bei der hintersten Säule, so können alle Kolonnen bis zur Sättigung ausgenützt werden. Bei Verwendung eines einstufigen Systems müsste hingegen die frische Füllung bereits vor der Sättigung erfolgen, d.h. sobald ein Durchbruch unerwünschter Aktivität eintritt. 
Kolonne 1

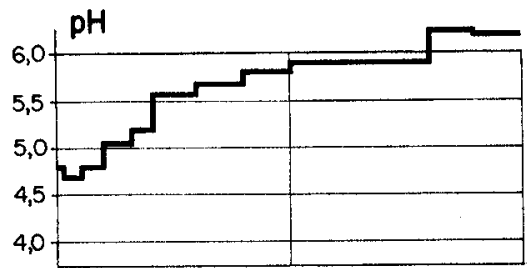

$\operatorname{Ca}\left(\frac{m g}{1}\right)$

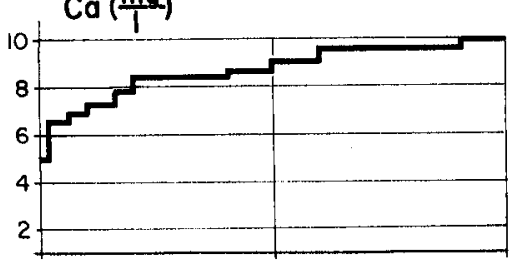

Zurückgehaltene Aktivität

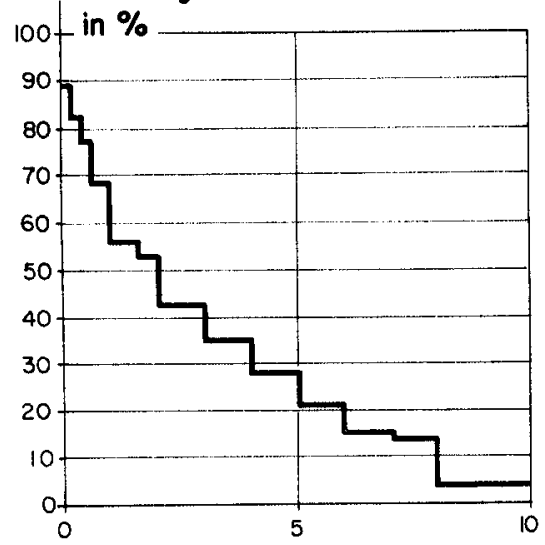

Kolonne I- II - III
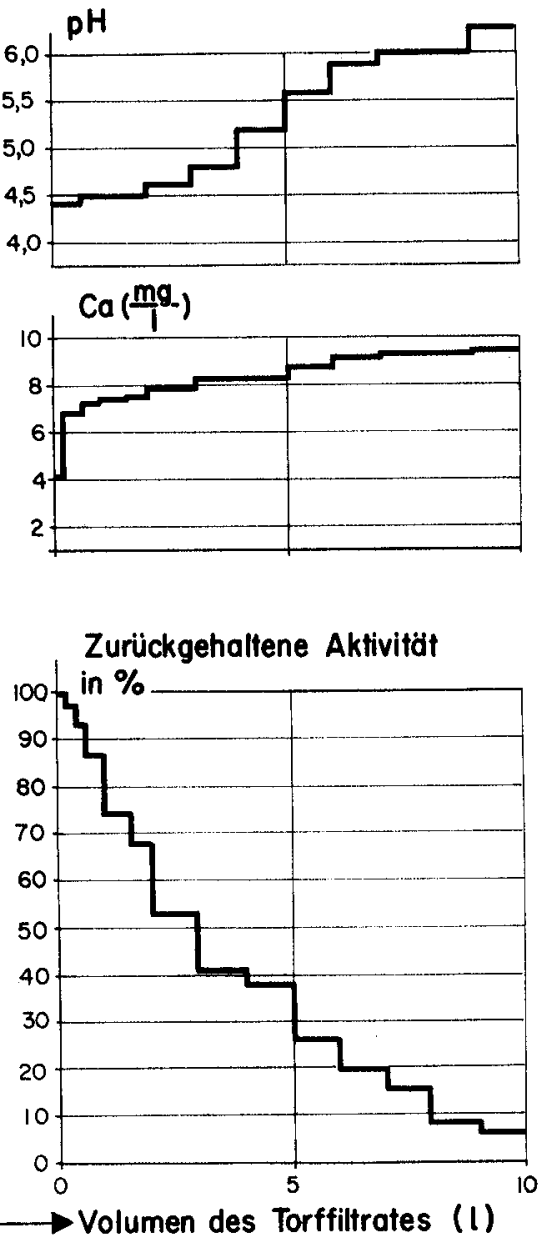

Abb. 4. Perkolationsversuche mit Torf Nr. 2, Kolonnenfüllung nach Methode c (bei $20^{\circ} \mathrm{C}$ getrockneter Torf). Einwaage äquivalent mit $6 \mathrm{~g}$ eines bei $103^{\circ} \mathrm{C}$ getrockneten Materials. Aktivität der Eingangslösung $=0,2 \mu \mathrm{Ci} / 1$, Ca-Gehait $=0,6 \mathrm{mäq} / 1$.

Für die gestaffelte Arbeitsweise der Kolonne soll das folgende Beispiel gegeben werden:

Zur Kontrolle unserer Messgenauigkeit bei der Bestimmung des Ca-Gehaltes wurde stets die Ca-Bilanz im System Eingangslösung/Torf/Eluat nach Abschluss einer Perkolation aufgenommen. Die Säulen wurden dabei einzeln berücksichtigt. Es zeigte sich, dass der Ca-Gehalt der Torfkolonnen gemäss ihrer Reihenfolge abnahm. Die dritte Kolonne enthielt etwa ein bis zwei Drittel des Ca-Gehaltes der ersten Kolonne. Die Abnahme der Aktivitätskonzentration erfolgte in analoger Weise.

Die Kolonnenfüllung nach der Methode «b» brachte keine wesentlichen Verbesserungen; auch hier entstanden Kanäle und Verstopfungen in den Säulen; die Perko- 
Kolonne 1

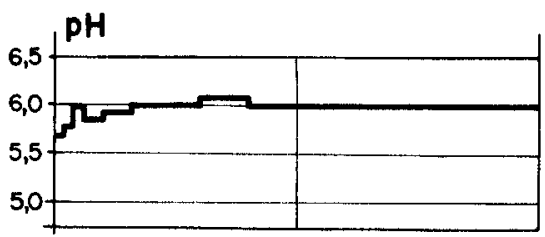

Ca ( $\left.\frac{\text { mg }}{1}\right)$

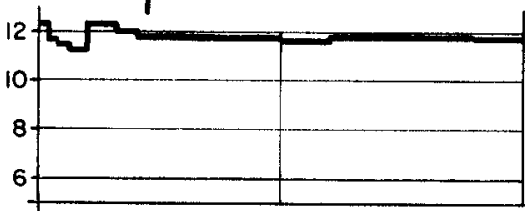

Zurückgehaltene Aktivitöt

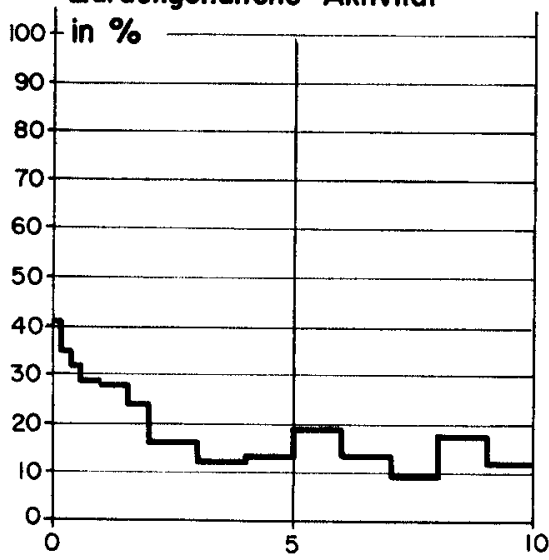

Kolonne I-II- III

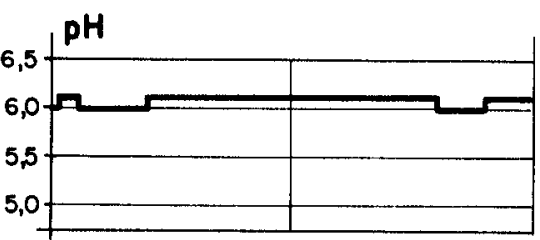

Ca (mg-)

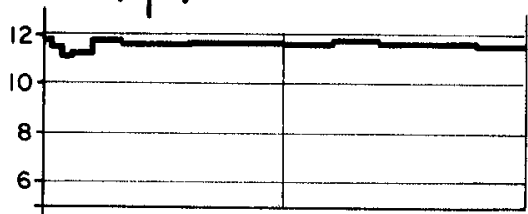

Zurückgehaltene Aktiviłäł

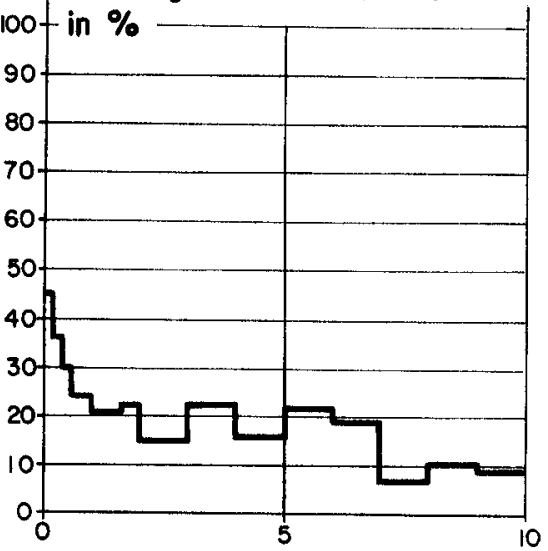

Abb.5. Perkolationsversuche mit Torf Nr.3, Kolonnenfüllung nach Methode c (bei $20^{\circ} \mathrm{C}$ getrockneter Torf). Einwaage äquivalent mit $6 \mathrm{~g}$ eines bei $103^{\circ} \mathrm{C}$ getrockneten Materials. Aktivität der Eingangslösung $=0,2 \mu \mathrm{Ci} / \mathrm{l}$, Ca-Gehalt $=0,6 \mathrm{mäq} / 1$.

lation musste sogar z.T. wegen totaler Verstopfung frühzeitig eingestellt werden. Die ermittelten Resultate bestätigten dennoch die bei der Methode «a» aufgeführten Feststellungen. Auf eine Wiedergabe dieser Messergebnisse wurde hier verzichtet.

Bei den Experimenten nach Methode "c» konnten sowohl die Durchlässigkeit als auch die Fließstärke bis zum Perkolationsschluss konstant gehalten werden. Hier wurden die Eluate in kleineren Fraktionen $(0,21)$ aufgefangen und untersucht. In den Abb. 3-5a sind diese Messergebnisse aufgezeichnet. Eine Gegenüberstellung der Resultate mit Torf Nr. 1, 2 und 3 zeigt, dass beim Torf Nr. 1 (Abb. 3) die Abnahme der zurückgehaltenen Aktivität von einem gleichzeitigen Anstieg des Ca-Gehaltes der Eluate begleitet war. Der pH-Wert stieg nur leicht an. Beim Torf Nr. 2 (Abb. 4) nahm. sowohl der $\mathrm{Ca}-\mathrm{Gehalt}$ als auch der $\mathrm{pH}$-Wert der Eluate bei Abnahme der zurückgehaltenen Aktivität in den Kolonnen merklich zu. Beim Torf Nr. 3 (Abb. 5) blieben 
Kolonne 1
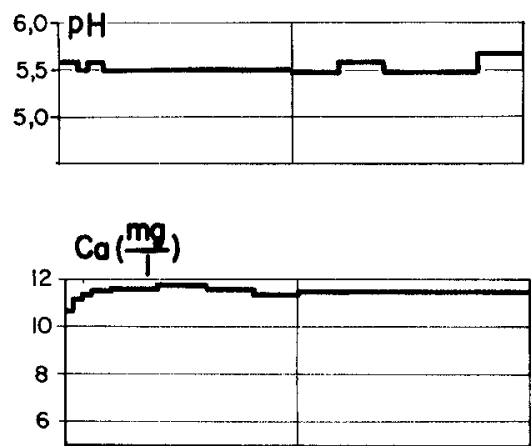

Zurückgehaltene. Aktivität

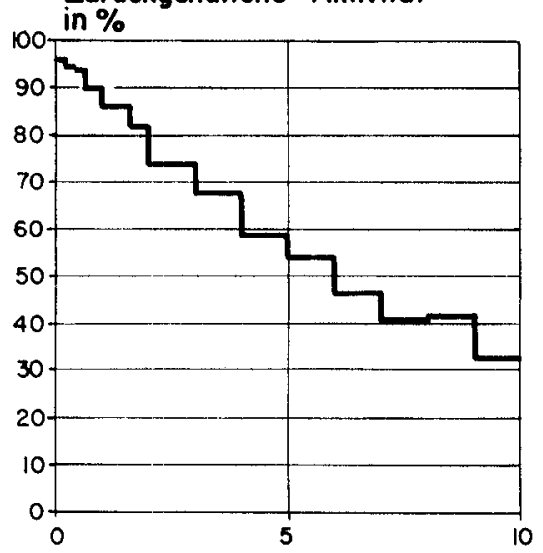

Kolonne I- II - III
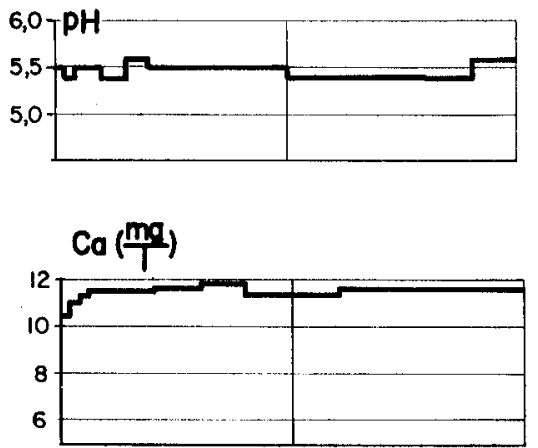

Zurückgehaltene Aktivitäł

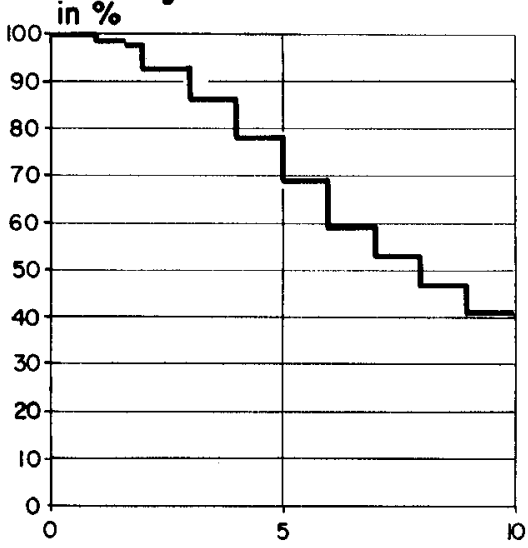

Volumen des Torffiltrates (I)

Abb.5a. Perkolationsversuche mit Torf Nr.3, Kolonnenfüllung nach Methode c (tiefgefrorener Torf, vor Einfüllung aufgetaut). Einwaage äquivalent mit $7 \mathrm{~g}$ eines bei $103^{\circ} \mathrm{C}$ getrockneten Materials. Aktivität der Eingangslösung $=0,2 \mu \mathrm{Ci} / \mathrm{l}$, Ca-Gehalt $=0,6 \mathrm{mäq} / 1$.

sowohl die Ca-Gehalte als auch der $\mathrm{pH}$-Wert der Eluate praktisch konstant. Dasselbe liess sich beim wiederholten Versuch mit Torf Nr. 3 (tiefgefroren konserviert) beobachten (Abb. 5a).

Die Ursache für die unterschiedliche Veränderung des Ca-Gehaltes und des $\mathrm{pH}$ Wertes der Torffiltrate liegt offenbar in der Natur der Torfe. Während die Torfproben Nr. 1 und Nr. 2 nur wenig Ca enthalten und einen niedrigen pH-Wert aufweisen, besitzt der Torf Nr. 3 einen relativ hohen Ca-Gehalt und einen erhöhten pH-Wert. Erfolgt nun eine Perkolation Ca-haltiger Lösung durch die Torfsäulen, so brechen die $\mathrm{Ca}-$ Ionen der Lösung gemäss dem $\mathrm{Ca}-\mathrm{Gehalt}$ bzw. den mit $\mathrm{Ca}$ nicht beladenen, austauschbaren Stellen der Torfe durch. Bei den Proben Nr. 1 und Nr. 2, in welchen der Austausch im wesentlichen zwischen den H-Ionen der funktionellen Gruppen des Torfes und den Ca-Ionen der Lösung erfolgt, gelangen die Ca-Ionen in die Eluate, sobald die zur Verfügung stehenden austauschbaren Stellen mit Ca vollständig beladen 
Zurückgehaltene Aktivität

in \%
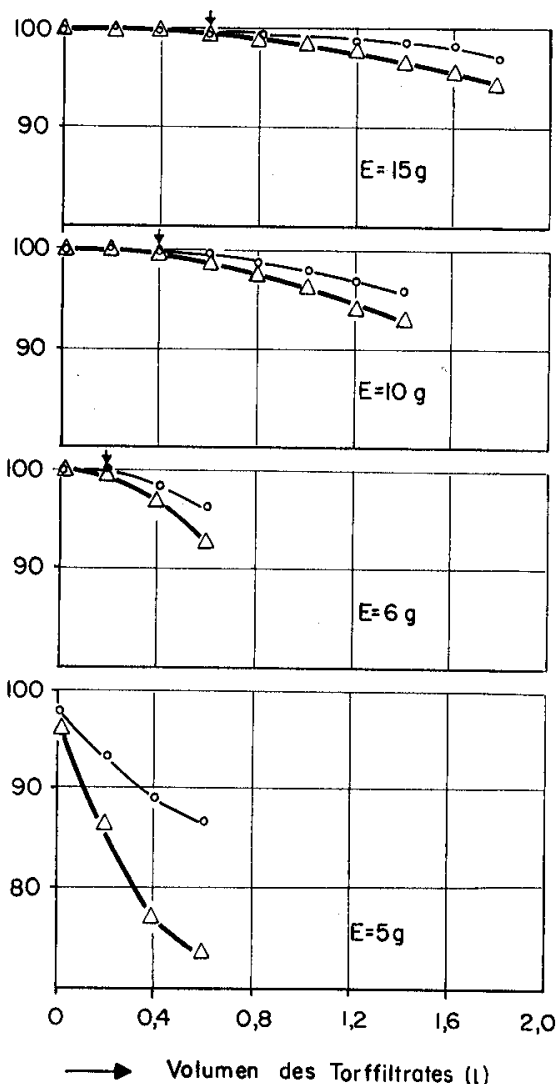

Abb. 6. Perkolationsversuche mit Torf Nr.1, Kolonnenfüllung nach Methode c (bei $20^{\circ} \mathrm{C}$ getrockneter Torf). Einwaage äquivalent mit einem bei $103^{\circ} \mathrm{C}$ getrockneten Material. Aktivität der Ein gangslösung $=0,2 \mu \mathrm{Ci} / \mathrm{l}, \mathrm{Ca}-$ Gehalt $=0,6 \mathrm{mäq} / \mathrm{l}$. $\bigcirc-$ Aktivität zur Zeit der Perkolation; $\Delta-$ Aktivität im radioaktiven Gleichgewicht.

sind. Die Ca-Konzentration der Eluate steigt dann mit der Fortsetzung der Perkolation bis zum Erreichen der Konzentration der Eingabelösung gemäss einer exponentiellen Kurve an. In unseren Versuchen wurde die Perkolation etwas früher eingestellt. Bei Torf Nr. 3 sind hingegen die austauschbaren Stellen des Torfmaterials bereits zum grössten Teil mit Ca beladen. Die Ca-Ionen der perkolierenden Lösung brechen deshalb schon am Anfang der Filtration beinahe quantitativ durch, und ihre Konzentration bleibt in den Eluaten während der Perkolation mit kleineren Schwankungen konstant.

Die Konzentrationsänderung der $\mathrm{Ca}$-Ionen in den Torffiltraten spiegelt sich auch in der $\mathrm{pH}$-Änderung der Eluate wider.

Die in den Vorversuchen angegebenen Aktivitätswerte sind durchwegs anhand der Messungen des ${ }^{90} \mathrm{Sr}-{ }^{90} \mathrm{Y}$ im radioaktiven Gleichgewicht berechnet worden. In den Hauptversuchen wurden jedoch die Radioaktivitätsverhältnisse sowohl zur Zeit der Perkolation als auch im radioaktiven Gleichgewicht festgestellt. 

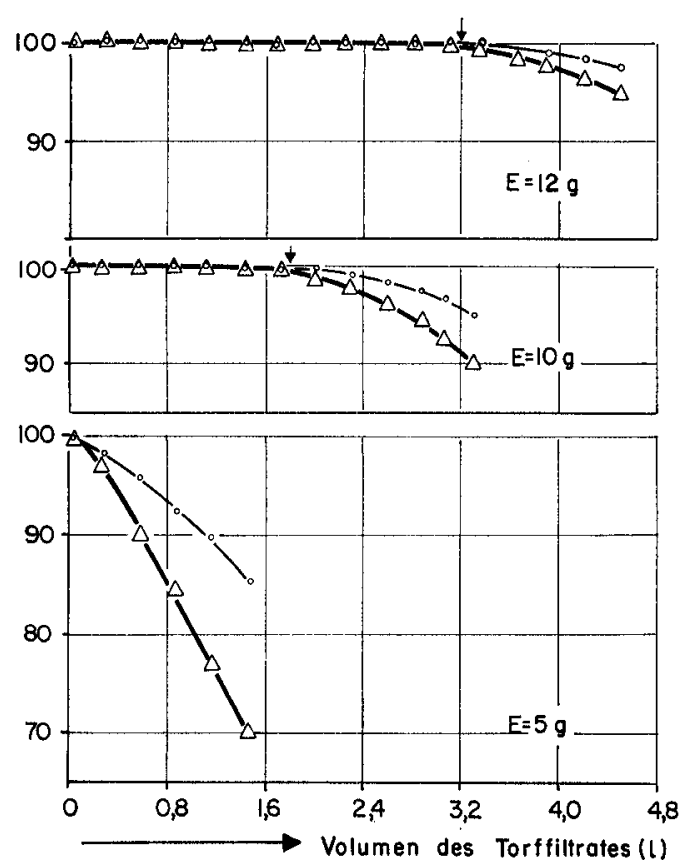

Abb.7. Perkolationsversuche mit Torf Nr.1, Kolonnenfüllung nach Methode c (tiefgefrorener Torf, vor Einfüllung aufgetaut). Einwaage äquivalent mit einem bei $103^{\circ} \mathrm{C}$ getrockneten Material. Aktivität der Eingangslösung $=0,2 \mu \mathrm{Ci} / 1, \mathrm{Ca}$-Gehalt $=0,6 \mathrm{mäq} / \mathrm{l}$. $\bigcirc-$ Aktivität zur Zeit der Perkolation; $\triangle-$ Aktivität im radioaktiven Gleichgewicht.

\subsection{Hauptversuche}

Nachdem eine befriedigende Methode (Methode «c») für die Kolonnenfüllung gefunden war, erfolgte die Prüfung des Rückhaltevermögens für ${ }^{90} \mathrm{Sr}-{ }^{90} \mathrm{Y}$ in Abhängigkeit von der Art und der Menge der Torfe. Die Experimente wurden im einstufigen Kolonnensystem gemäss der oben aufgeführten Versuchsanordnung vorgenommen. Von den in 20-ml-Fraktionen aufgefangenen Eluaten wurde jede zehnte auf ihre Radioaktivität geprüft. Die Messungen erfolgten sowohl unmittelbar nach der Perknlation als auch im radioaktiven Gleichgewicht. Die graphischen Darstellungen (Abb. 6-11) zeigen die Messergebnisse.

3.321 Beziehung zwischen der zurückgehaltenen Aktivität und der Torfmenge

In den Abb. 6 und 7 sind die Messergebnisse für Torf Nr. 1, eingefüllt in trockenem bzw. nassem Zustand, aufgetragen. Die Linie o - bedeutet die zurückgehaltene Aktivität zur Zeit der Perkolation und $\Delta-$ - die im radioaktiven Gleichgewicht. Die Pfeile zeigen das Volumen des Torffiltrates zu Beginn des Aktivitätsdurchbruchs. Aus diesen Darstellungen kann folgendes abgelesen werden:

1. Der Kurvenverlauf hängt von der Einwaage (E) ab: je grösser die eingewogene Torfmenge ist, um so flacher werden die Kurven. 


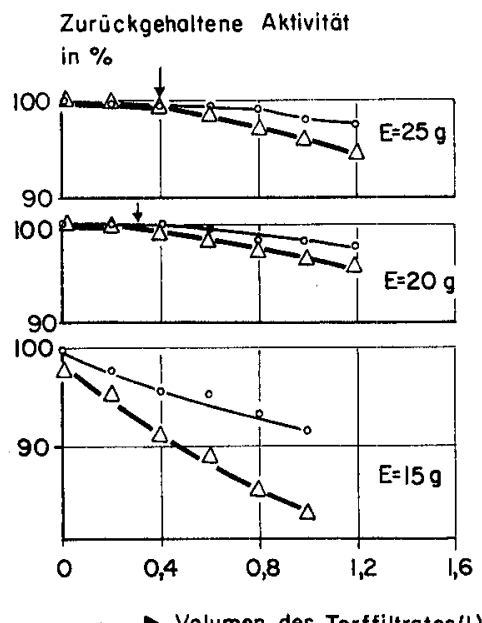

Abb.8. Perkolationsversuche mit Torf Nr.2, Kolonnenfüllung nach Methode c (bei $20^{\circ} \mathrm{C}$ getrockneter Torf). Einwaage äquivalent mit einem bei $103^{\circ} \mathrm{C}$ getrockneten Material. Aktivität der Eingangslösung $=0,2 \mu \mathrm{Ci} / 1, \mathrm{Ca}-$ Gehalt $=0,6 \mathrm{mäq} / 1 . \bigcirc-$ Aktivität zur Zeit der Perkolation; $\triangle-A \mathrm{kti}-$ vität im radioaktiven Gleichgewicht.

2. Eine 100prozentige Rückhaltung der Radioaktivität benötigt eine Mindestmenge von Torf.

3. Die zurückgehaltene Aktivität, berechnet für das radioaktive Gleichgewicht, lag bei allen Einwaagen tiefer als zur Zeit der Perkolation. Das zeigt, dass die Aktivi-

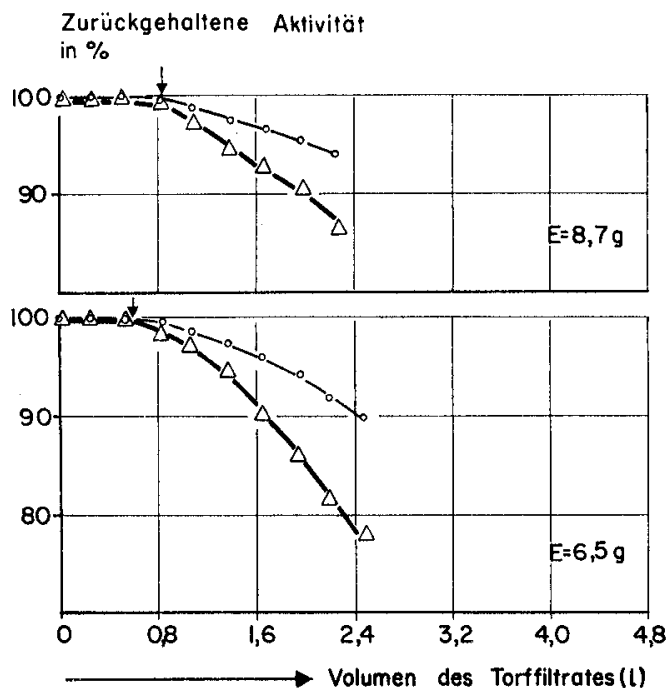

Abb.9. Perkolationsversuche mit Torf Nr.2, Kolonnenfüllung nach Methode c (tiefgefrorener Torf, vor Einfüllung aufgetaut). Einwaage äquivalent mit einem bei $103^{\circ} \mathrm{C}$ getrockneten Material. Aktivität der Eingangslösung $=0,2 \mu \mathrm{Ci} / 1, \mathrm{Ca}-\mathrm{Gehalt}=0,6 \mathrm{mäq} / 1 . \mathrm{O}-$ Aktivität zur Zeit der Perkolation; $\triangle$-Aktivität im radioaktiven Gleichgewicht. 
tät der Eluate bis zum radioaktiven Gleichgewicht zunahm. Die Verdoppelung der Werte nach 14 Tagen (= Einwachszeit des ${ }^{90} \mathrm{Y}$ in das ${ }^{90} \mathrm{Sr}$ ) ergab, dass die durchgebrochene Aktivität von reinem ${ }^{90} \mathrm{Sr}$ herrührte.

Dieselben Feststellungen gelten auch für die Torfe Nr. 2 (Abb. 8, 9) und Nr. 3 (Abb. 10, 11).

Berechnet man die spezifische Durchbruchskapazität $\left(D_{\gamma}\right)$ anhand der Beziehung

$$
D_{\gamma}=V / g \text {, }
$$

wobei $V$ das Volumen des Torffiltrates bis zum Durchbruch der Radioaktivität und $g$ das Gewicht des Torfes (bezogen auf getrocknetes Material, $103^{\circ} \mathrm{C}$ ) bedeuten, dann erhält man die spezifische Durchbruchskapazität der Torfe für das Volumen des Modellwassers. Eine Multiplikation des Volumens $V$ in der Gleichung (1) mit der spezifischen Aktivität $\mu \mathrm{Ci} / \mathrm{l}$ des Modellwassers ergibt die Beziehung:

$$
D_{\mu \mathrm{Ci}}=\mu \mathrm{Ci} / g \text {, }
$$

wobei $D_{\mu \mathrm{ci}}$ die spezifische Durchbruchskapazität der Torfe für die Radioaktivität des Modellwassers angibt. Die Tab. 6 fasst die so berechneten $D_{\gamma^{-}}$und $D_{\mu \mathrm{Ci}^{-}}$-Werte zusammen.

Tab.6. Spezifische Durchbruchskapazität der Torfe.

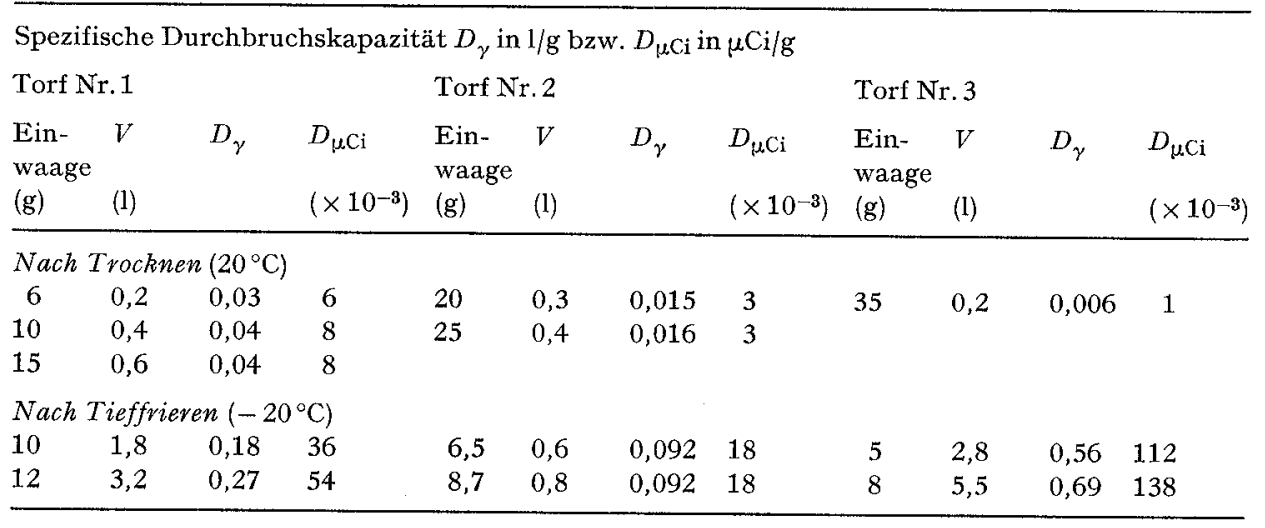

Die aus der Tab. 6 gemittelten $\bar{D}_{\mu \mathrm{Ci}^{-}}$-Werte ergeben, dass das Rückhaltevermögen der Torfe je nach ihrer Art variiert. Sie lassen sich in folgende Reihe einordnen:

Tab.7. Rückhaltevermögen der Torfe für ${ }^{90} \mathrm{Sr}^{90} \mathrm{Y}$.

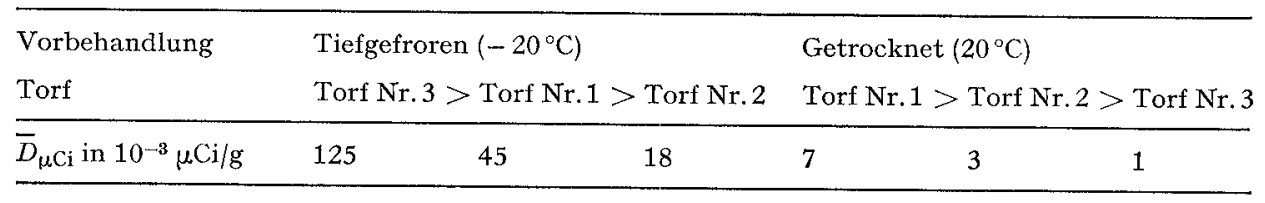

Anhand dieser Versuchsergebnisse lässt sich feststellen, dass die ermittelten $D_{\mu \mathrm{Ci}}$-Werte bei den verschiedenen Einwaagen des gleichen Torfmaterials mit gewis- 

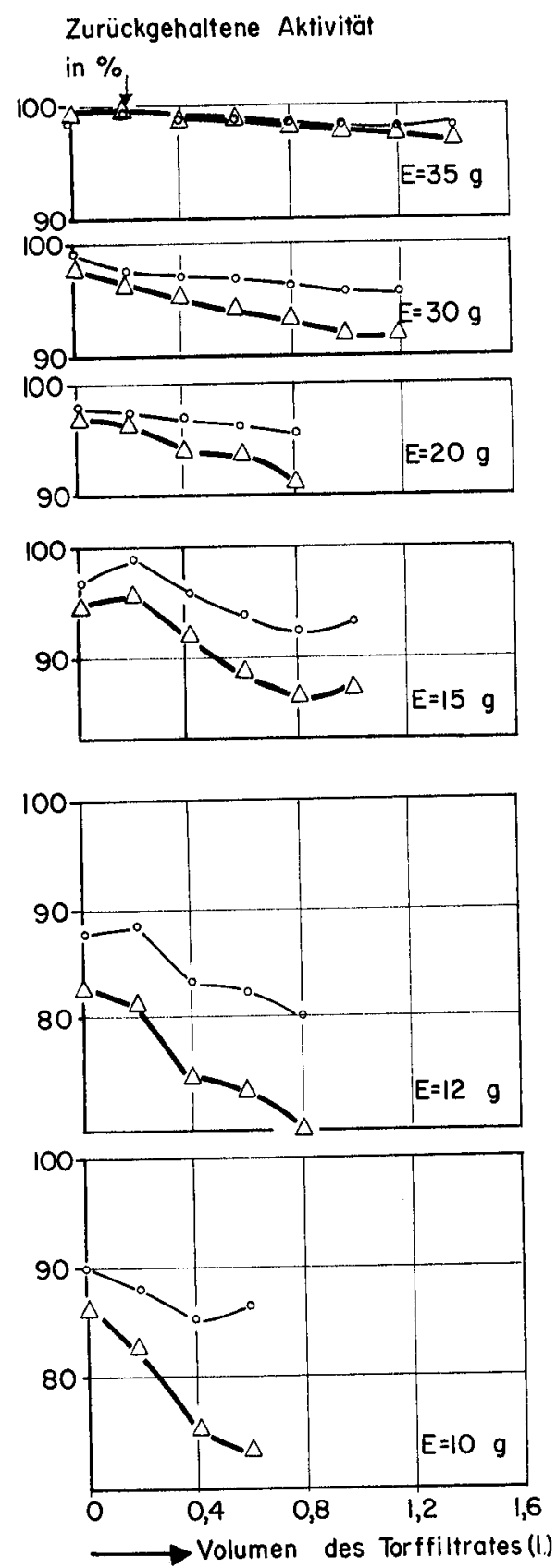

Abb. 10. Perkolationsversuche mit Torf Nr.3, Kolonnenfüllung nach Methode c (bei $20^{\circ} \mathrm{C}$ getrockneter Torf). Einwaage äquivalent mit einem bei $103^{\circ} \mathrm{C}$ getrockneten Material. Aktivität der Eingangslösung $=0,2 \mu \mathrm{Ci} / 1$. Ca-Gehalt $=0,6 \mathrm{mäq} / 1 . \mathrm{O}-$ Aktivität zur Zeit der Perkolation; $\triangle-$ Aktivität im radioaktiven Gleichgewicht. 
Zurückgehaltene Aktivität

in $\%$

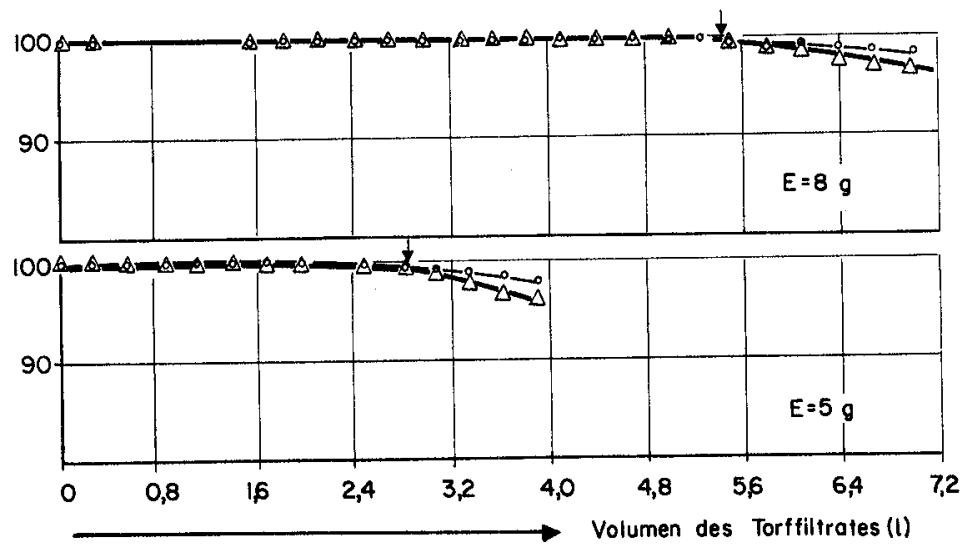

Abb.11. Perkolationsversuche mit Torf Nr.3, Kolonnenfüllung nach Methode $c$ (tiefgefrorener Torf, vor Einfüllung aufgetaut). Einwaage äquivalent mit einem bei $103^{\circ} \mathrm{C}$ getrockneten Material. Aktivität der Eingangslösung $=0,2 \mu \mathrm{Ci} / \mathrm{l}$, Ca-Gehalt $=0,6 \mathrm{mäq} / \mathrm{l} . \mathrm{O}-$ Aktivität zur Zeit der Perkolation; $\triangle-$ Aktivität im radioaktiven Gleichgewicht.

sen Schwankungen, welche in erster Linie auf die Inhomogenität des Torfmaterials und auf die Messfehler zurückzuführen sind, konstant bleiben. Hieraus ist zu schliessen, dass zwischen dem Rückhaltevermögen und der Einwaage - unter den hier gewählten Versuchsbedingungen - eine lineare Abhängigkeit besteht und die Methode eine brauchbare Reproduzierbarkeit gewährleistet.

3.322 Beziehung zwischen der zurückgehaltenen Aktivität und der Art der Torfe. Einfluss der Trocknung und des Tieffrierens

Unter der Bezeichnung "Art" der Torfe wird die in der Einleitung bereits angegebene Einteilung des Torfmaterials (Torf Nr. 1, 2 und 3) verstanden.

Die getrockneten Torfe wiesen durchwegs niedrigere Durchbruchskapazitäten auf als die tiefgefrorenen Proben. Besonders auffallend ist dieser Unterschied beim Torf Nr. 3, der in getrocknetem Zustand die niedrigste, nach Tieffrieren hingegen die höchste Durchbruchskapazität zeigte.

Zur Erklärung der Unterschiede in den Sorptionseigenschaften der Torfe, wie sie infolge Trocknung bzw. Tieffrierens entstehen, sind die Einflüsse dieser Prozesse auf den Torf einzeln zu diskutieren:

a) Einfluss des Trocknungsprozesses: In der Literatur wird verschiedentlich darauf hingewiesen, dass der Trocknungsprozess eine Veränderung der Austauschkapazität der Torfe bewirkt. So stellte PuUstjärvi [18] anhand von Messungen an luftgetrockneten Proben fest, dass die Torfe infolge der Trocknung in gewissen Fällen Kapazitätszunahmen, in anderen eine Kapazitätsabnahme erfahren. Zur Erklärung dieses Verhaltens wurde die Möglichkeit erwogen, dass die Torfkolloide bei der Trocknung einer irreversiblen oder schwer reversiblen Umwandlung unterliegen. Seine diesbezüglichen Untersuchungen erwiesen jedoch, dass irreversible Umwandlungen der Kolloide für die Änderung der Kationenaustauschkapazität keine ausschlaggebende Rolle spielen. 
Die Resultate dieses Autors führen vielmehr zur Vorstellung, dass beim Trocknungsprozess eine Oxydation organischer Komponenten oder/und ein Abbau gewisser aktiver Gruppen auftritt. Die Kapazitätszunahme wäre mit der Oxydation organischer Komponenten (Humus, Lignin) zu erklären, welche zu einer Abnahme der schwach sauren und zu einer Zunahme der stärker sauren Gruppen führt. Die Kapazitätsabnahme wird hingegen durch den Abbau gewisser aktiver Gruppen bedingt. Von wesentlichem Einfluss soll dabei nach PuUsTJÄRvi und Mattson [20] der Basengehalt sein: ein hoher Basengehalt bewirkt eine Kapazitätszunahme, ein niedriger eine Kapazitätsabnahme.

Von Frscher und KADNER [19] wird vermutet, dass die Umtauschkapazitätsabnahme infolge des Trocknungsprozesses mit einer Art Schrumpfung im Torfmaterial zu erklären sei, welche das Innenkapillarvolumen stark verringere, wobei die austauschaktiven Gruppen für die Ionen nicht mehr zugänglich würden. Die Autoren zeigten anhand von Untersuchungen luftgetrockneter Proben, dass die Austauschkapazitätsänderung eine Funktion des Trocknungsgrades ist: die Kapazitätsabnahme durch schwaches Trocknen ist gefolgt von einer Kapazitätszunahme bei stärkerer Trocknung; schliesslich tritt in wasserfreiem Zustand wieder eine Kapazitätsabnahme ein. Die Maxima lagen bei den meisten untersuchten Torfproben bei einem Wassergehalt von $80-90 \%$ (annähernd grubenfeucht) bzw. bei 10-20\% und wiesen häufig dieselbe Höhe auf. Die Beobachtung wurde mit den folgenden Überlegungen erklärt: Bei zunehmendem Trocknungsprozess erfolgt zunächst eine Abnahme der Leitporen und dadurch der Umtauschkapazität, später soll dann aber ein gewisser Aufschluss der inneren Oberfläche durch Ausbildung von Spannungsrissen eintreten, der einen Anstieg der Kapazität verursacht [21].

In Anlehnung an die Feststellungen von Fischer [19] könnte angenommen werden, dass der Unterschied in der Austauschkapazität zwischen den getrockneten und tiefgefrorenen Materialien in unserem Falle nur zum Teil vom Trocknungsprozess verursacht wurde, da die Torfe mit einem Wassergehalt zwischen 9 und $12 \%$ zur Untersuchung gelangten und damit im Bereich der maximalen Austauschkapazität vorlagen.

Eine erhebliche Verminderung der Austauschkapazität infolge des Trocknungsprozesses im Vergleich zu einem grubenfeuchten Material wäre dann sehr unwahrscheinlich. Sollte jedoch der entstandene Unterschied im wesentlichen nur vom Trocknungsprozess herrühren, so müsste geschlossen werden, dass das Tieffrieren die grubenfeuchten Materialien konservierte und dadurch ihre ursprüngliche Austauschfähigkeit bewahrte. In diesem Falle müsste aber der Torf Nr. 3 mit dem grössten CaGehalt (vgl. Tab. 5a) infolge der Trocknung die grösste Kapazitätsabnahme erfahren, was mit den Feststellungen von PuUSTJÄRvi [18] in Widerspruch stände.

Zur Abklärung dieser Fragen sind Messungen an grubenfeuchten Torfen durchgeführt worden. Es wurden drei Torfproben (Nr. II/1, Nr. II/2 und Nr. II/3) an den auf Seite 235 angegebenen Stellen entnommen und im naturbelassenen Zustand auf ihre Austausch- und Durchbruchskapazität unmittelbar nach der Probeentnahme untersucht. Zum Vergleich sind dieselben Proben nach Trocknen bei $20^{\circ} \mathrm{C}$ analog geprüft worden. Die stoffliche Zusammensetzung dieser neu erhobenen Torfmaterialien ist in Tab. 8 angegeben ${ }^{4}$ ). Die mikroskopischen Analysen ${ }^{5}$ ) ergaben diefolgenden Ergebnisse:

$\left.{ }^{4}\right)$ Analysen durchgeführt von der Eidg. Agrikulturchemischen Versuchsanstalt Liebefeld, Bern.

5) Analysen durchgeführt von der Botanischen Anstalt der Universität Basel. 
Tab. 8. Ergebnisse der Allgemein- und Stoffgruppenanalyse der Torfproben II/1-II/3.

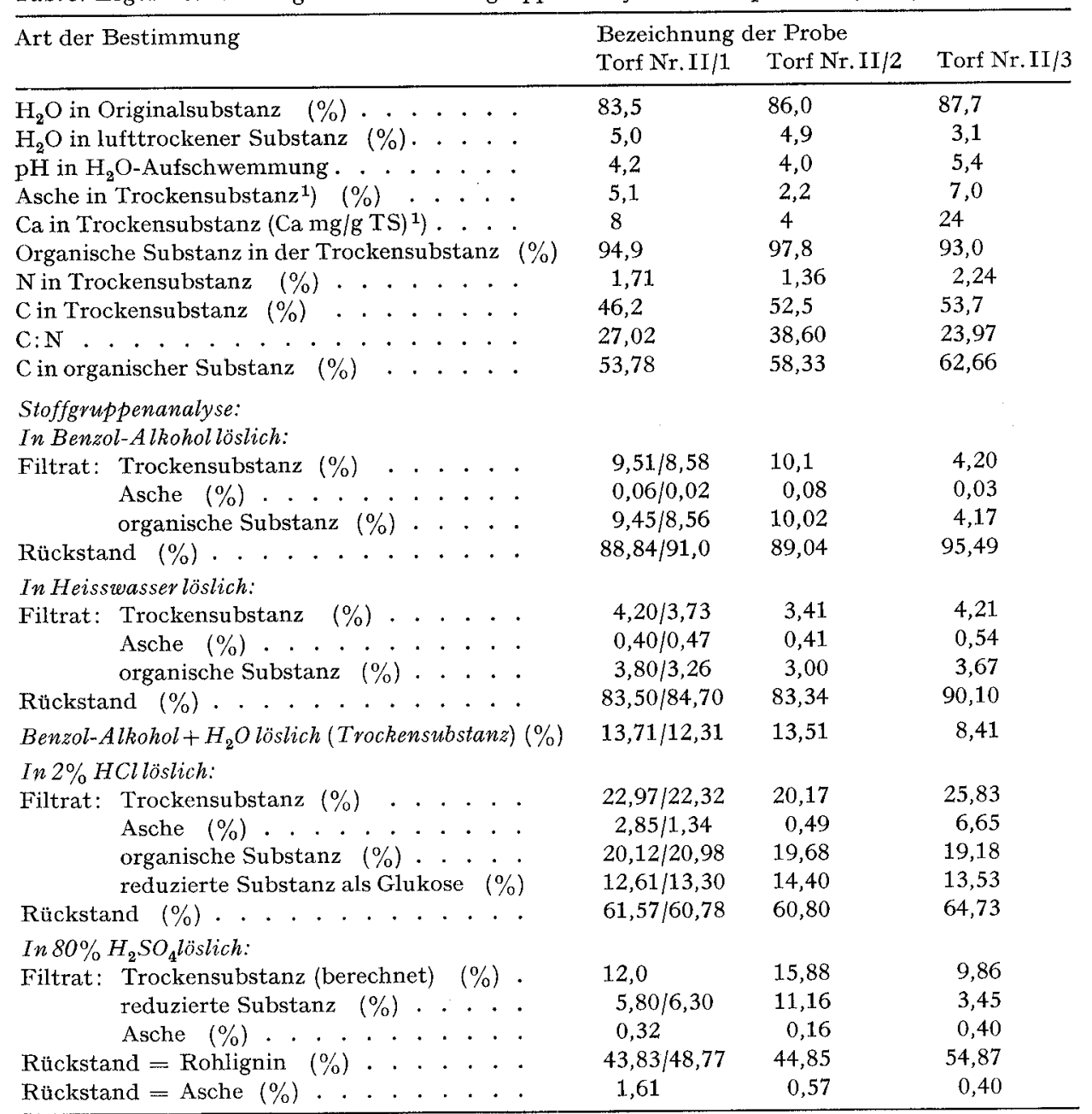

1) Messung durchgeführt in der EAWAG, Zürich.

\section{Torfprobe Nr. II/1}

Konsistenz: sehr inhomogen; teils stark, teils schwach zersetzt.

Grossreste: ïberwiegend Feindetritus, Radizellen recht häufig, zahlreiche SphagnumBlättchen, vereinzelt auch ganze Sphagnum-Ästchen. Wenige Laubmoosreste. Dikotylen-Blattstïckchen (max. $2 \mathrm{~mm}$ ) recht selten. Wenig Holzkohle. Alter des Torfs: höchstens 2000 Jahre.

Torfprobe $N r . I I / 2$

Konsistenz: mässig zersetzter, lockerer Torf mit reichlichen Eriophorum-Resten. Grossreste: Bruchstücke von Cypraceae (1-15 mm lang), 
Sphagnaceae und Radizellen dominieren. Wenig Feindetritus. Vereinzelte Holzstückchen und Holzfragmente. 1 Picea-Nadel.

Alter des Torfs: $3000-5000$ Jahre.

\section{Torfprobe $N r . I I / 3$}

Konsistenz: stark zersetzter Torf.

Grossreste: Überwiegend Radizellen ( $1-4 \mathrm{~mm}$ lang), die zu kompakter Masse ineinander verfilzt sind. Dazwischen sehr viel Feindetritus. Vereinzelte Laubmoosästchen und Dikotylen-Blattstücke. Wenig Holzkohle. Entflügelte Nuss von Betula. 1 Frucht und Rhizomstück von Cypraceae.

Alter des Torfs: 8000-9000 Jahre.

Die ermittelten Austauschkapazitätswerte sind in Tab. 9 zusammengefasst.

Tab.9. Kationenaustauschkapazität der Torfe.

\begin{tabular}{lll}
\hline Torf & $\begin{array}{l}\text { Kationenaustauschkapazität in mäq/g Torf } \\
\mathrm{NaCl} \mathrm{MgSO}_{4} \text { (Austausch) } \\
\text { Nach Trocknen }\left(20^{\circ} \mathrm{C}\right)\end{array}$ & Grubenfeucht \\
\hline II $/ 1$ & 0,7 & 0,8 \\
II $/ 2$ & 0,5 & 0,7 \\
II $/ 3$ & 0,4 & 1,0 \\
\hline
\end{tabular}

Aus diesen Resultaten geht hervor, dass alle Austauschkapazitätswerte der grubenfeuchten Torfe höher liegen als jene der getrockneten Materialien. Der Torf Nr. II/3 weist in grubenfeuchtem Zustand die höchste, nach Trocknen die niedrigste Austauschkapazität auf.

Deutlicher zeigt sich der Austauschkapazitätsunterschied zwischen den grubenfeuchten und den getrockneten Materialien anhand der ermittelten Durchbruchskapazitätswerte. Die Abb. 12-14 stellen diese Messergebnisse graphisch dar.

Wie weit der Trocknungsgrad einen Einfluss auf die Austausch- und Durchbruchskapazität der Torfe hat, wurde ebenfalls überprüft. Die Proben wurden bei etwa $20^{\circ} \mathrm{C}$ an der Luft bis zu verschiedenem Wassergehalt getrocknet und ihre Austauschund Durchbruchskapazität ermittelt. Es zeigte sich, dass die Austauschkapazität keine signifikante Korrelation mit dem Wassergehalt der Torfe aufweist. Eine deutliche Abhängigkeit besteht jedoch bei den Werten der Durchbruchskapazität. In Abb. 15 ist ihre Grösse für Torfmaterialien, welche an der Luft bis zu einem Wassergehalt von etwa $50 \%$ gebracht worden sind, graphisch dargestellt. Ein Vergleich mit den Abb. 12-14 ergibt, dass die Verminderung des Wassergehaltes (bis zu etwa 50\%) zunächst eine leichte Zunahme ${ }^{6}$ ) und nachher (bei 10-16\% Wassergehalt) eine Abnahme der spezifischen Durchbruchskapazität bewirkt. Eine graphische Darstellung der spezifischen Durchbruchskapazitäten in Abhängigkeit des Trocknungsgrades bzw. des Wassergehaltes der Proben (Abb. 16) zeigt Kurvenverläufe mit Maxima bei einem Wassergehalt von etwa $50 \%$.

b) Bei diesem Vergleich sind die unterschiedlichen Torfeinwaagen zu beachten. 


\section{b) Einfluss des Tieffrierens}

In der Fachliteratur wird verschiedentlich darauf hingewiesen, dass der Frost eine Strukturverbesserung der Moorböden bewirkt. VAN DIJK [22] stellte fest, dass die Schrumpfung stark herabgesetzt wird, wenn der Moorboden vor dem Eintrocknen durchfriert.

Man könnte sich vorstellen, dass das Tieffrieren zu einer strukturellen Änderung des Torfes führt, welche eine dem Trocknungsprozess entgegengesetzte Wirkung ausübt, indem wegen der Eisbildung anstelle der Schrumpfung eine Vergrösserung des Innenkapillarvolumens eintritt. Die erhöhte Austauschkapazität könnte dann mit der grösseren Zugänglichkeit der austauschaktiven Gruppen erklärt werden. Es ist auch denkbar, dass der grubenfeuchte Torf durch das Tieffrieren einfach "konserviert" wurde und dadurch seine ursprüngliche Sorptionsfähigkeit bewahrte.
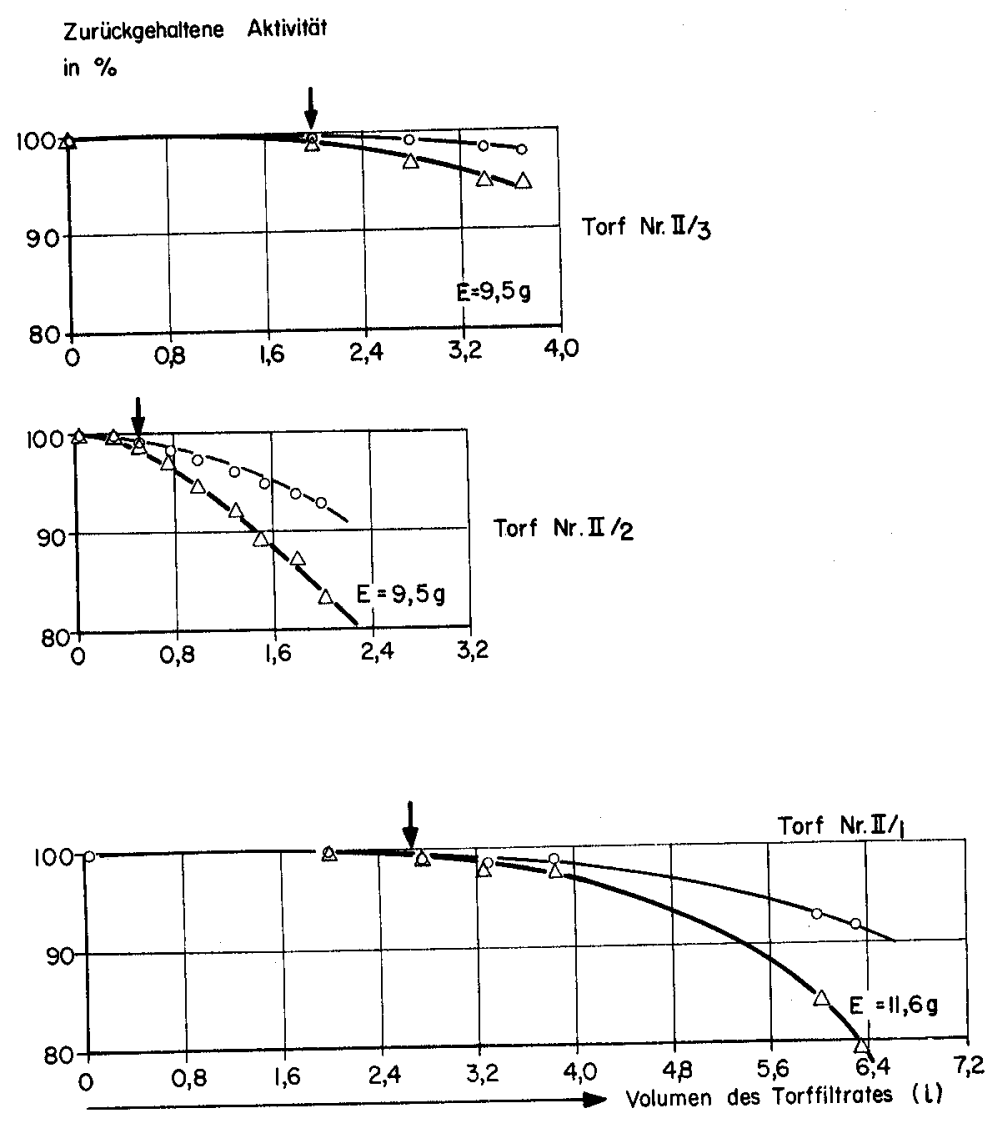

Abb. 12. Perkolationsversuche mit Torf Nr. II/1-II/3, Kolonnenfüllung nach Methode c (grubenA Eingangslösung $=0,25 \mu \mathrm{Ci} / \mathrm{l}$, Ca-Gehalt $=0,6 \mathrm{mäq} / \mathrm{l}$. $\mathrm{O}$-Aktivität zur Zeit der Perkolation; $\triangle$ - Aktivität im radioaktiven Gleichgewicht. 
Die Kurven der Durchbruchskapazitäten in Abb. 17 zeigen im Vergleich mit Abb. 12, dass kein wesentlicher Unterschied zwischen den grubenfeuchten und den tiefgefrorenen Materialien besteht. Torf Nr. II/3 wies sogar übereinstimmende Werte auf.

Wir schliessen zusammenfassend, dass der Trocknungsprozess bis zu einem 50prozentigen Wassergehalt eine leichte Zunahme, bei höherem Trocknungsgrad (d.h. Wassergehalt unter 50\%) eine starke Verminderung der Durchbruchskapazität verursacht. Das Tieffrieren konserviert das grubenfeuchte Torfmaterial, so dass sein Rückhaltevermögen eine kaum merkbare Änderung erfährt.

Es ist noch zu bemerken, dass das Tieffrieren eine deutliche Verbesserung der Durchlässigkeit der Torfsäulen gegenüber der Verwendung des Torfes im Originalbzw. im getrockneten Zustand bewirkte.

Es stellt sich nun die Frage, wie sich das einmal tiefgefrorene Torfmaterial gegenüber einer späteren Trocknung verhält. Die entsprechenden Versuche ergaben (Abb.

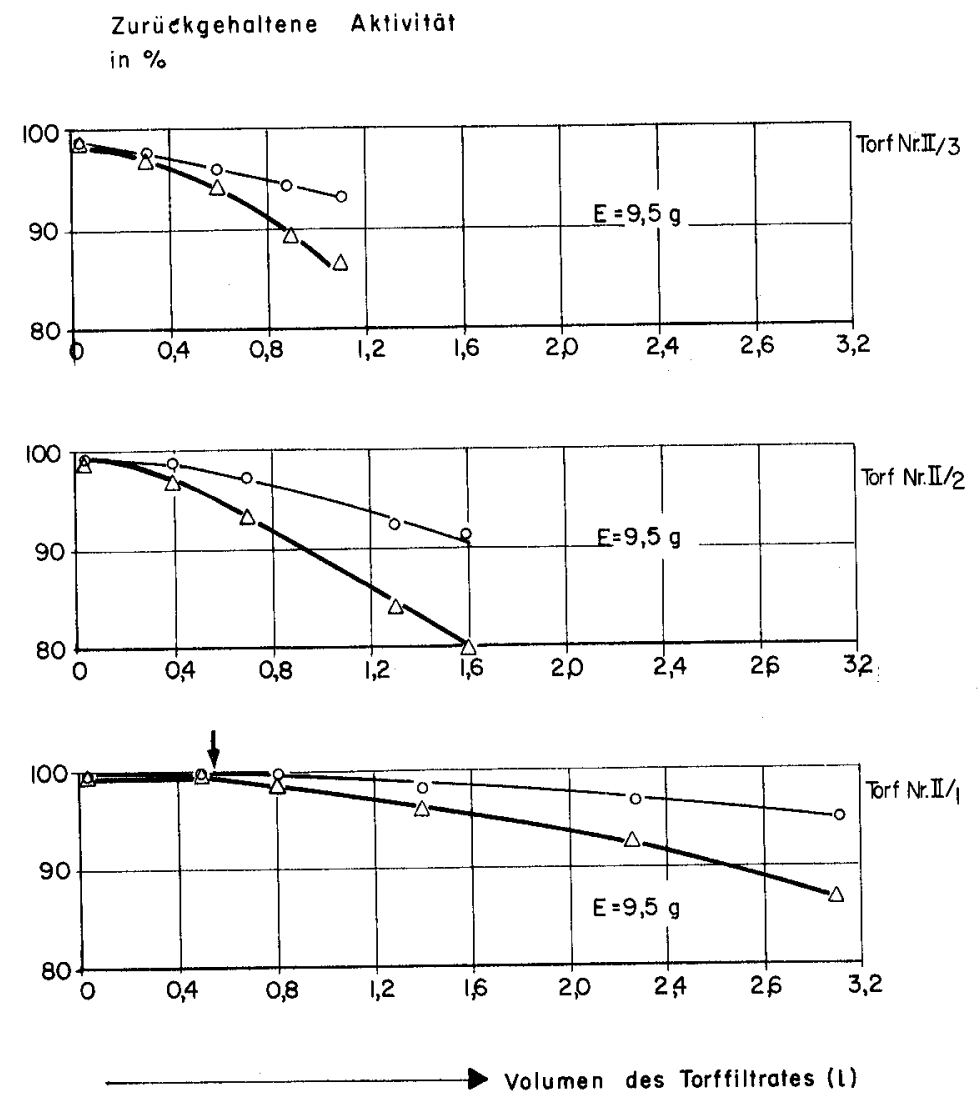

Abb.13. Perkolationsversuche mit Torf Nr. II/1-II/3, Kolonnenfüllung nach Methode c (luftgetrockneter Torf). Einwaage äquivalent mit einem bei $103^{\circ} \mathrm{C}$ getrockneten Material. Aktivität der Eingangslösung $=0,25 \mu \mathrm{Ci} / \mathrm{l}, \mathrm{Ca}-\mathrm{Gehalt}=0,6 \mathrm{mäq} / \mathrm{l} . \mathrm{O}$ - Aktivität zur Zeit der Perkolation; $\triangle$ - Aktivität im radioaktiven Gleichgewicht. 

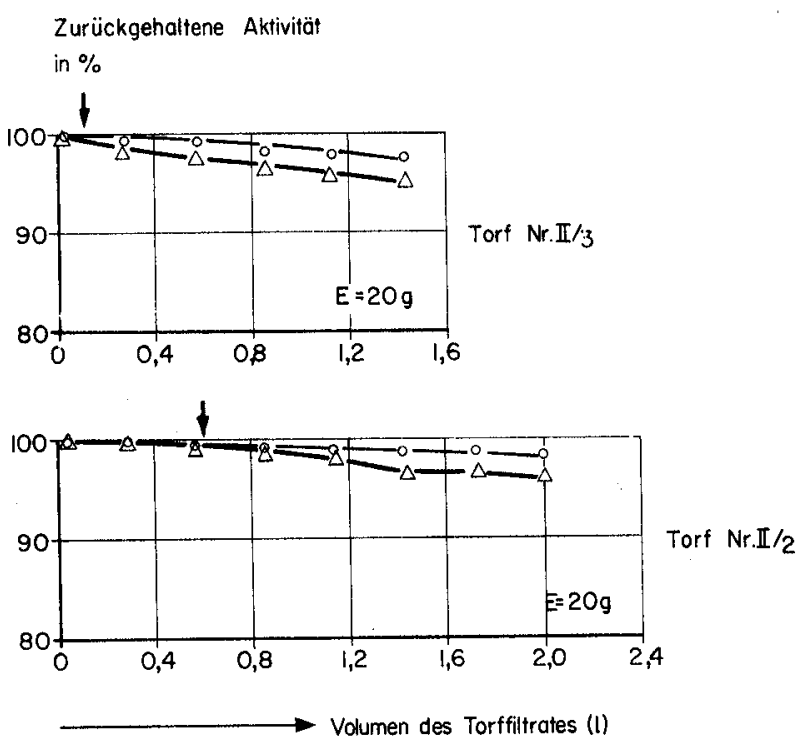

Abb.14. Perkolationsversuche mit Torf Nr. II/2-II/3, Kolonnenfüllung nach Methode c (luftgetrockneter Torf). Einwage äquivalent mit einem bei $103^{\circ} \mathrm{C}$ getrockneten Material. Aktivität der Eingangslösung $=0,25 \mu \mathrm{Ci} / \mathrm{l}$, Ca-Gehalt $=0,6 \mathrm{mäq} / \mathrm{l}$. $\bigcirc$ - Aktivität zur Zeit der Perkolation; $\triangle$ - Aktivität im radioaktiven Gleichgewicht.
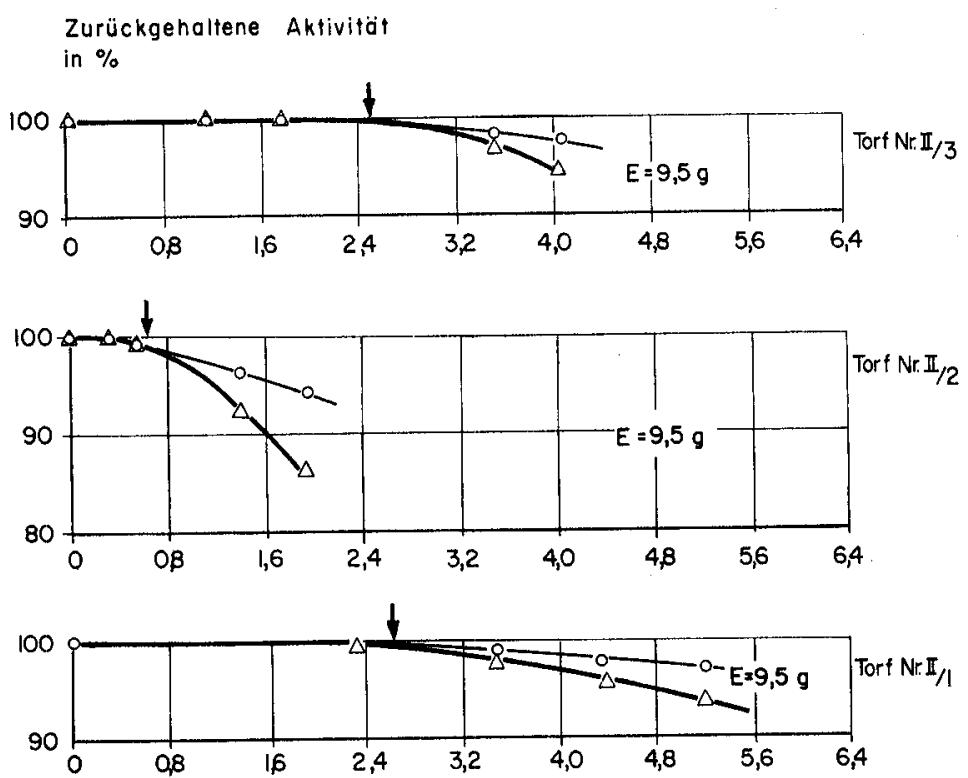

Abb.15. Perkolationsversuche mit Torf Nr. II/1-II/3, Kolonnenfüllung nach Methode c (angetrockneter Torf, ca. $50 \% \mathrm{H}_{2} \mathrm{O}$ ). Einwaage äquivalent mit einem bei $103^{\circ} \mathrm{C}$ getrockneten Material. Aktivität der Eingangslösung $=0,25 \mu \mathrm{Ci} / 1$, Ca-Gehalt $=0,6$ mäq/1. $\bigcirc$ - Aktivität zur Zeit der Perkolation; $\triangle$-Aktivität im radioaktiven Gleichgewicht. 
Spezifische Durchbruchskapazitäł
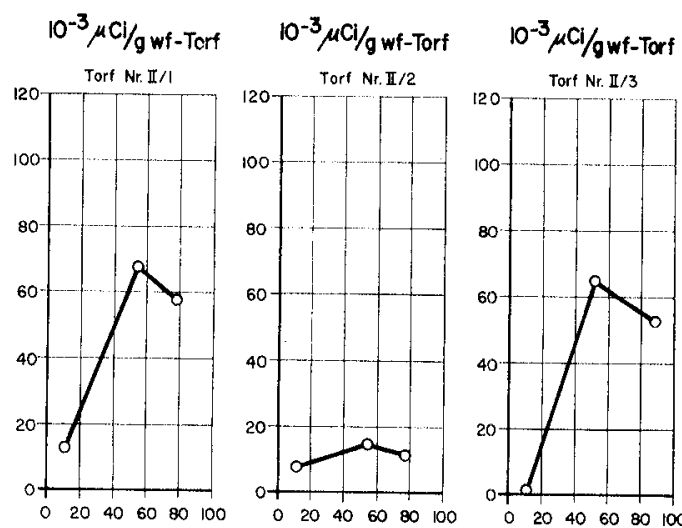

Torf Nr. I/2

Torf Nr. II/3
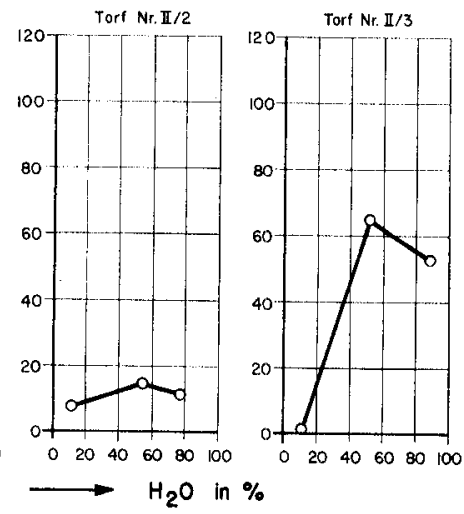

Abb. 16. Spezifische Durchbruchskapazität $\left(10^{-3} \mu \mathrm{Ci} / \mathrm{g}\right.$ wasserfreier Torf $)$ der Torfe Nr. II/1-1I/3 in Abhängigkeit des Wassergehaltes.

18-19), dass das Rückhaltevermögen für ${ }^{90} \mathrm{Sr}--^{90} \mathrm{Y}$ in grubenfeuchtem Zustand auch nach dem Trocknen auf 11\% Wassergehalt gut erhalten bleibt, wenn der Torf vorher eingefroren wird. Torf Nr. II/3 zeigte eine stark erhöhte Rückhaltung gegenüber dem grubenfeuchten Zustand, deren Ursache noch abgeklärt werden müsste.

Bezüglich der Durchlässigkeit des vor dem Trocknen tiefgefrorenen Materials konnten ähnlich gute Erfahrungen gemacht werden wie mit den tiefgefrorenen Proben.

Diese Feststellungen dürften vor allem aus praktischen Gründen von Interesse sein, da der tiefgefrorene und anschliessend getrocknete Torf bei seiner Anwendung als Entaktivierungsmittel gegenüber dem grubenfeuchten Material viele Vorteile bietet (Vereinfachung von Lagerung und Transport, konstante Durchlässigkeit beim Kolonnenverfahren usw.).

Die ermittelten spezifischen Durchbruchskapazitätswerte der verschiedenen Torfe nach dem Trocknen, in grubenfeuchtem Zustand, nach dem Tieffrieren und nach dem Tieffrieren plus Trocknen sind in der Tab. 10 zusammengefasst.

\subsection{Einfluss der Fliessgeschwindigkeit}

Es soll an dieser Stelle noch darauf hingewiesen werden, dass die spezifischen Durchbruchskapazitäten nur aus Versuchen mit identischen und konstanten Versuchsbedingungen (Konzentration und $\mathrm{pH}$ der Modellösung, Fliessgeschwindigkeit usw.) berechnet worden sind. Schwankungen der Fliessgeschwindigkeit zu extrem grossen oder extrem kleinen Werten können die Resultate stark verfälschen.

Abb. 20 und Tab. 11. zeigen die Messwerte für den Torf Nr. I/1 in grubenfeuchtem Zustand und nach Tieffrieren bei extrem geringer Fliessgeschwindigkeit $(1 \mathrm{~cm} / \mathrm{min})$. Ein Vergleich mit den graphischen Darstellungen 12 und 17 bzw. mit der Tab. 10 ergibt, dass die Verminderung der Fliessgeschwindigkeit von $3,6 \mathrm{~cm} / \mathrm{min}$ auf $1 \mathrm{~cm} / \mathrm{min}$ die Durchbruchskapazität auf das rund Vierfache erhöhte. 
Tab.10. Spezifische Durchbruchskapazität der Torfe (II).

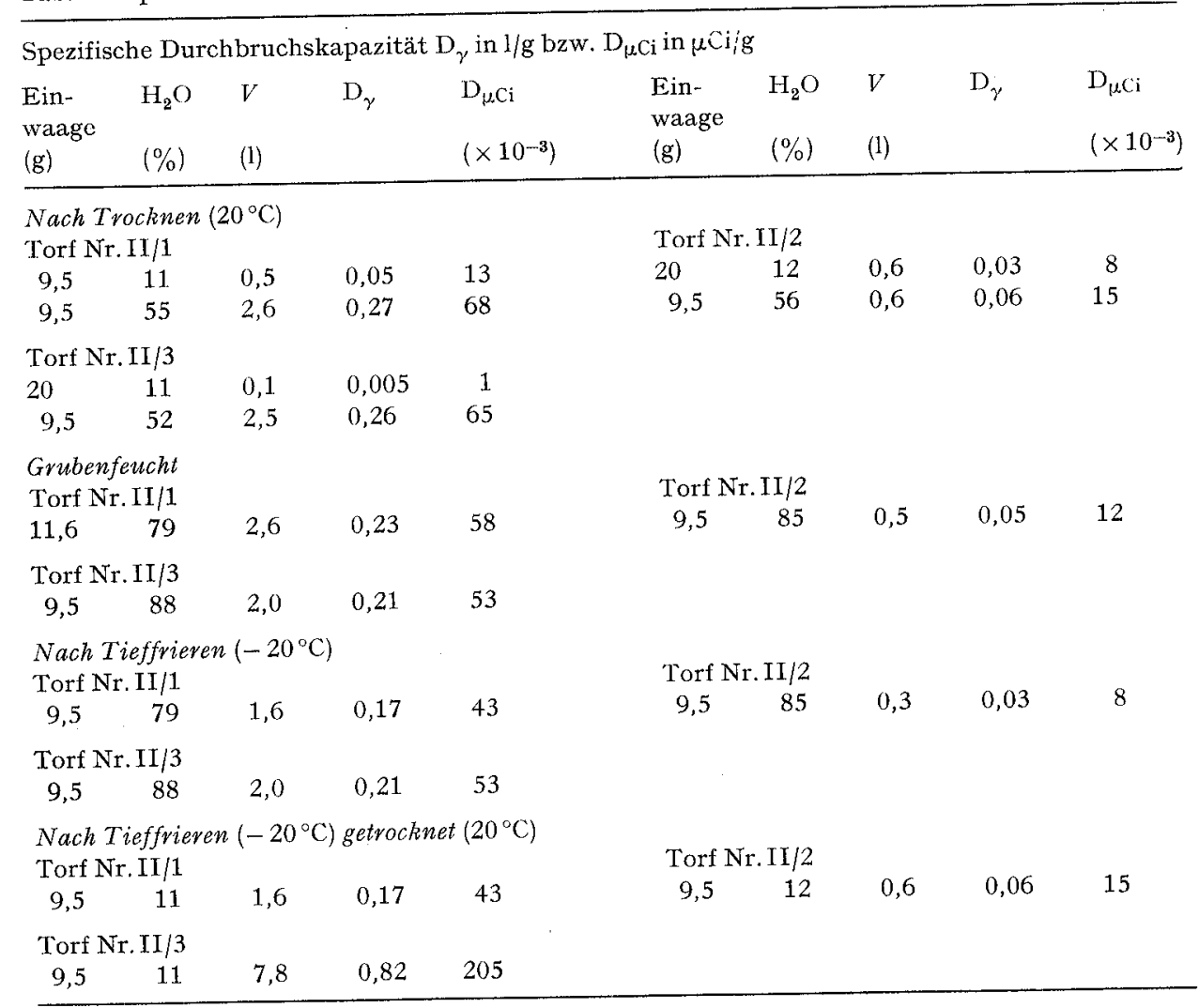

Tab.11. Spezifische Durchbruchskapazität des Torfes (Nr.II/1) bei extrem langsamer Fliessgeschwindigkeit $(1 \mathrm{~cm} / \mathrm{min})$.

\begin{tabular}{|c|c|c|c|c|}
\hline $\begin{array}{l}\text { Einwaage } \\
\text { (g) }\end{array}$ & $\begin{array}{l}\mathrm{H}_{2} \mathrm{O} \\
(\%)\end{array}$ & $\begin{array}{l}V \\
(1) \\
\end{array}$ & $\begin{array}{l}D_{\gamma} \\
(1 / g)\end{array}$ & $\begin{array}{l}D_{\mu \mathrm{Ci}} \\
\left(10^{-3} \mu \mathrm{Ci} / \mathrm{g}\right)\end{array}$ \\
\hline \multicolumn{5}{|c|}{ Grubenfeucht } \\
\hline 10,7 & 79 & 8,4 & 0,79 & 197 \\
\hline \multicolumn{5}{|c|}{ Nach Tieffrieven $\left(-20^{\circ} \mathrm{C}\right)$} \\
\hline 10,7 & 77 & 8,4 & 0,79 & 197 \\
\hline
\end{tabular}

Für die Laboruntersuchungen wurde trotzdem die hohe Fliessgeschwindigkeit von $3,6 \mathrm{~cm} / \mathrm{min}$ beibehalten, um die grosse Anzahl der Perkolationen in einem vernünftigen Zeitraum durchführen zu können.

Im technischen Maßstab kann hingegen bei relativ kleiner Fliessgeschwindigkeit (v) gearbeitet werden, wenn der Säulendurchmesser ausreichend gross gewählt wird. So ergibt sich beispielsweise mit $v=1 \mathrm{~cm} / \mathrm{min}$ bei einem Säulendurchmesser von 

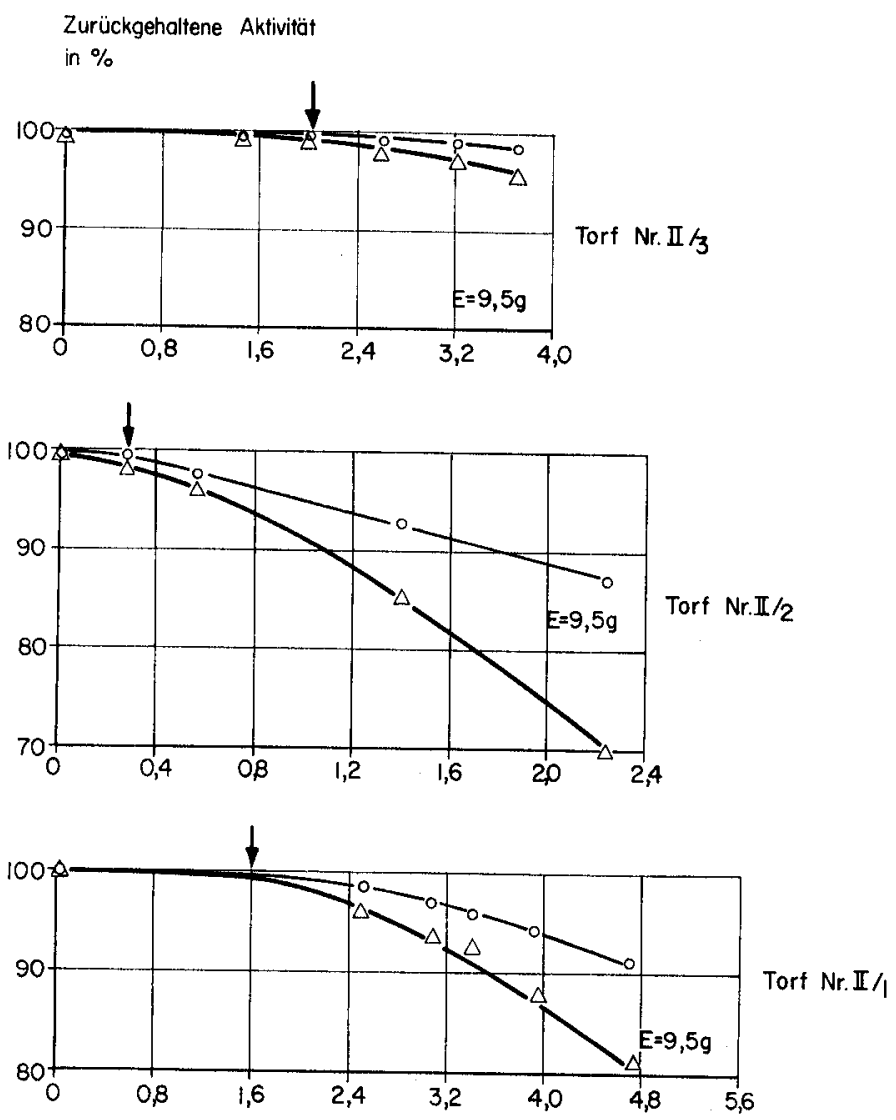

Volumen des Torffiltrates (1)

Abb. 17. Perkolationsversuche mit Torf $\mathrm{Nr}$. II/1-II/3, Kolonnenfüllung nach Methode c (tiefgefrorener Torf, vor Einfüllung aufgetaut). Einwaage äquivalent mit einem bei $103^{\circ} \mathrm{C}$ getrockneten Material. Aktivität der Eingangslösung $=0,25 \mu \mathrm{Ci} / 1$, Ca-Gehalt $=0,6 \mathrm{mäq} / 1$. $\bigcirc$ - Aktivität zur Zeit der Perkolation; $\triangle-$ Aktivität im radioaktiven Gleichgewicht.

$2 \mathrm{~cm}$, d.h. $F=3,14 \mathrm{~cm}^{2}$ (Laboratoriumsversuche) für $Q$ nach der Gleichung $Q=v \cdot F$ ein Durchfluss von $Q=3,14 \mathrm{~cm}^{3} / \mathrm{min}$; bei einem Säulendurchmesser von $20 \mathrm{~cm}$, d.h. $F=314 \mathrm{~cm}^{2}$ (technische Apparatur), jedoch bereits ein Wert von $Q=314 \mathrm{~cm}^{3} / \mathrm{min}$.

\subsection{Einfluss von Volumen und Korngrösse des Torfmaterials}

Das Volumen der Torfeinwaagen in den Filtersäulen liess sich nur schwer reproduzieren. Wir haben deshalb von einer Umrechnung der Messergebnisse in Volumeneinheiten der Torfproben abgesehen. Die Versuche wurden jedoch so angeordnet, dass die Säulenhöhen mindestens das Sechsfache des Durchmessers betrugen. Bei einer Vergrösserung der Säulenhöhen bis zum 10fachen Durchmesser liess sich kein Einfluss auf den Entaktivierungseffekt beobachten. Es musste auch darauf verzichtet werden, eine bestimmte Granulometrie der Torfproben einzuhalten, da eine Korn- 
Zurückgehaltene Aktivitöł

in $\%$
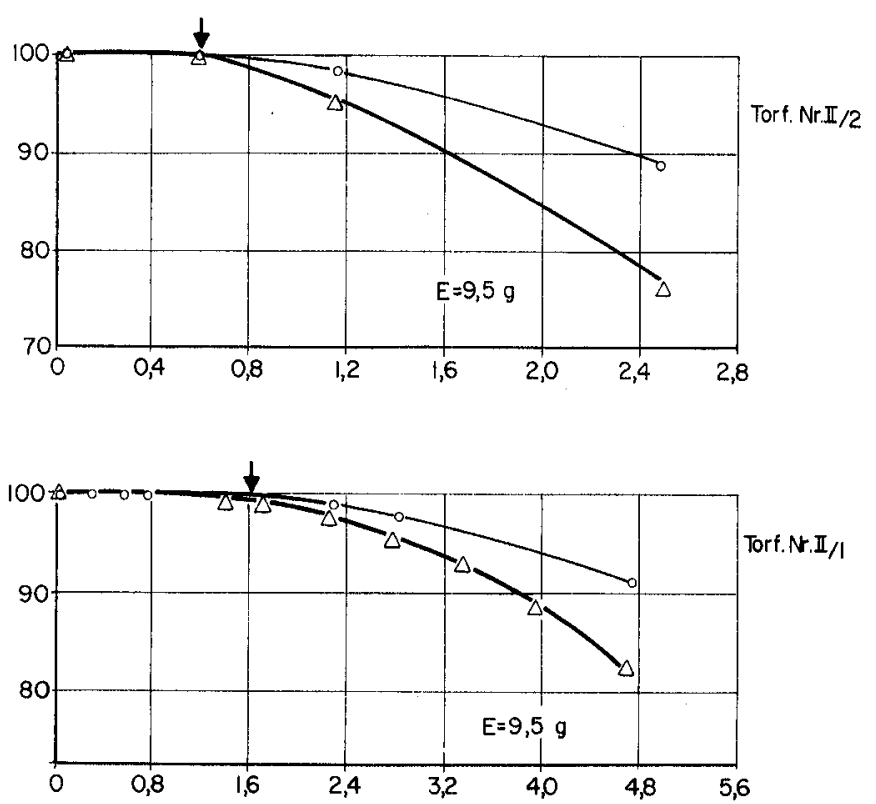

Abb.18. Perkolationsversuche mit Torf Nr. II/1-II/2, Kolonnenfüllung nach Methode $\mathrm{c}$ (tief gefrorener und nachträglich getrockneter Torf). Einwaage äquivalent mit einem bei $103^{\circ} \mathrm{C}$ getrockneten Material. Aktivität der Eingangslösung $=0,25 \mu \mathrm{Ci} / \mathrm{l}$, Ca-Gehalt $=0,6 \mathrm{mäq} / \mathrm{l}$. O-Aktivität zur Zeit der Perkolation; $\triangle$-Aktivität im radioaktiven Gleichgewicht.

grössentrennung bei grubenfeuchtem und tiefgefrorenem Material kaum realisierbar ist. Beim getrockneten Torf liess sich zwischen den Austauschkapazitätswerten fein zerkleinerter und gröberer Proben kein Unterschied feststellen.

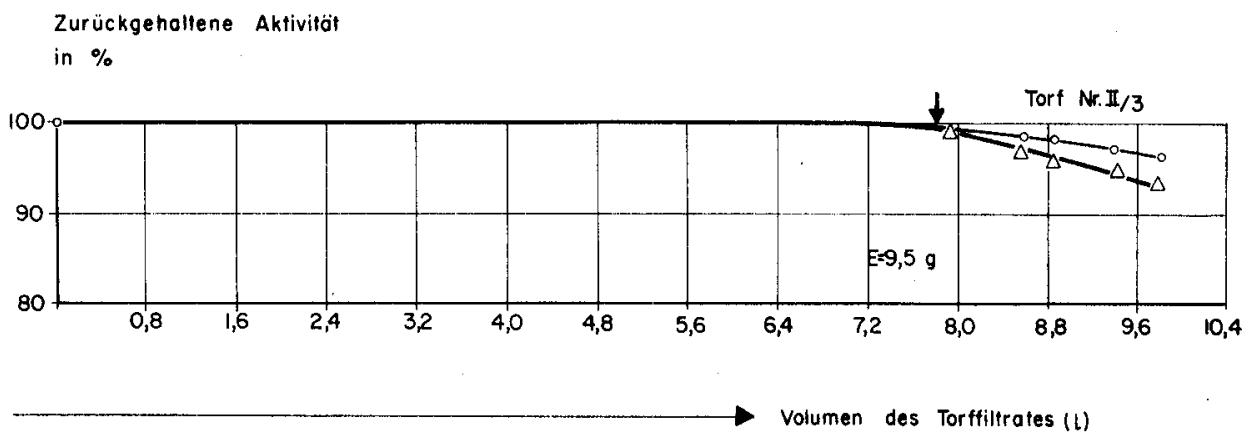

Abb. 19. Perkolationsversuche mit Torf Nr. II/3, Kolonnenfüllung nach Methode c (tiefgefrorener und nachträglich getrockneter Torf). Einwaage äquivalent mit einem bei $103^{\circ} \mathrm{C}$ getrockneten Material. Altivität der Eingangslösung $=0,25 \mu \mathrm{Ci} / 1, \mathrm{Ca}-\mathrm{Gehalt}=0,6 \mathrm{mäq} / \mathrm{l} .0-$ Aktivität zur Zeit der Perkolation; $\triangle$-Aktivität im radioaktiven Gleichgewicht. 
Zurückgeholtene Aktivität

in $\%$
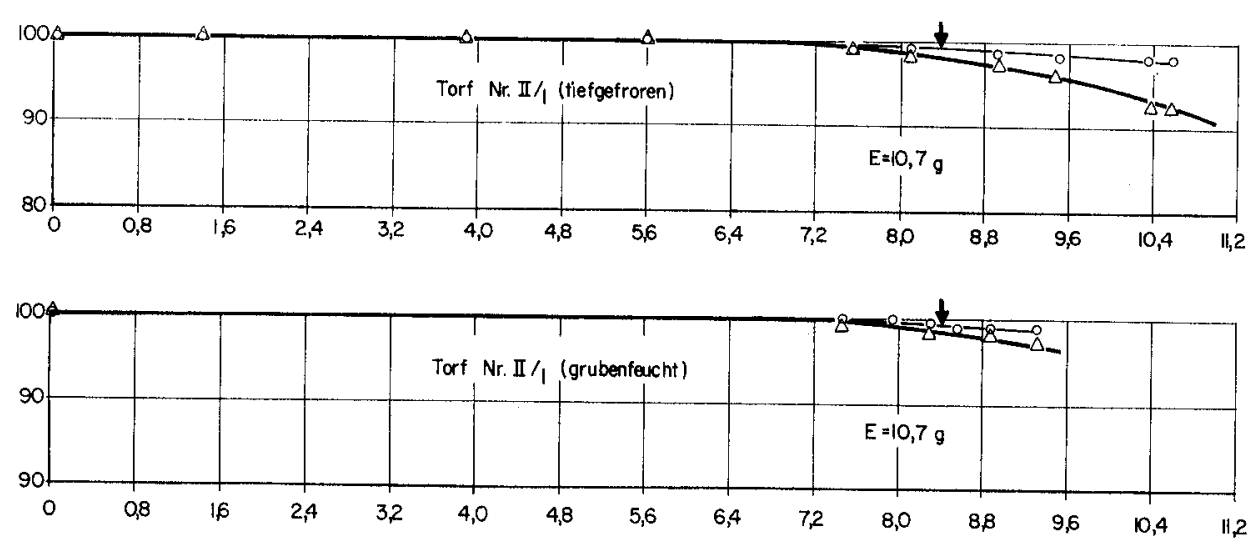

Volumen des Torffiltrates (1)

Abb.20. Perkolationsversuche mit Torf Nr. Il/1, Kolonnenfüllung nach Methode c (grubenfeuchter bzw. tiefgefrorener Torf, vor Einfüllung aufgetaut). Einwaage äquivalent mit einem bei $103^{\circ} \mathrm{C}$ getrockneten Material. Aktivität der Eingangslösung $=0,25 \mu \mathrm{Ci} / \mathrm{l}$, Ca-Gehalt $=0,6 \mathrm{mäq} / 1$. O- Aktivität zur Zeit der Perkolation; $\triangle$-Aktivität im radioaktiven Gleichgewicht.

\subsection{Schlussfolgerung für die Praxis}

Aus den Laboratoriumsversuchen mit einer ${ }^{90} \mathrm{Sr}-{ }^{90} \mathrm{Y}$-haltigen Modellösung $(0,2-0,3 \mu \mathrm{Ci} / 1)$, welche eine chemische Zusammensetzung analog derjenigen eines Zisternenwassers aufwies, können für die Praxis die folgenden Schlüsse gezogen werden:

a) Torf ist in der Lage, ${ }^{90} \mathrm{Sr}-{ }^{90} \mathrm{Y}$-Isotope aus der Modellösung quantitativ zurückzuhalten.

b) Das grubenfeuchte Material weist einen höheren Entaktivierungseffekt auf als der an der Luft bei $20^{\circ} \mathrm{C}$ getrocknete Torf (Wassergehalt 10-12\%). Bei Torfen, welche an der Luft nur bis zu einem Wassergehalt von etwa $50 \%$ getrocknet werden, bleibt die Entaktivierungsfähigkeit des grubenfeuchten Zustandes erhalten oder sie verbessert sich sogar.

c) Tiefgefrorenes Torfmaterial zeigt in aufgetautem Zustand und auch nach nachträglicher Trocknung denselben Entaktivierungseffekt wie der grubenfeuchte Torf. Manchmal tritt sogar eine Verbesserung der Effekte auf. Das Tieffrieren bewirkt zudem eine Strukturverbesserung, welche sich in der guten Durchlässigkeit der Torffiltersäulen äussert.

d) Der höchste Entaktivierungseffekt ergab sich beim Niedermoortorf (Nr. 3 bzw. II/3, grösster Ca-Gehalt, höchster pH-Wert und grösster Zersetzungsgrad), wenn er grubenfeucht, halbgetrocknet $\left(50 \% \mathrm{H}_{2} \mathrm{O}\right)$ oder nach Tieffrieren mit oder ohne nachträgliche Trocknung verwendet wurde. Bei starker Trocknung erfuhr er jedoch den grössten Verlust an Wirkungsgrad im Vergleich zu den Hochmoortorfen.

e) Für die Durchbruchskapazität (zurückgehaltene Aktivität bis zum Durchbruch) grubenfeuchter oder vorher tiefgefrorener Torfe ergaben sich Werte zwischen 8 und 
rund $200 \mu \mathrm{Ci} / \mathrm{kg}$ wasserfreien Torfs bei der Perkolation mit Modellwasser. Torfe, welche nach der Probeentnahme getrocknet wurden, wiesen Durchbruchskapazitäten zwischen $1-13 \mu \mathrm{Ci} / \mathrm{kg}$ wasserfreier Substanz auf.

f) Der Entaktivierungseffekt für ${ }^{90} \mathrm{Sr}-{ }^{90} \mathrm{Y}$ ist durch die Austauschkapazität der Torfe bedingt. Als begrenzende Faktoren wirken deshalb bei einem gegebenen Torf die für die Austauschkapazität massgebenden Grössen, d.h. vor allem der pH-Wert und der Kationengehalt der zu entaktivierenden Lösung.

g) Mit abnehmender Fliessgeschwindigkeit erhöht sich der Entaktivierungseffekt.

h) Torfe, deren $\mathrm{pH}-$ Wert im sauren Bereich liegt und die infolge ihrer Pufferkapazität eine Perkolationslösung anzusäuern vermögen, halten dreiwertige Kationen quantitativ zurïck.

i) Mehrstufige Filtersysteme erzielen keinen besseren Entaktivierungseffekt als eine einzige Filtersäule. Sie bieten jedoch gegenüber einem einstufigen System verschiedene Vorteile: Die einzelnen Kolonnen können kleiner dimensioniert und dadurch einfacher gehandhabt werden; sie lassen sich nach einer Aktivitätssättigung einzeln auswechseln. Auf diese Weise können die Torfkolonnen bis zur Sättigung benützt werden.

j) Die Eluate lagen nach den ersten Fraktionen weitgehend farblos vor, was auf das Fehlen leichtlöslicher Humate im Torf zurückzuführen ist. Besonders gute Erfahrungen konnten mit den Torfen Nr. 3 und II/3 gemacht werden, wenn sie nach dem Tieffrieren getrocknet zur Untersuchung gelangten.

\section{Rückhaltevermögen der Torfe für ${ }^{131} \mathbf{J}$}

Mit Hilfe der Methode zur Prüfung der Durchbruchskapazität der Torfe gegenüber kationisch vorliegenden ${ }^{90} \mathrm{Sr}-{ }^{90} \mathrm{Y}$-Isotopen wurden auch einige Orientierungsversuche mit ${ }^{131} \mathrm{~J}^{7}$ ) vorgenommen.

Die Perkolationsversuche erfolgten in einstufigen Ionenaustauschersäulen mit den Torfproben der zweiten Probeentnahme (Kolonnenfüllung erfolgte nach Methode «c», vgl. S. 238). Die Torffiltrate wurden in 25-ml-Fraktionen aufgefangen und je $5 \mathrm{ml}$ mittels Betamessungen (gemäss den uns zur Verfügung stehenden Messapparaturen) auf Radioalktivität geprüft.

Auf eine Ermittlung der Anionenaustauschkapazität wurde verzichtet, da bei den Torfen keine Anionenumtauschfähigkeit zu erwarten ist.

\subsection{Ergebnisse von Laboratoriumsexperimenten}

Es wurde zunächst überprüft, ob die Beta-Aktivitätsbestimmung der ${ }^{131} \mathrm{~J}$-haltigen Lösungen, welche zur Messung eingedampft werden mussten, reproduzierbare Resultate ergeben würde oder ob grosse Schwankungen wegen Verdampfungsverlusten zu erwarten waren. Je $5 \mathrm{ml}$ demineralisiertes Wasser mit Zusatz von trägerarmen ${ }^{131} \mathrm{~J}$ wurden unter Zugabe von $\mathrm{Na}_{2} \mathrm{CO}_{3}\left(2\right.$ Tropfen $2 \mathrm{~N} \mathrm{Na}_{2} \mathrm{CO}_{3}$ ) in den Zählschälchen eingedampft und die Impulsrate der Präparate bestimmt. Die Schwankungen zwischen den gemessenen Impulsraten hielten sich innerhalb des statistischen Zählfehlers. Dies

7) Trägerarm, gelöst in $0,1 \mathrm{~N} \mathrm{NaOH}$. Hergestellt im Eidg. Institut für Reaktorforschung, Würenlingen. 
beweist die gute Reproduzierbarkeit der Resultate; ferner liess sich im Laufe der Präparation kein messbarer Aktivitätsverlust nachweisen.

Wir haben auch die Aktivität offen aufbewahrter Zählpräparate innerhalb von 24 Tagen mehrmals kontrolliert. Die Abnahme der Impulsraten ergab innerhalb der statistischen Zählfehler eine gute Úbereinstimmung mit der theoretischen Zerfallskurve des ${ }^{131} \mathrm{~J}$. Ein Entweichen von ${ }^{131} \mathrm{~J}$ während 24 Tagen konnte deshalb ausgeschlossen werden.

Diese Messungen zeigten ferner, dass das ${ }^{131} \mathrm{~J}$ nicht mit nachweisbaren Mengen anderer radioaktiver Isotopen verunreinigt war.

Im Sinne von Orientierungsversuchen über den Konzentrationsbereich, in welchem eine Rückhaltung des ${ }^{131} \mathrm{~J}$ an Torf möglich ist, wurden zunächst $2,10^{-3}, 10^{-9}, 10^{-12}$ molare, mit ${ }^{131} \mathrm{~J}$ markierte Lösungen $(\mathrm{pH}=6,8)$ durch die Torfsäulen perkoliert, die Eluate fraktionenweise aufgefangen und ihre Beta-Aktivität gemessen. Abb. 21 zeigt, dass die prozentuale Rückhaltung der Aktivität stark von der Verdünnung der Na JLösungen abhängt: je stärker die Lösung verdünnt ist, um so grösser wird die prozentuale Rückhaltung. Bei NaJ-Molaritäten über $10^{-3}$ lässt sich keine Rückhaltung mehr nachweisen. Diese Messungen wurden mit dem grubenfeuchten Torf Nr. II/1 bei einer Einwaage von 9,5 g wasserfreier Substanz und einer Fliessgeschwindigkeit von $2,6 \mathrm{~cm} / \mathrm{min}$ durchgeführt. Bei einer halb so grossen Einwaage und Fliessgeschwindigkeiten zwischen 1,3 und 2,6 cm/min lagen die Messwerte in derselben Grössenordnung.

Bestimmungen im Bereich von weniger als $10^{-12}$ Mol Na J, d. h. im Konzentrationsgebiet, in welchem das aktive, trägerarme Jod nach der Verdünnung in der Lösung vorlag, konnten mangels genauer Angaben über die spezifische Aktivität des Jodpräparates nicht durchgeführt werden. Aus Abb. 21 geht jedoch hervor, dass die Beziehung zwischen der zurückgehaltenen Aktivität und der Molarität der Jodlösung einen exponentiellen Verlauf aufweist. Bei einer extrem grossen Verdünnung $\left(<10^{-12}\right.$ Mol) sollte demnach ein relativ starker Anstieg der prozentualen Rückhaltung eintreten. In der Tat konnten mit einem $\mathrm{Na}^{\mathbf{1 3 1}} \mathrm{J}$-Präparat, dessen Molarität nach der Verdünnung offenbar im Bereich von $<10^{-12}$ Mol lag, zwischen 60 und 90\% Rück-

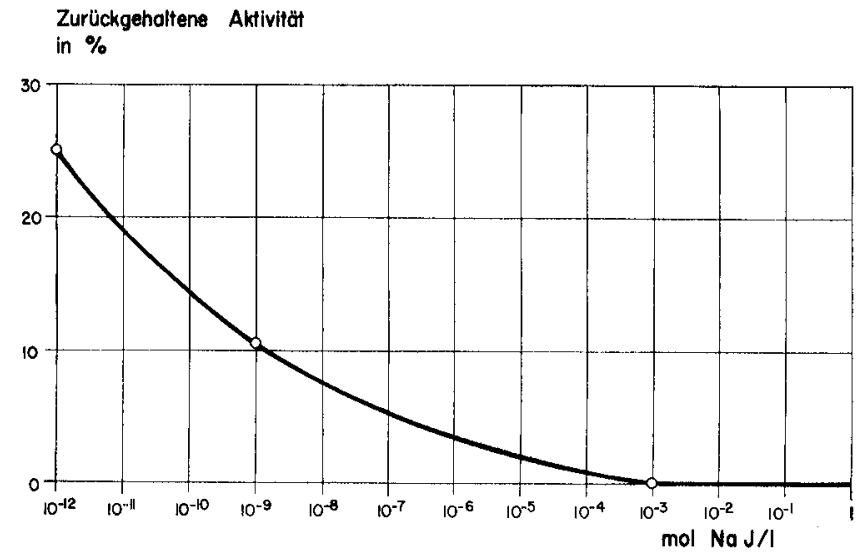

Abb.21. Prozentual zurückgehaltene ${ }^{131} \mathrm{~J}$-Aktivität am Torf Nr. II/1, Kolonnenfüllung nach Methode c (grubenfeuchter Torf) 
haltung festgestellt werden. Die Untersuchung erfolgte an den Torfproben Nr. II/1, Nr. II/2 und Nr. II/3 grubenfeucht bzw. tiefgefroren und anschliessend getrocknet. Als perkolierende Lösung diente ein Modellwasser mit $0,1 \mu \mathrm{Ci} / 1$ 13.1 $\mathrm{J}$, einem $\mathrm{pH}$-Wert von 6,8 und einem $\mathrm{Ca}$-Gehalt von 0,6 mäq/l. Ein wesentlicher Unterschied zwischen dem Rückhaltevermögen der grubenfeuchten und den nach Tieffrieren getrockneten Materialien konnte wiederum nicht beobachtet werden. Die Entaktivierungseffekte betrugen bei den Torfen II/1 und II/3 rund 70-90\%, bei Torf Nr. II/2 etwa $50-70 \%$.

Mit dem grubenfeuchten Torf Nr. II/1 wurde die Perkolation bis zum «Durchbruch $»^{8}$ ) weitergeführt. Es liessen sich 421 des $\mathrm{Na}{ }^{131} \mathrm{~J}$-haltigen Modellwassers bis zu $90 \%$ entaktivieren. Bei weiterem Durchfluss nahm die prozentuale Rückhaltung allmählich ab.

Mit dem grubenfeuchten Torf Nr. II/1 wurde der Einfluss der Fliessgeschwindigkeit auf die prozentual zurückgehaltene ${ }^{131} \mathrm{~J}$-Aktivität geprüft. Im Bereich zwischen 1,5 und $4 \mathrm{~cm} / \mathrm{min}$ trat kein messbarer Einfluss dieses Faktors auf.

\subsection{Schlussfolgerung aus den Laboratoriumsversuchen mit ${ }^{\mathbf{1 3 1}} \mathbf{\mathrm { J }}$}

Anhand dieser wenigen, einleitenden Versuche wurde gezeigt, dass das Torfmaterial ${ }^{131} \mathrm{~J}$ zurïckzuhalten vermag. Eine wichtige Rolle spielt dabei die Konzentration der ${ }^{131} \mathrm{~J}$-haltigen Lösung. Eine messbare Rückhaltung liess sich erst in extrem kleinen Konzentrationsbereichen $\left(<10^{-9} \mathrm{Mol} \mathrm{NaJ} / \mathrm{l}\right)$ nachweisen. Mit zunehmender Verdünnung steigt die prozentuale Rückhaltung exponentiell an.

Es soll hier noch darauf hingewiesen werden, dass das Torfmaterial je nach seiner Zusammensetzung und dem Polymerisationsgrad der Huminstoffe ein mehr oder weniger beträchtliches Reduktionsvermögen besitzt. Wie weit sein Redoxpotential auf das Redoxsystem $\mathrm{J}_{2}, \mathrm{~J}^{-}, \mathrm{JO}^{-}$einwirkt und die Rückhaltung des Jods nachhaltig beeinflusst, müsste noch überprüft werden. Es ist denkbar, dass die Rückhaltung des Jods an Torf mit einer günstigen Verschiebung des Redoxpotentials der Torfsubstanzen erhöht werden könnte.

\section{Versuche in halbtechnischem Maßstab mit ${ }^{90} \mathrm{Sr}-{ }^{90} \mathrm{Y}-$ und ${ }^{131} \mathrm{~J}$-haltiger Modellösung und Regenwasser}

\subsection{Resultate}

Es wurde cin Modellwasser mit der auf Seite 237 angegebenen Zusammensetzung hergestellt und ihm $0,25 \mu \mathrm{Ci} /{ }^{90} \mathrm{Sr}-{ }^{90} \mathrm{Y}$ und $0,1 \mu \mathrm{Ci} / 1{ }^{131} \mathrm{~J}$ zugefügt. Als Ionenaustauschersäule wurde ein Eheim-Saugfilter $(\varnothing 9 \mathrm{~cm})$ mit einer Universalkreiselpumpe verwendet. Der Apparat wurde mit Torf Nr. II/3 (tiefgefroren und anschliessend getrocknet) nach der Methode "c" gefüllt. Die Einwaage entsprach $137 \mathrm{~g}$ eines bei $103^{\circ} \mathrm{C}$ getrockneten Materials. Vor der Perkolation wurde der Torf während 24 Stunden in demineralisiertem Wasser stehengelassen. Der Durchfluss des Modellwassers erfolgte von unten nach oben mit einer Fliessgeschwindigkeit von $1 \mathrm{~cm} / \mathrm{min}$. Die Radioaktivität wurde in den Torffiltraten stichprobenweise laufend kontrolliert. Weitere Aktivitätsmessungen erfolgten nach dem Erreichen des radioaktiven Gleichgewichtes zwischen $\mathrm{d} \approx m$ durchgebrochenen ${ }^{90} \mathrm{Sr}$ und dessen Tochterprodukt ${ }^{90} \mathrm{Y}$.

$\left.{ }^{8}\right)$ D.h. Unterschreitung von $90 \%$ Rückhaltung. 


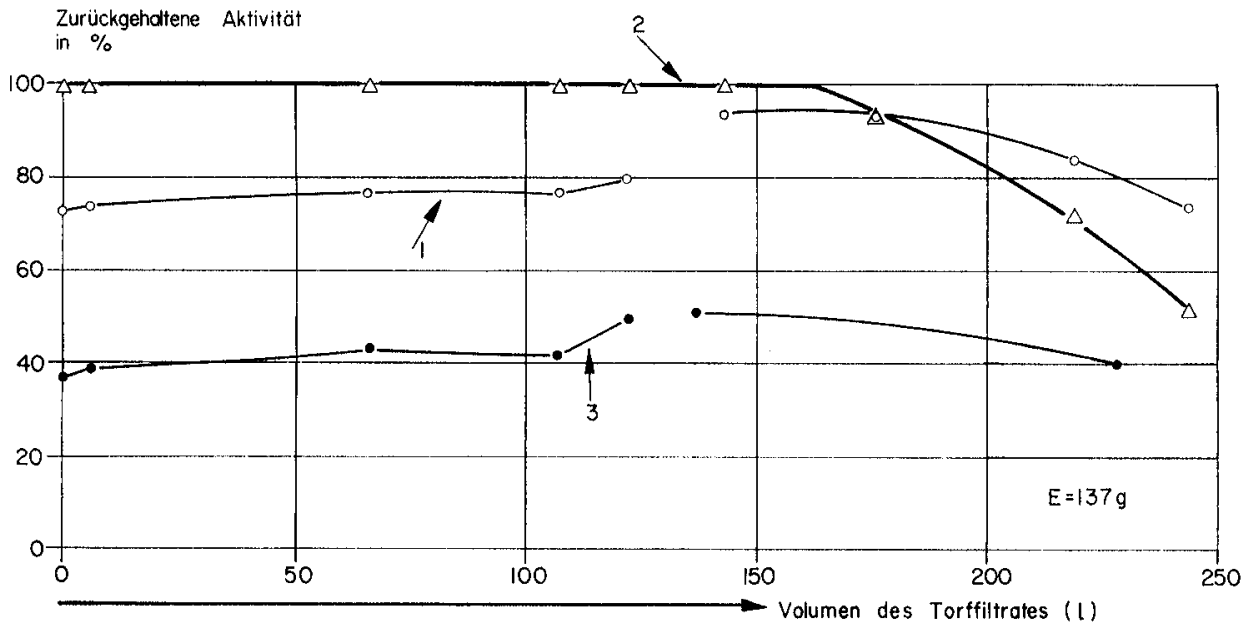

Abb. 22. Prozentual zurückgehaltene Aktivität. Kurve 1: Gesamt-Beta-Aktivität, bezogen auf die Gesamt-Beta-Aktivität der Eingangslösung; Kurve 2: ${ }^{90} \mathrm{Sr}-{ }^{90} \mathrm{Y}$-Aktivität, bezogen auf die ${ }^{90} \mathrm{Sr}-$ ${ }^{90} \mathrm{Y}$-Aktivität der Eingangslösung; Kurve 3: ${ }^{131} \mathrm{~J}$-Aktivität, bezogen auf die ${ }^{131} \mathrm{~J}$-Aktivität der Eingangslösung. Kolonnenfüllung nach Methode $\mathrm{c}$ (tiefgefrorener und nach träglich getrockneter Torf $\mathrm{Nr}$. II/3). Einwaage äquivalent mit cinem be $103^{\circ} \mathrm{C}$ getrockneten Material.

Die Ermittlung des ${ }^{90} \mathrm{Sr}-\mathrm{bzw}$. des ${ }^{131} \mathrm{~J}$-Anteils an der Gesamtbeta-Aktivität der Eluate konnte mittels Absorptionsmessungen vorgenommen werden, da die maximalen Beta-Energien des ${ }^{\mathbf{9}} \mathrm{Sr}(0,54 \mathrm{MeV})$ und des ${ }^{\mathbf{1 3 1}} \mathrm{J}(0,60 \mathrm{MeV})$ in derselben Grössenordnung liegen und damit von der maximalen Beta-Energie des Tochterproduktes ${ }^{90} \mathrm{Y}$ $(2,24 \mathrm{MeV})$ stark abweichen. Die Präparate wurden im radioaktiven Gleichgewicht mit einer Al-Folie $\left(135 \mathrm{mg} / \mathrm{cm}^{2}\right)$ zugedeckt und die Impulsrate der vom ${ }^{90} \mathrm{Y}$ herrührenden Betastrahlung gemessen. Unter Berücksichtigung der Absorptionsfaktoren wurde die ${ }^{90}$ Sr-Aktivität berechnet. Die Differenz zwischen der Gesamt-Beta-Aktivität der Präparate und der Aktivität des ${ }^{\mathbf{9 0}} \mathrm{Sr}{ }^{\mathbf{0} 0} \mathrm{Y}$ ergab die ${ }^{\mathbf{1 3 1}} \mathrm{J}$-Aktivität zur Zeit der Messung. Nach Korrektur mit dem Zcrfallsfaktor des ${ }^{\mathbf{1 3 1}} \mathrm{J}$ liess sich die ${ }^{\mathbf{1 3 1}} \mathrm{J}$-Aktivität zur Zeit der Perkolation berechnen.

Die Darstellung in Abb. 22 zeigt, dass die prozentual zurückgehaltene Aktivität, bezogen auf die Gesamt-Beta-Aktivität der Eingangslösung (Kurve 1), bis zum Durchbruch des ${ }^{90} \mathrm{Sr}$ (Kurve 2) von der prozentual zurückgehaltenen Aktivität des ${ }^{131} \mathrm{~J}$, bezogen auf die ${ }^{131} \mathrm{~J}$-Aktivität der Eingangslösung (Kurve 3), bestimmt ist. Der plötzliche Anstieg der Kurven 1. und 3 nach Perkolation von mehr als 120 lentstand durch den Einsatz einer frischen Lösung, deren ${ }^{131} \mathrm{~J}$-Gehalt nur etwa halb so gross war.

Ein Vergleich der Durchbruchskapazität des Torfes Nr. II/3 für ${ }^{90} \mathrm{Sr}$ mit den Laboratoriumsversuchen (vgl. Tab. 10) ergibt eine gute Ubereinstimmung. Die spezifische Durchbruchskapazität $\left(D_{\mu \mathrm{Ci}}=300 \times 10^{-3} \mu \mathrm{Ci} / \mathrm{g}\right.$ wasserfreie Substanz $)$ fiel im halbtechnischen Maßstab etwas höher aus, da die Fliessgeschwindigkeit geringer war. Die prozentual zurückgehaltene ${ }^{\mathbf{1 3 1}} \mathrm{J}$-Aktivität betrug $40 \%$ bis zum Lösungswechsel und stieg mit der frischen Lösung etwas an.

Ähnliche Resultate liessen sich bei einem Versuch mit der Hälfte der Torfeinwaage und mit einer dünneren Ionenaustauschersäule $(\varnothing 4 \mathrm{~cm})$ erzielen (Abb. 23). Die spe- 


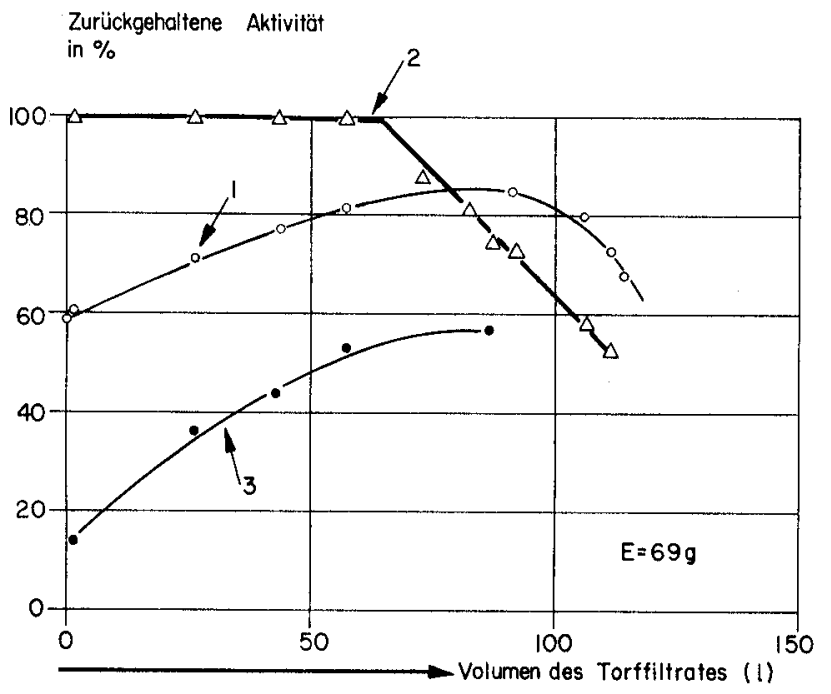

Abb. 23. Prozentual zurückgehaltene Aktivität. Kurve 1: Gesamt-Beta-Aktivität, bezogen auf die Gesamt-Beta-Aktivität der Eingangslösung; Kurve 2: ${ }^{90} \mathrm{Sr}-{ }^{90} \mathrm{Y}$-Aktivität, bezogen auf die ${ }^{90} \mathrm{Sr}-$ ${ }^{90} \mathrm{Y}$-Aktivität der Eingangslösung; Kurve 3: ${ }^{131} \mathrm{~J}$-Aktivität, bezogen auf die ${ }^{131} \mathrm{~J}$-Aktivität der Eingangslösung. Kolonnenfüllung nach Methode $\mathrm{c}$ (tiefgefrorener und nachträglich getrockneter Torf Nr. II/3). Einwaage äquivalent mit einem bei $103^{\circ} \mathrm{C}$ getrockneten Material.

zifische Durchbruchskapazität betrug $245 \times 10^{-3} \mu \mathrm{Ci} / g$ wasserfreien Torfes. Der Entaktivierungseffekt lag damit zwischen jenem der Laborversuche und dem des Experiments mit dem Eheim-Filter. Für die prozentuale Rückhaltung des ${ }^{131} \mathrm{~J}$ ergaben sich Werte zwischen 20 und 60\%. Eine Wiederholung dieses Versuches mit einer Regenwasserprobe (gleicher Ca-Gehalt und $\mathrm{pH}$-Wert wie das Modellwasser) führte zu identischen Ergebnissen. Die in Abb. 23 dargestellten Messpunkte gelten deshalb sowohl für die Versuche mit dem Modellwasser als auch für die mit dem Regenwasser.

\subsection{Schlussfolgerung aus den halbtechnischen Versuchen}

Die Experimente im halbtechnischen Maßstab bestätigten die Ergebnisse der Laboratoriumsuntersuchungen. Für ${ }^{90} \mathrm{Sr}$ liess sich eine spezifische Durchbruchskapazität von $300 \mu \mathrm{Ci} / \mathrm{kg}$ wasserfreien Torfs (Torf $\mathrm{Nr}$. II/3, tiefgefroren und anschliessend getrocknet) feststellen. Die gegenüber den Laboruntersuchungen etwas erhöhte Durchbruchskapazität ist auf die kleinere Fliessgeschwindigkeit zurückzuführen. Das ${ }^{\mathbf{1 3 1}} \mathrm{J}$ blieb während der Perkolation zu 20-60\% (bezogen auf die ${ }^{131}$ J-Aktivität der Eingangslösung, 0,05-0,1 $\mu \mathrm{Ci} / \mathrm{l})$ in der Torfsäule zurück. Beim Starten einer Perkolation liessen sich starke ${ }^{131} \mathrm{~J}$-Durchbrüche feststellen, deren Ursache noch abgeklärt werden muss.

\section{Zusammenfassung}

Es wurden Versuche zur Entaktivierung von ${ }^{90} \mathrm{Sr}_{-}{ }^{90} \mathrm{Y}-,{ }^{131} \mathrm{~J}$-haltigem Modellwasser und Regenwasser mit drei verschiedenen Torfen durchgeführt. Die chemische Zusammensetzung des Modellwassers entsprach einem Regen- bzw. Zisternenwasser. Die Torfproben sind im Neuenburger Jura entnommen worden. 
Für die Bestimmung der Entaktivierungsfähigkeit der drei Torftypen sind sowohl Perkolationsversuche mit Laboratoriums-Ionenaustauschersäulen in üblichen Dimensionen als auch in halbtechnischem Maßstab vorgenommen worden.

Gute Entaktivierungseffekte liessen sich für ${ }^{90} \mathrm{Sr}-{ }^{90} \mathrm{Y}$ feststellen. Die wichtigsten Grössen, welche die Durchbruchskapazität beeinflussen, sind: Torfart, Trocknungsgrad und Tieffrieren. Daneben spielen weitere Faktoren, welche für die Austauschkapazität der Torfe massgebend sind, eine Rolle (vgl. Schlussfolgerungen auf S. 263).

Eine messbare Rückhaltung von anionisch vorliegendem ${ }^{131} \mathrm{~J}$ liess sich nur in extrem kleiner Konzentration $\left(<10^{-9} \mathrm{Mol} \mathrm{NaJ} / \mathrm{l}\right)$ nachweisen. Die Rückhaltung steigt mit der Zunahme der Verdünnung exponentiell an. Bei einer Lösung mit $<10^{-12} \mathrm{Mol}$ $\mathrm{Na}{ }^{131} \mathrm{~J} / 1$ liessen sich für die prozentual zurückgehaltene Aktivität, bezogen auf die Eingangslösung, Werte zwischen 60 und $90 \%$ feststellen.

Die Experimente geben wertvolle Hinweise auf bodenkundliche Probleme. Besonders hervorzuheben sind in diesem Zusammenhang die beobachteten irreversiblen Strukturveränderungen der Torfe infolge Tieffrierens und Trocknens sowie die Korrelation zwischen dem Ca-Gehalt oder dem Zersetzungsgrad und der Austauschbzw. Durchbruchskapazität für Kationen.

\section{SUMMARY}

Experiments were carried out with the objective to determine the decontamination of rain and model water containing ${ }^{90} \mathrm{Sr}^{90} \mathrm{Y},{ }^{131} \mathrm{I}$ by various peats. The chemical composition of the model water was similar to rain resp. cistern water. Peat samples were taken in the Jura mountains, Neuchâtel region, Switzerland.

Percolation experiments were carried out in laboratory ion-exchange columns of the usual dimensions and in pilot scale installations to determine the decontamination capacity of three types of peat.

Good decontamination effects were determined for ${ }^{90} \mathrm{Sr}_{-}{ }^{90} \mathrm{Y}$. The main parameters influencing the breakthrough capacity are: Type of peat, degree of drying and deep freezing. In addition, other factors particularly those with regard to exchange capacity are also significant (see conclusions, p. 263).

A measurable retention of anionically available ${ }^{131} \mathrm{I}$ was observed at extremely low concentrations only $\left(<10^{-9} \mathrm{Mol} \mathrm{NaT} /\right.$ liter $)$. Retention increases exponentially with increasing dilution ratios. A solution of $<10^{-12} \mathrm{Mol} \mathrm{Na}{ }^{131} \mathrm{I} /$ liter showed a retained activity of 60 to 90 percent, related to the inflowing solution.

The experiments yielded useful findings with regard to soil science. Particularly interesting are the irreversible structure changes of peat due to deep freezing and drying, and the correlation between calcium content or degree of decomposition and exchange or breakthrough capacity for cations.

Herrn Prof. Dr. O. Jaag, Direktor der Eidg. Anstalt für Wasserversorgung, Abwasserreinigung und Gewässerschutz, Dübendorf, danke ich herzlich für die Anregung und Unterstützung dieser Arbeit. Ferner danke ich Herrn Prof. Dr. K. Wuhrmann für die wertvollen Diskussionen sowie Herrn D. Meierhans und meinen anderen Mitarbeitern für die Mithilfe bei den Laboratoriumsarbeiten. Für die chemischen und mikroskopischen Analysen sowie für die Bestimmung des Zersetzungsgrades an Torfproben möchte ich meinen besten Dank der Direktion der Eidg. Agrikulturchemischen Versuchsanstalt, Liebefeld-Bern, Herrn Prof. Dr. H. Zoller, Universität Basel, und dipl. Landw. W. Borberg, Rostock, aussprechen. Herr Prof. Dr. R.Bach, ETH, Zürich, hat mir freundlicherweise wertvolle Hinweise bei der Auswahl der Torfproben gegeben, für die ich ihm zu Dank verpflichtet bin. 
Diese Arbeit wurde im Rahmen der Tätigkeit der Eidg. Anstalt für Wasserversorgung, Abwasserreinigung und Gewässerschutz, Dübendorf, für die Eidg. Kommission zur Úberwachung der Radioaktivität durchgeführt.

\section{LITERATURVERZEICHINIS}

[1] JaAg O., Rottenberg W. und Bezzegh M. M., Radioaktives Trinkwasser in Regenwasserzisternen; Entaktivierung mit Hilfe von Torf, Mitteilung EAWAG, Zürich (1959).

[2] WINILER R. und GENS J., Die Eignung von Torf für die Reinigung vadioahtiver Abwässer, Isotopentechnik 1, $219(1960 / 61) ; \%, 246(1960 / 61)$.

[3] SAChSe G. und Winkler R., Anwendungsprobleme eines Torf-Ton-Austauschers bei der Reinigungradioaktiver Lösungen, als Manuskript gedruckt, Zentralinstitut für Kernphysik, Rossendorf bei Dresden (1963).

[4] Schmid E., Strpanits P. und Hechт F., Verwendung von Torf als Kationenaustauscher bei der A ufarbeitung radioaktiver Abwässer, Öst. Chem.-Ztg. 65, 9 (1964).

[5] Szalay A. und Szulágy M., Retention of Fission Products by Peat Humic Acid. A New Possibility in Waste Water Treatment, A/CONF. 28/P/784 (1964).

[6] Zarnowitcki K., Iostyrko A. und Holsztynska M., Sorption of Heavy Radioactive Isotopes from Liquid Radioactive Wastes on Peat, IInd International Atomic Energy Agency 203/RB Research Contract Semiannual Progress Report (NP-14668) (1963).

[7] Anraschko J., Strpanits P. and Hecht F., Die Anreicherung von Uran an Torf, Mikrochimica Acta 1, 124 (1964).

[8] KaDNER R. und FIScher W., Uber die sorptiven Eigenschaften dev Torfe, Freiberger Forschungshefte A154 (Akademie-Verlag, Berlin 1960).

[9] Scheffer F. und Schachtschablel P, Lehrbuch dev Bodenkunde (Ferdinand Enke Verlag, Stuttgart 1966).

[10] Baden W. und Grosse-Brauckmann G., Wasser und Boden 16, 155 (1964).

[11] KLEIST, H., Stabile, freie Radikale in Huminsäuren und ihren Metallvevbindungen, 4. Torfkolloquium DDR-VR Polen I/4, Deutsches Brennstoffinstitut Freiberg, Abt. Torfinstitut Rostock
(1967).

[12] LudwIEG F., Radioaktive Isotope in Futter und Nahrungsmitteln (Verlag Karl Thiemig KG, München 1962).

[13] Krefer H. und MaushaRt R., Überwachung der Radioaktivität in Abwasser und Abluft (B. G. Teubner, Stuttgart 1967).

[14] Minder W., Dosimetrie der Strahlungen radioaktiver Stoffe (Springer-Verlag, Wien 1961).

[15] Joyet G. und Miller M. (Mlle), Essai de dosage vationnel du traitement radio-actif des hyperthyréoses parl'131 J, Ann. Radiol. 5, 21 (1962).

16] Friedler H. J., Die Untersuchung der Böden (Verlag Theodor Steinkopff, Dresden und Leipzig), Bd. 1 (1964); Bd. 2 (1965).

[17] Schwarzenbach G., Komplexon; Titrationen mit Hilfe von Komplexon nach Prof. Schwarzenbach, Siegfried Aktiengesellschaft, Zofingen, Schweiz (1963).

[18] PuUstJÄrvi V., On the Cation Exchange of Peats and the Factors of Influence upon Its Formation, Acta agric. scand. 6, 410 (1956).

[19] FIScher W. und KADNER, R., Kationenaustauschkapazitäten von Torf-und Braunkohlenproben, untersucht nach der Methode von Mehlich-Schachtschabel, Freiberger Forschungshefto A 254 (Akademic-Verlag, Berlin 1962).

120] Matrson S. und Koutler-Anderson E., The Acid-Base Condition in Vegetation, Litter and Humus; Products of Partial Oxidation and Ammonia Fixation, Ann. Agr. Coll. Sweden 5, 284 (1942).

[21] Griesbach IR., Austauschadsorption in Theorie und Praxis. Allgemeiner Teil (AkademieVerlag, Berlin 1957).

[22] VAN DrJx H., Physikalisch-chemische Untersuchungen über die Ursachen der irreversiblen Eintrocknung von Moorböden und Möglichkeiten zur Verbesserung, als Manuskript gedruckt, Institut voor Bodemvruchtbaarheid, Groningen (1962).

Separatdruck aus der Schweiz. Zeitschrift für Hydrologie 32, Fasc. 1 (1970)
Herausgegeben mit Unterstützung

der Stiftung der Wirtschaft zur Förderung des Gewässerschutzes in der Schweiz 